\title{
Rock Riprap Design Methods and their Applicability to Long-Term Protection of Uranium Mill Tailings Impoundments
}

Prepared by W. H. Walters

Pacific Northwest Laboratory

Operated by

Battelle Memorial Institute

\section{Prepared for}

U.S. Nuclear Regulatory

Commission 


\section{NOTICE}

This report was prepared as an account of work sponsored by an agency of the United States Government. Neither the United States Government nor any agency thereof, or any of their employees, makes any warranty, expressed or implied, or assumes any legal liability of responsibility for any third party's use, or the results of such use, of any information, apparatus, product or process disclosed in this report, or represents that its use by such third party would not infringe privately owned rights.

\section{Availability of Reference Materials Cited in NRC Publications}

Most documents cited in NRC publications will be available from one of the following sources:

1. The NRC Public Document Room, 1717 H Street, N.W. Washington, DC 20555

2. The NRC/GPO Sales Program, U.S. Nuclear Regulatory Commission, Washington, DC 20555

3. The National Technical Information Service, Springfield, VA 22161

Although the listing that follows represents the majority of documents cited in NRC publications, it is not intended to be exhaustive.

Referenced documents available for inspection and copying for a fee from the NRC Public Document Room include NRC correspondence and irternal NRC memoranda; NRC Office of Inspection and Enforcement bulletins, circulars, information notices, inspection and investigation notices; Licensee Event Reports; vendor reports and correspondence; Commission papers; and applicant and licensee documents and correspondence.

The following documents in the NUREG series are available for purchase from the NAC/GPO Sales Program: formal NRC staff and contractor reports, NRC-sponsored conference proceedings, and NRC booklets and brochures. Also available are Regulatory Guides, NRC regulations in the Code of Federal Regulations, and Nuclear Regulatory Commission /ssuances.

Documents available from the National Technical Information Service include NUREG series reports and technical reports prepared by other federal agencies and reports prepared by the Atomic Energy Commission, forerunner agency to the Nuclear Regulatory Commission.

Documents available from public and special technical libraries include all open literature iterns, such as books, journal and periodical articles, and transactions. Federal Register notices, federal and state legislation, and congressional reports can usually be obtained from these libraries.

Documents such as theses, dissertations, foreign reports and translations, and non-NAC conference proceedings are available for purchase from the organization sponsoring the publication cited.

Single copies of NRC draft reports are available free upon written request to the Division of Tech. nical Information and Document Control, U.S. Nuclear Regulatory Commission, Washington, DC 20555.

Copies of industry codes and standards used in a substantive manner in the NRC regulatory process are maintained at the NAC Library, 7920 Norfolk Avenue, Bethesda, Maryland, and are available there for reference use by the public. Codes and standards are usually copyrighted and may be purchased from the originating organization or, if they are American National Standards, from the American National Standards Institute, 1430 8roadway, New York, NY 10018. 
NUREG/ CR-2684

PNL-4252

RU

\section{Rock Riprap Design Methods and their Applicability to Long-Term Protection of Uranium Mill Tailings Impoundments}

Manuscript Completed: July 1982

Date Published: August 1982

Prepared by

W. H. Walters

Pacific Northwest Laboratory

Richland, WA 99352

\section{Prepared for}

Division of Health, Siting and Waste Management

Office of Nuclear Regulatory Research

U.S. Nuclear Regulatory Commission

Washington, D.C. 20555

NRC FIN B2370 



\section{ABSTRACT}

This report reviews the more accepted or recommended riprap design methods currently used to design rock riprap protection against soil erosion by flowing water. The basic theories used to develop the various methods are presented. The Riprap Design with Safety Factors Method is identified as the logical choice for uranium mill tailings impoundments. This method is compared to the other methods and its applicability to the protection requirements of tailings impoundments is discussed. Other design problems are identified and investigative studies recommended. 

Pacific Northwest Laboratory (PNL) is studying the mitigation of erosion through the use of rock revetment, commonly referred to as riprap. This report reviews the available rock riprap design methods and their development, and provides a preliminary assessment of their applicability for long-term protection of uranium mill tailings impoundments against flood erosion. Other items regarding the application of riprap (e.g., placement, causes of failures, rock gradation, and rock durability) are discussed.

Rock riprap design methods have been developed around the concept of the initiation of motion of a single particle. Hydrodynamic lift and drag are the primary forces acting on a rock particle subjected to flowing water. The submerged weight of the particle resists these forces. When motion of an individual rock is about to occur, the lift and drag forces are just balanced by the resisting force (submerged weight) of the rock. This is the condition of incipient motion. Three basic approaches are used by engineers to explain and describe the beginning of particle motion: 1) critical velocity approach, 2) critical shear stress approach, and 3) lift force mechanism.

The critical velocity approach considers a force balance on a rock particle where the flow imposes both a lift and drag force that tends to dislodge and entrain the particle. This approach lacks a good definition of an appropriate velocity and its measurement.

The critical shear stress approach considers a force balance on a water prism and the resulting shear force over the particle. This approach has been popular because a critical shear stress can be easily related to flow parameters.

The lift force mechanism involves a pressure difference on the particle, as well as upward velocity components resulting from turbulence. The pressure difference is due to the steep gradient along the rock particle. Most of the work in this area has been in the attempt to understand and describe the lift forces on particles, but has not provided any critical lift criteria. Another drawback is that drag forces are ignored.

Most riprap design methods were developed by Federal and state agencies for application to particular public works projects. Typical projects requiring riprap protection are highway embankments, bridges, flood channels, canals, and stilling basins. The type of project to be protected and the experience of each agency greatiy influence the method chosen.

Six riprap design methods are reviewed in this report. The first method reviewed is the one most recently developed (by Colorado State University for the Wyoming Highway Department). This method incorporates the concept of a design safety factor and provides a much more versatile approach than the other methods. A stone size is determined through sets of equations developed for four basic flow conditions. This method offers the most promise as a procedure 
to be used to design riprap for the protection of tailings impoundments. It is usually referred to as the Riprap Design with Safety Factors Method.

Two other methods are reviewed in detail to illustrate typical approaches to riprap design. These are the design procedures recommended by the U.S. Army Corps of Engineers and the California Highway Department. Both procedures use graphical techniques developed from basic equations to solve for the required stone sizes. This step in the design procedure is relatively simple. The rest of the design procedure is guided by written specifications and relies heavily on engineering experience. Three other methods are briefly reviewed for comparison. These are the U.S. Bureau of Reclamation and the U.S. Bureau of Public Roads design methods, and the recommendations of the American Society of Civil Engineers Sedimentation Manual.

The application of a riprap design method to the 1ong-term protection of tailings impoundments depends on the impoundment location in the drainage basin. All tailings impoundments are subjected to overland erosional processes from rainfall runoff. Impoundments located in the lowland watershed areas or on flood plains can be expected to experience both severe flooding and overland erosion. Impoundments located in upland watershed areas experience flooding to a lesser extent. The riprap design methods presented in this report would normally be used to design riprap for flood protection and not for overland erosion. However, the Riprap Design with Safety Factors Method can be used to assist in designing riprap on side slopes when no lateral flow is expected.

The long-term protection requirement for decommissioned tailings impoundments introduces three problem areas: 1) the effect of climate changes on a design flood magnitude, 2) local scour and hydrodynamic forces on the structure during floods, and 3 ) rock durability over long time periods.

Allowances for shifts in the climatic regime may be required in design flood calculations. This is based on the fact that a much wetter climate than that of today existed only about 150 years ago and extended back in time for several hundred years. The probable maximum flood (PMF) method is recommended for the determination of a design flood but may need to be modified to accomodate climatic changes. Local scour would be a result of nonuniform flow regions caused by the irregular shape of a tailings impoundment opposing the passage of a flood wave. This type of scour could severely damage or undermine the riprap protection. This type of problem is usually investigated through laboratory flume studies. Rock durability is a measure of the resistance of the rock material to the process of mechanical weathering or physical disintegration, and chemical weathering or decomposition. Several tests are available to assist in improving the quality of the selected rock but do not provide an estimate of the time a rock will resist weathering or remain durable. 


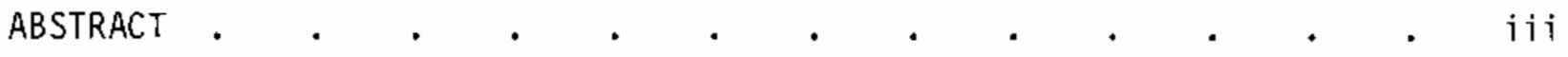

SUMMARY .

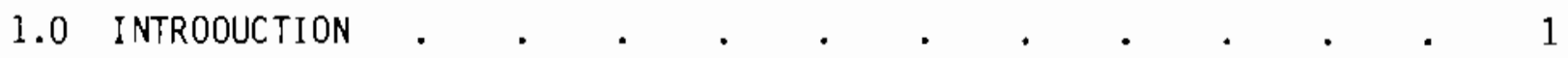

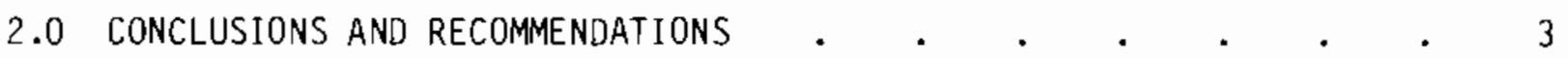

3.0 HISTORICAL USES OF RIPRAP $\quad$. $\quad . \quad$. $\quad$. 5

4.0 PROTECTION REQUIREMENTS OF TAILINGS IMPOUNOMENTS * . . . • 7

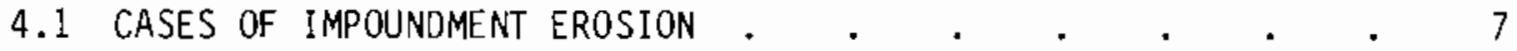

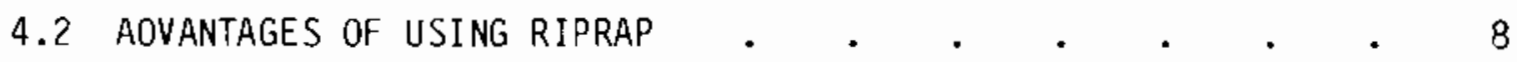

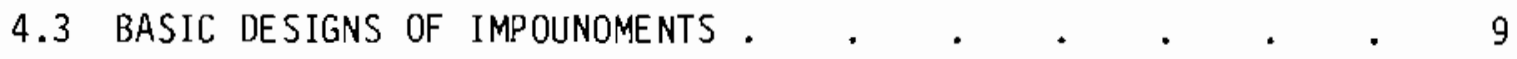

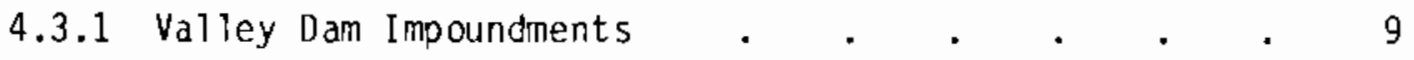

4.3.2 Dike Impoundments . . . . . . . . . . . . 9

4.3 .3 In-Pit Disposal . . . . . . . . . . 10

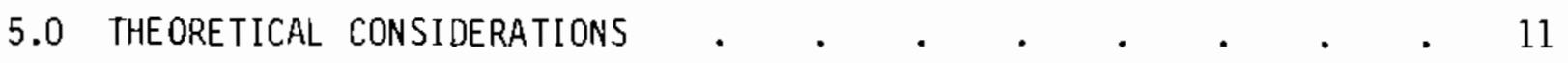

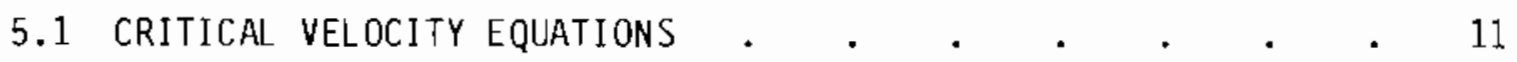

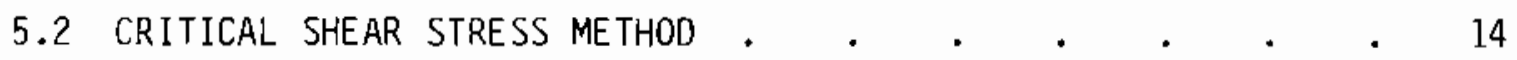

5.3 LIFT FORCE MECHANISM $\quad . \quad$. . . . . . . . . . . 16

5.4 DISCUSSION $\quad . \quad . \quad . \quad . \quad . \quad . \quad . \quad . \quad . \quad . \quad . \quad . \quad 18$

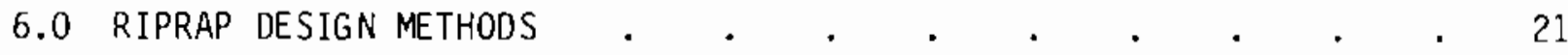

6.1 RIPRAP DESIGN WITH SAFETY FACTORS METHOO . . . . 21

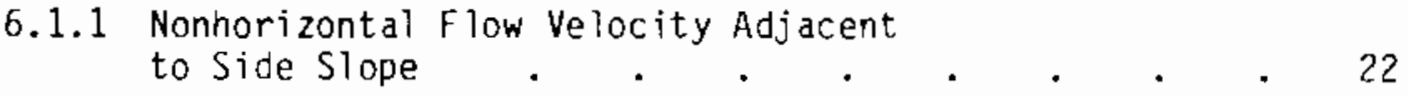

6.1 .2 Horizontal Flow on a Side Slope . . . . . 23

6.1.3 Flow Over a Plane Sloping Bed . . . . . 24

6.1.4 Flow Over a Horizontal Bed . . . . . . . 24

6.2 U.S. ARMY CORPS OF ENGINEERS METHOD $\quad$. . . . . . . 25 
6.2.1 Riprap Design for High Turbulence Conditions . $\quad 25$

6.2.2 Riprap Design for Flood Channels . . . . . . . 26

6.3 CALIFORNIA HIGHWAY DEPARTMENT METHOD $\quad$. $\quad$. 36

6.3.1 Streambank Protection . . . . . . . . 36

6.3.2 Shoreline Protection . . . . . . . 37

6.4 OTHER METHODS . . . . . . . . . . . . 40

6.4.1 Bureau of Reclamation Method . . . . . 42

6.4.2 Bureau of Public Roads. . . . . . . . . 42

6.4.3 ASCE Recommendations . . . . . . . . . 42

6.5 COMPARISON OF METHODS . . . . . . . . . . . . 45

6.5 .1 Discussion $. \quad . \quad . \quad . \quad . \quad . \quad . \quad . \quad . \quad . \quad . \quad . \quad 48$

7.0 APPLICATION OF RIPRAP DESIGN METHODS TO TAILINGS
IMPOUNDMENTS

7.1 RIPRAP DESIGN REQUIREMENTS OF TAILINGS

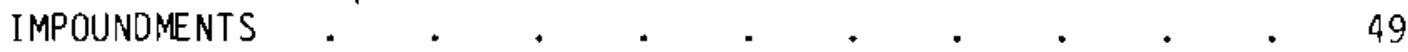

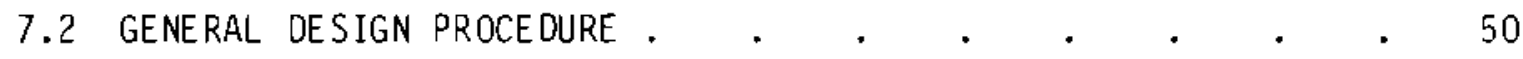

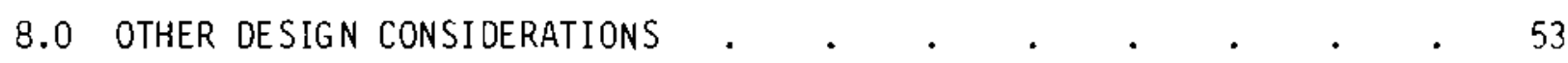

8.1 DESIGN FLOOD CRITERIA . . . . . . . . . . . 53

8.2 DESIGN FLOOD ANALYSIS . . . . . . . . . . . . . 54

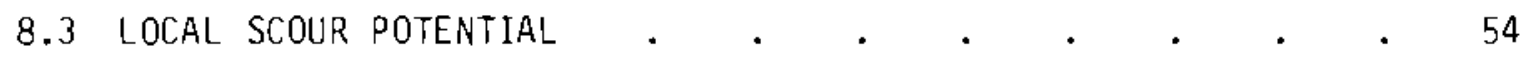

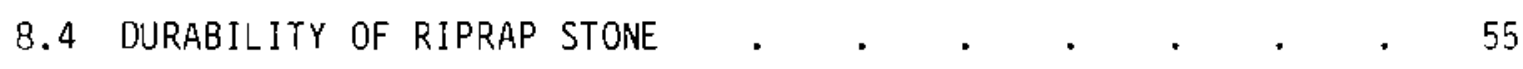

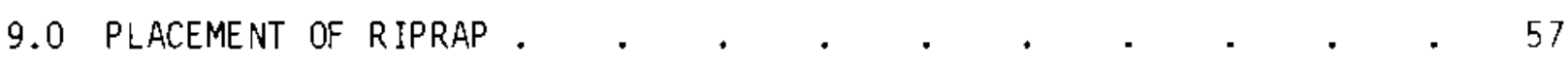

9.1 GRAVEL FILTERS . . . . . . . . . . . . . 57

9.2 CAUSES OF RIPRAP PROTECTION FAILURES $\quad . \quad$. $\quad . \quad$. $\quad . \quad 58$

9.3 CONTROL OF RIPRAP GRADATION $\quad$. $\quad . \quad$. $\quad . \quad$. $\quad . \quad$. 59

9.4 RiPRAP PLACEMENT PROCEDURES . . . . . . . . . 60 


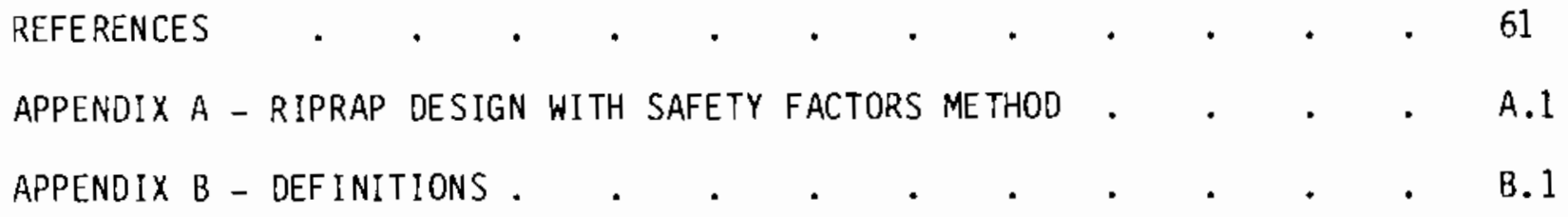




\section{FIGURES}

3.1 Streambank Riprap Protection . . . . . . . . . 5

3.2 Shoreline Riprap Protection . $\quad$. $\quad$. . . . . . . . 6

4.1 Typical Cross-Section of a Valley Dam Impoundment . . . . 9

4.2 Section Through Tailings Impoundment Illustrating

Four Elements . . . . . . . . . . . . . 10

5.1 Force Diagram on Particles in a Cohesionless

Loose Bed . . . . . . . . . . . 1 ?

5.2 Forces Acting on a Water Prism . . . . . . . . 14

6.1 Velocity Versus Stone Diameter and Weight for Average

Velocities Between 5 and $10 \mathrm{fps}$, from Equations (6.13) and $(6.14)$

6.2 Velocity Versus Stone Diameter and Weight for Average Velocities Between 10 and $22 \mathrm{fps}$, from Equations

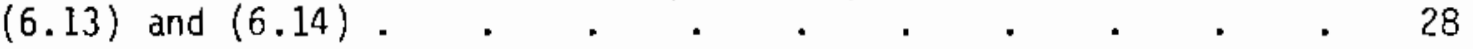

6.3 Relationship of Local Boundary Shear Stress to the
Median Rock Diameter and Local Depth . . . . . . . 30

6.4 Reiationship of Average Boundary Shear Stress in

Approach Channel to Local Boundary Shear Stress

in Bends Based on Experiments . . . . . . . . . 31

6.5 Maximum Shear Stress at Channe] Bends . . . . . . . 32

6.6 Design Shear for Riprap on the Channel Bottom

from Equation $(6.21)$. . . . . . . . . . 33

6.7 Design Shear Ratios for Riprap in Trapezoidal Channels

6.8 Nomograph for Design of Streambank Rock Slope
Protection . . . . . . . . . . . . . . . 38

6.9 Nomograph for Design of Deep Water Rock Slope

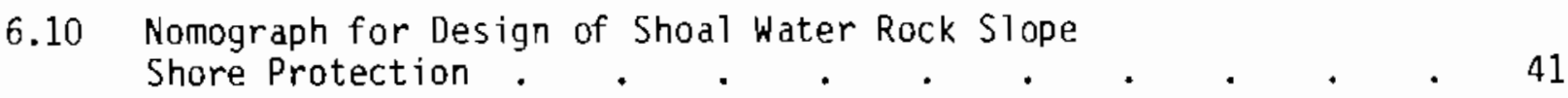

6.11 Rock Size for the Bureau of Reclamation Design . . . . . . 43 
6.12 Rock Size for the Bureau of Public Roads Design . . . . 44

6.13 Safety Factors for Corps of Engineers and California Highway Department Riprap Design . . . . . . . . 46

6.14 Comparison of the Bureau of Reclanation Method and the Incipient Motion Curve for the Riprap Design with Safety Factors Method . . . . . . . . . . 47

A.1 Diagrams for Riprap Stability Analysis . . . . . . A.3

A.2 Ratio of Stability Factors. . . . . . . . . . A.8 



\subsection{INTROOUCTION}

The long-tem protection of uranium mill tailings piles is a serious concern for the uranium mining industry and for Government regulatory agencies. of particular concern is the long-term protection from radon gas release. Radium-226 decays to radon gas and is supported by thorium-230, which has a half-life of 80,000 years.

The tailings are permanently stored in impoundments, either above-ground or below-ground, and are usually covered with an earthen $c$ ap several feet thick. The cap serves as a suppression cover to prevent the release of airborne pollutants. Because tailings impoundments are often located in flood plains or along other surface-water pathways, water erosion poses a serious long-term problem. Pacific Northwest Laboratory (PNL) is studying the mitigation of erosion through the use of rock revetment, commonly referred to as riprap. Whereas the objective of the overall study, sponsored by the Nuclear Regulatory Commission (NRC), is to develop and recommend generically applicable guidance on the effective use of riprap, this report discusses rock riprap design methods and their applicability for long-term protection against flood damage.

This report begins with a synopsis of the historical uses of riprap and the protection requirements of tailings impoundments. Theoretical considerations necessary to the development of design methods are given. Finally, existing riprap design methods and the applicability of rock protection to tailings impoundments are discussed. One riprap design method, Riprap Design with Safety Factors, is discussed in more depth in Appendix A. Appendix B contains a list of definitions used throughout the document. 



\subsection{CONCLUSIONS AND RECOMMENDATIONS}

Riprap design methods currently used to design protection against erosion by flowing water follow a general design procedure that includes hydraulic computations to determine flow-field characteristics; computations of average rock size, using a graphical method; and determination of riprap layer design dimensions from written guidelines and engineering judgment. The written specifications and design tables (such as those recommended by the corps of Engineers and the California Division of Highways) necessary to complete the design of the riprap blanket dimensions give an indication of the specifications required for tailings impoundments.

The Safety Factor Method (Stevens, Simons and Lewis 1976) offers a versatile approach based on the concepts of hydrodynamic lift and drag and critical shear stress that is clearly superior to other methods. This method allows more flexibility in design and could be adapted to mill tailings impoundments. The set of equations applicable to typical conditions at impoundment locations would be selected and graphical solutions developed to speed up calculations. An outstanding feature of this method is the accurate determination of a safety factor associated with the stone size and weight.

Because of the long-term protection requirements and the various irregular shapes of tailings impoundments, certain riprap design problems arise. These include the selection of a representative design flood criteria, rock durability over long time periods (1000 years or more), and the extent of local scour from high velocity flood flows that could cause the rock layer to fail. Several procedures are available for computing peak flood discharges. To select a method, the length of time riprap protection will be required must be determined to ascertain if climate changes need to be considered. Computing the expected flood discharge by the probable maximum flood (PMF) method appears to be the best approach whether or not climate change is to be a design factor. Potential climatic changes could be integrated into the PMF procedure if it becomes a significant factor. The hydraulic calculations required to determine the design velocity, water surface elevation, and tractive force exerted on the rock could be determined through the use of an accepted technique for backwater computations. Perhaps the best approach is the computer program HEC-2 (U.S. Army Corps of Engineers 1976), which could adequately describe the flow field. Local scour conditions would have to be determined by physical model studies of the flow patterns around an impoundment shape.

Based on the above conclusions the following research is suggested:

- A physical model study is recommended to evaluate the flow field around various impoundment shapes to determine local scour problems and forces on the structure due to the impoundment geometry.

- The calculation of potential flood flows using the PMF approach should be evaluated to determine if any modification due to climate change should be included into the procedure. 



\subsection{HISTORICAL USES OF RIPRAP}

Rock riprap is commonly used to protect rivers and canals against erosion resulting from periods of high velocity flows. The concave bankline of a river bendway frequently is paved with the rock to prevent bankline migration. The rock courses usually are extended helow the channel bed elevation to a depth below the scour expected during high flows (Figure 3.1). If scour is allowed to develop below the riprap protection, the rock could fail inasmuch as only gravity holds the structure together. A gravel blanket normally is placed beneath the riprap courses to protect the graded bankline against rill and gully erosion because the interstitial openings between the individual rocks can be large enough to al low local erosion of the embankment surface. The small-size gravel or crushed stone also allows for normal bankline seepage without causing an abnormal increase of hydrostatic pressure in the embankment material. The design high water elevation is determined by estimating the elevation of a particular flood event (i.e., a 100-year flood). The freeboard decreases the probability of overtopping. Design high water may be modified by factors such as the economics of riprap placement to a certain elevation and the ability of the upper embankment to resist damage from overtopping.

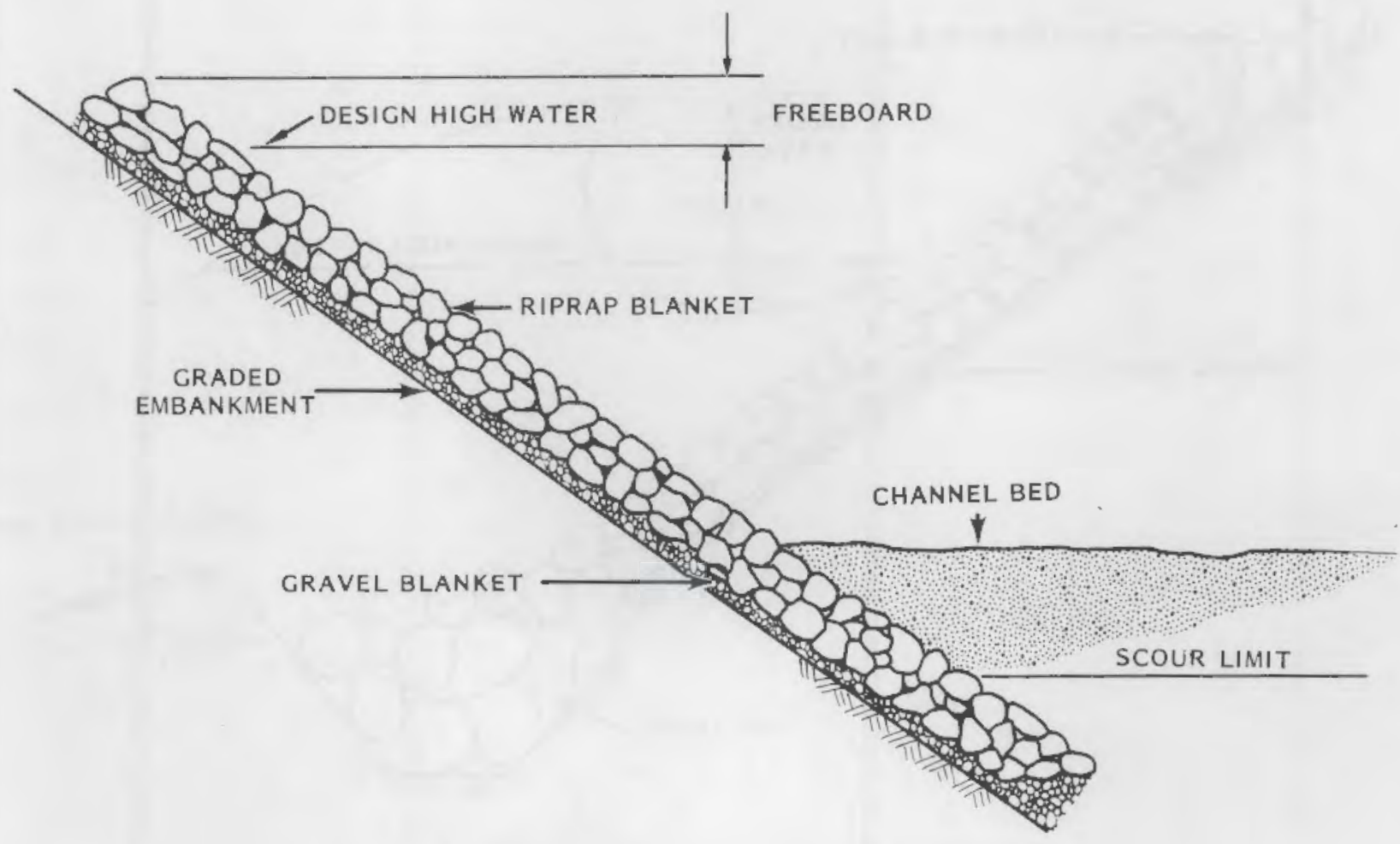

FIGURE 3.1. Streambank Riprap Protection 
Riprap is a standard method of protection against wave damage along coastal and lake shorelines and the upstream faces of earth dams. Wave erosion can be severe along unprotected shoreline embankments, particularly for material containing some quantity of sand. The design high water is determined by the mean sea level elevation and the maximum tidal range (Figure 3.2). The height of the riprap protection above design high water and the sizing of the stone usually are determined by estimating a design wave height. Although the riprap surface is rough, which tends to reduce wave runup on the slope face, some freeboard must be allowed to prevent continual overtopping of the rock layer.

Rock riprap also is used to protect earthen embankments adjacent to hydraulic structures where extremely high flow velocities and large-scale turbulence are generated (e.g., stream channel beds downstream of stilling basins, spillways, and culvert and siphon outlets). These channel beds must resist erosion by approach flow velocities that far exceed normal velocities. The erosion caused by such conditions is commonly called local scour, the severity of which is unique to a particular structure. Thus, the riprap design usually is determined by laboratory model studies and engineering experience.

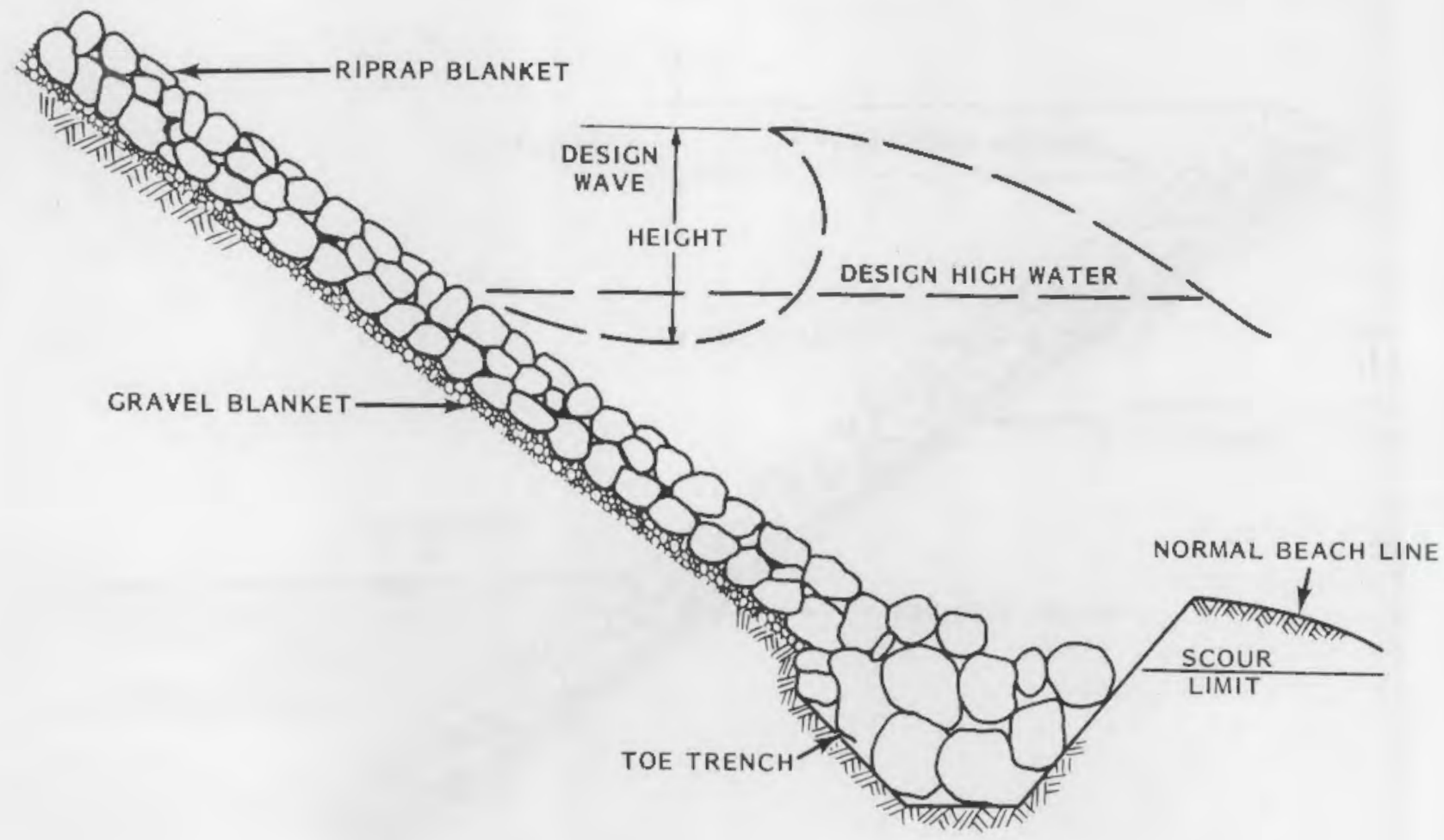

FIGURE 3.2. Shoreline Riprap Protection 


\subsection{PROTECTION REQUIREMENTS OF TAILINGS IMPOUNDMENTS}

The performance of engineering structures cannot be predicted for the length of time involved in the management of tailings impoundments. Over a time period of 1000 years or more, the variables affecting the impoundments' structural integrity are going to change significantly in importance. When and how much these variables will change is difficult to define. Shepherd and Nelson (1978) have defined three basic time periods when changes in the major variables are assumed to occur during the management life of a tailings impoundment.

The first period begins with completion of the planned reclamation and stabilization effort and lasts a few hundred years to when institutional control over land uses cannot be expected. According to the authors, this length of time roughly corresponds with the period of our industrial history.

The intermediate period extends from the end of the first period for a few thousand years into the future. This represents a transition interval between the time when institutional control and engineering solutions are considered valid to when they become unreliable.

The long-term period involves about 100,000 years, which approximates the half-life of thorium-230. This period was specified to allow time for the natural processes to stabilize tailings impoundments.

\subsection{CASES OF IMPOUNDMENT EROSION}

Riprap has been suggested as a means to armor the prepared earthen cap against water erosion caused by surface runoff (overland erosion) or by large flood events. The extent of the erosion depends on the frequency, intensity, and duration of rainfall that leads to overland erosion, and on the flood flow velocities the cap will encounter.

The first step in the overland erosion process is the wetting and detachment of soil by raindrops. The falling raindrops break down soil aggregates for detachinent and transport of the particles. This leads to sheet erosion, which moves the fine soil particles such as clays and silts in a uniform manner over an exposed slope with the surface runoff. As the surface runoff concentrates in depressions, soil may be removed, forming small, well-defined channels called rills. These are usually closely spaced and parallel. As more flow concentrates in rills, the erosive power increases and gullies are developed. The steeper the side slope, the more the gullies tend to incise and the more severe the damage. Most, if not all, impoundments will be subjected to such erosion processes. Riprap armoring will protect against these processes if the foundation upon which it is placed remains stable.

Flood events that exceed the top bank capacity of a stream channel can traverse the flood plain, producing areas of local scour and sediment deposition. The manner in which this scour and deposition occurs is difficult to 
predict. Because tailings impoundment structures produce large-scale irregularities in the topography when located on the floodplain, they will cause local flow velocity increases. These increases can cause scour holes to develop in the loosely compacted floodplain soils adjacent to the structure, possibly undermining sections of the cap and leading to rupture of the impoundment. Flood flows could erode the decommissioning $\mathrm{c}$ ap and much of the impoundment during one event.

Rock riprap has effectively prevented both types of erosional processes. Overland erosion involves sheets of water and is easily protected against by gravel and cobble-sized rock particles. Rock on the order of several feet in mean diameter may be required for protection against flood flows because of their extremely high velocities.

\subsection{ADVANTAGES OF USING RIPRAP}

Riprap basically consists of rock courses placed directly upon an embankment, providing a flexible, self-adjusting armor against erosion. According to extensive studies by the California Division of Highways (1970), this type of revetment has the following advantages (most of which would apply as well to uranium tailings impoundments):

- Riprap is flexible and is not impaired or weakened by slight settlement movement of the embankment.

- Local damage or loss is easily repaired by the addition of rock.

- Construction is not complicated and no special equipment is necessary.

- Appearance is natural.

- If riprap is exposed to fresh water, vegetation will often grow through the rocks, strengthening the embankment material and restoring natural roughness.

- Additional rock can be added at the toe to offset possible scour.

- Wave run-up is less by as much as $70 \%$ with riprap than with smoother surf aces.

- Riprap is salvageable and may be stockpiled and reused.

- Riprap is less susceptible to ice damage than are other protection methods. 


\subsection{BASIC DESIGNS OF IMPOUNDMENTS}

Robertson, Bamberg and Lange (1978) described three basic types of mine and mill tailings storage facilities: 1) valley dam impoundments, 2) ring dike impoundments, and 3) in-pit impoundments. All three types have an earthen $c a p$ and other decommissioning or reclamation facilities that must be protected against erosion and rupture by water forces.

\subsubsection{Valley Dam Impoundments}

This type of impoundment is constructed by placing a dam across a valley, making use of natural topographic features (Figure 4.1). The shape and location of the impoundment basin depends on suitable sites in the vicinity of the mine property. The valley topography and the dam wall extending across the valley form the perimeter of the impoundment.

Runoff from rainfall or snowmelt concentrates in the impoundment area. The concentration of flow could be diverted around a valley impoundment structure, but the cover would still need to be protected from sheet erosion and gullying. If the upstream watershed area is large, the risk of failure as a result of flash flooding could be the most critical factor in the protection of the impoundment. This is especially true in considering long-term protection since the probability of an extremely large flood event increases.

\subsubsection{Dike Impoundments}

The main elements for an above-ground ring dike impoundment are shown in Figure 4.2. The site location is more flexible because natural topographic features are not as important. Flatter land surface areas are favored because they allow a greater average depth for the same maximum dike height. Although this type of impoundment can be constructed away from stream channels, flat topography usually indicates a flood plain. The closer the tailings impoundment is to the main river channel, the greater the opportunity for severe flood erosion of the impoundment cover material. Because the tailings pile and

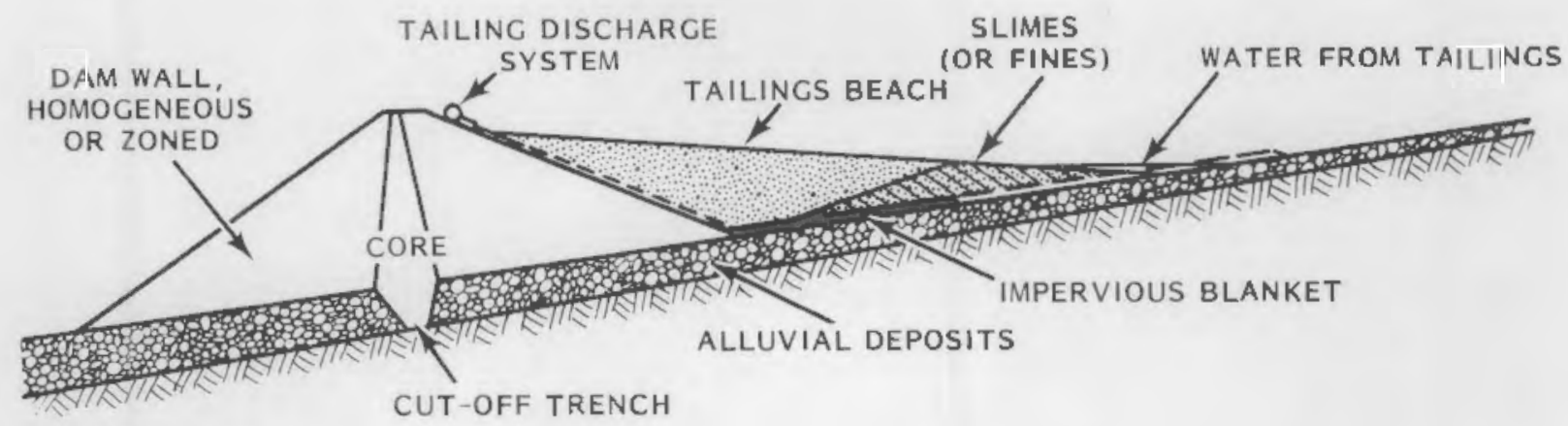

OTHER SOIL STRATA

OR BEDROCK

FIGURE 4.1. Typical Cross-Section of a Valley Dam Impoundment 


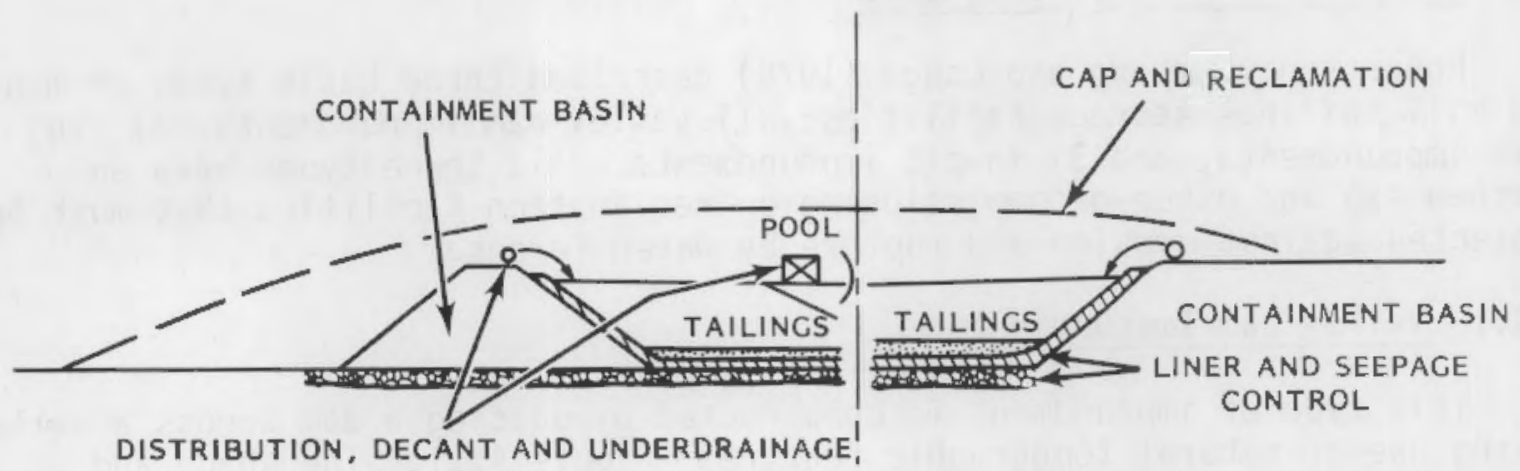

DIKED SURFACEIMPOUNDMENT $\longleftarrow \mid \longrightarrow$ IN PIT OR NATURAL BASIN

FIGURE 4.2. Section Through Tailings Impoundment Illustrating Four Elements

decommissioning cap wi11 extend a number of feet above the flood plain surface, the stresses imposed on the pile by a large flood could easily destroy the structural integrity of the cap and ring dike.

\subsubsection{In-Pit Disposal}

The in-pit disposal method does not require a dike because the storage is below existing ground level, as shown in Figure 4.2. Only the decommissioning cap would be above ground level. This type of impoundment does not produce the prominent surface structure of the dike method, but would be subject to the same erosional forces described for the dike impoundment. 


\subsection{THEORETICAL CONSIOERATIONS}

Rock riprap design methods have been developed around the concept of the initiation of motion of a single particle. Most of the theory comes from sediment transport research based on observation of the phenomena in laboratory flumes and in nature. Because the initial movement of individual particles must be observed, the definition is based on the observers' subjective interpretation of when movement occurs. This is difficult because beginning movement is not instantaneous for all particles of the same size in the surface layer of material. Sorne particles will move while others will not. Movement of a layer of uniformly sized particles is intermittent because of the turbulent flow conditions, which implies a statistical nature to the phenomenon. When the flow over a layer of rock riprap approaches a velocity sufficient to momentarily entrain individual rocks, the rock particles continuously bounce and move back and forth, but generally have no net displacement. A slight increase in velocity would remove some rocks and destroy the structural integrity of the rock armor, exposing the easily erodible soil surface underneath. Scour of the subsurface would rapidly weaken the adjacent rock protection.

The forces acting on a particle subjected to flowing water are the submerged weight of the particle, the lift force, and the drag force. Under critical or threshold conditions the hydrodynamic forces acting on a rock particle are just balanced by the resisting force of the particle. When this force balance has been reached the particle is said to be at the point of incipient motion.

Graf (1971) discusses three basic approaches to the explanation of the physics of beginning movement:

- critical velocity equations, which consider the impact of flowing water on the particles

- critical shear stress equations, which consider frictional drag of the flow on the particles

- lift force mechanism, which accounts for the pressure differences caused by the gradient of the velocity.

\subsection{CRITICAL VELOCITY EQUATIONS}

The critical velocity is sometimes referred to as a competent velocity that is just able to move the material of a given size and of a given specific weight. This velocity $c$ an also be defined: 1) as a competent mean velocity considering the total flow, or 2) a competent bottom (or bed) velocity. The latter is more difficult to define. The concept of relating one of the above velocities to the particle size is quite old. The earliest documented equation of this type was derived by A. Brahms in 1753 (Graf 1971). It was expressed as: 


$$
\left(U_{b}\right)=k w^{1 / 6}
$$

where

$$
\begin{aligned}
\left\langle U_{0}\right) & =\text { bottom velocity } \\
W & =\text { weight of grain } \\
k & =\text { constant. }
\end{aligned}
$$

Using some basic concepts of physics and fluid mechanics, a similar equation can be derived with respect to the forces acting on a particle in flowing water for a condition of incipient movement. This can be initially described by the following equation:

$$
\tan \phi=\frac{F_{t}}{F_{n}}
$$

where $F_{t}$ and $F_{n}$ are the forces parallel and normal to the angle of repose ( $\left.\phi\right)$ of the material. The forces $F_{t}$ and $F_{n}$ are the resultants of the drag and lift forces resulting from the flowing water and the submerged weight of the particle. The angle of repose is the angle of slope formed by rock material under the critical equilibrium condition of incipient sliding. The force diagram for this condition is shown in Figure 5.1.

By resolving the submerged weight into its component vectors, the balance of forces for incipient motion becomes

$$
\tan \phi=\frac{W \sin \alpha+F_{D}}{W \cos \alpha+F_{L}}
$$

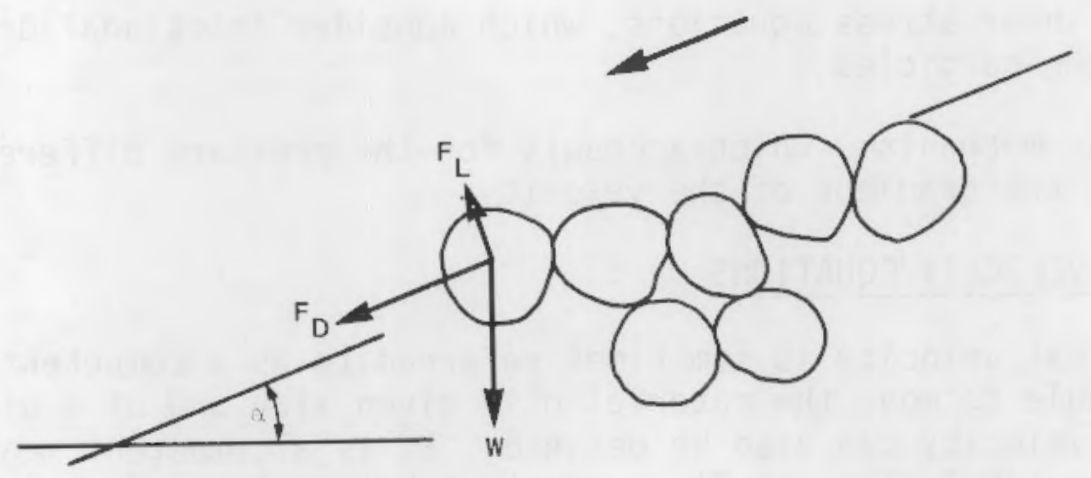

FIGURE 5.1. Force Diagram on Particles in a Cohesionless Loose Bed 
where angle $\alpha$ is the bed slope. If the drag and lift forces are expressed in the usual way by

$$
F_{D}=C_{0} k_{1} d^{2} \frac{U_{b}^{2}}{2}
$$

and

$$
F_{L}=C_{L} k_{2} d^{2} \frac{\rho U_{b}^{2}}{2}
$$

where

$$
\begin{aligned}
U_{b} & =\text { bottom velocity } \\
C_{0}, C_{L} & =\text { drag and lift coefficients, respectively } \\
d & =\text { particle diameter } \\
k_{1}, k_{2} & =\text { particle shape factors } \\
\rho & =\text { water density. }
\end{aligned}
$$

Then the submerged weight of a particle can be written as

$$
W=k_{3}\left(\rho_{s}-\rho\right) g d^{3}
$$

where

$$
\begin{aligned}
\mathrm{k}_{3} & =\text { shape } \text { factor } \\
\mathrm{P}_{5} & =\text { solid-particle density } \\
\mathrm{g} & =\text { gravitational acceleration. }
\end{aligned}
$$

Substitution of Equations (5.4), (5.5), and (5.6) into (5.3) yields

$$
\frac{\left(U_{b}^{2}\right)_{c r}}{\left(\rho_{S} / \rho-1\right) g d}=\frac{2 k_{3}(\tan \phi \cos \alpha-\sin a)}{C_{D} k_{1}+C_{L} k_{2} \tan \phi}=A
$$

where $\left(U_{b}\right)_{c r}=$ critical bottom velocity at incipient motion.

The right-hand side of Equation (5.7) can be written as a single coefficient, $A$, that depends on particle characteristics, dynamics of flow as related to $C_{D}$ and $C_{L}$ values, channel slope, and the angle of repose which also depends on particle properties.

Inherent in this approach is the lack of a good definition of bottom velocity and difficulties in measuring it accurately (Graf 1971). Garde and Ranga Raju (1977) discuss several investigators who have attempted this 
approach, all of whom present their own concept or definition of velocity. Graf (1971) states that the unanswered questions regarding bottom velocity and the proper relationship between bottom velocity and average velocity have led many engineers to accept the more satisfactory approach of using bottom shear stress as a criterion.

\subsection{CRITICAL SHEAR STRESS METHOD}

This method is more commonly referred to as the tractive force approach. When water flows in a channel, across a flood plain, or along an embankment (all of which could be protected against erosion by rock riprap), a force is developed that acts in the direction of flow. The force is essentially the pull of the water on the wetted area. For uniform flow conditions, a common assumption in engineering problems, the tractive force is equal to the effective component of the gravity force acting on the body of water. The problem can be defined by a force diagram on a water prism (Figure 5.2.).

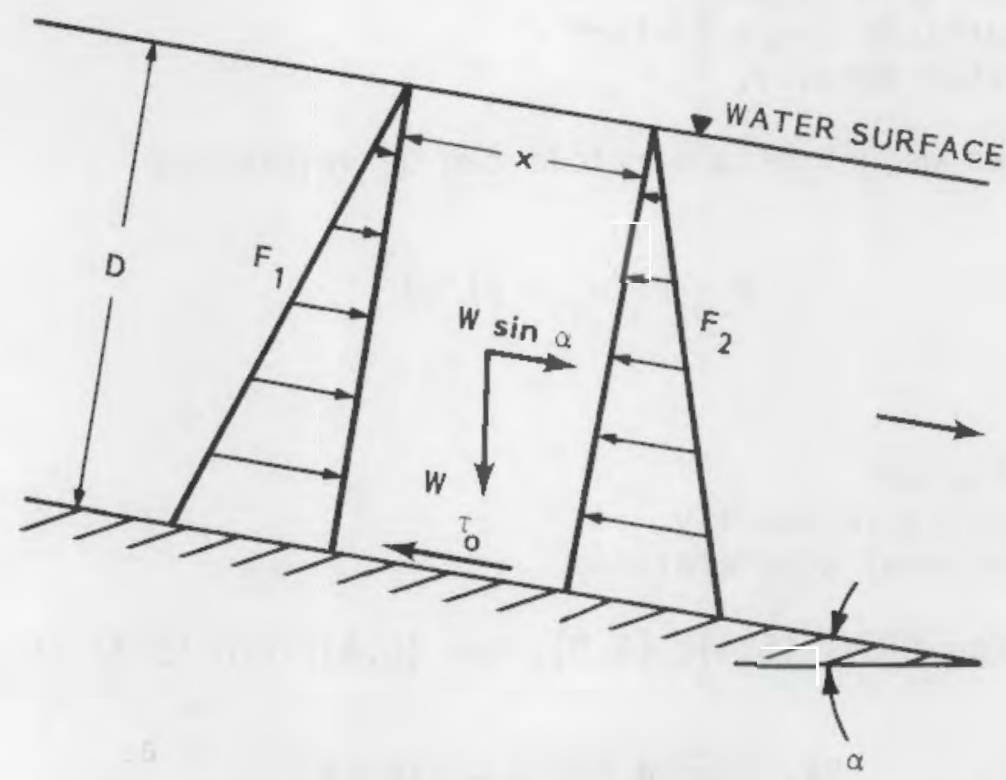

FIGURE 5.2. Forces Acting on a Water Prism

For uniform flow conditions, the water does not accelerate; therefore, a condition of equilibrium can be defined where the summation of all forces acting in the water prism must be zero. The force balance can be written as follows:

$$
\Sigma F=F_{1}+W \sin a-F_{2}-\tau_{0}(P)=0
$$


where $F_{1}=F_{2}=$ hydrostatic forces

$W=$ weight of water prism

$\tau_{0}=$ average shear stress acting on the wetted perimeter, $P$.

Because the forces $F_{1}$ and $F_{2}$ are equal for uniform flow conditions, it follows that $\tau_{0}$ equals (Wsina)/P. For purposes of hydraulic calculations it is usually desirable to assume a rectangular cross-sectional shape and to replace the variables $W$ and $P$ with the hydraulic radius, $R$, which is the crosssectional area divided by the wetted perimeter. The variables $W$ and $P$ can be written in terms of their dimensions $\left(W=B D X_{Y}, P=B+2 D\right)$ where $B$ and $D$ are the water surface width and depth, respectively, $X=$ prism length, and $\gamma=$ unit weight of water.

With the above information, Equation (5.8) can be rewritten and the shear stress, $\tau_{0}$, solved for as follows:

$$
\begin{aligned}
\tau_{0} & =\frac{B D X r \sin \alpha}{(B+2 D) X} \\
& =r R \sin \alpha
\end{aligned}
$$

where $R=\frac{B D}{B+2 D}=$ hydraulic radius.

In most instances where this methodology has been applied, the slope is small; therefore, for small $\alpha, \sin \alpha \cong \tan \alpha=S=$ slope of the bed. The relationship for tractive force then reduces to:

$$
\tau_{0}=\gamma R S
$$

Another way to express the relationship between the weight component of the water column and the friction force at the bottom is as follows:

$$
r R S_{E}=k U^{2}=\tau_{0}
$$

where

$$
\begin{aligned}
S_{E} & =\text { the slope of the energy grade line } \\
k & =a \text { constant } \\
U & =\text { mean velocity of the flow. }
\end{aligned}
$$

By replacing the channel bed slope, S, with the slope of the energy grade line, a mean flow velocity variable is introduced in the equation. The energy grade 
line is the total energy gradient represented by a line located a distance $\mathrm{U}^{2} / 2 \mathrm{~g}$ above the free water surface. Substitution of the relationships of Equation (5.11) into Equation (5.7) yields the following:

$$
\frac{\tau_{0}}{\left(\gamma_{s}-\gamma\right) d}=A
$$

In this relationship the constant, $k$, is included in the term, $A$, and the unit weight of water replaces the density values, $\rho S$ and $\rho$, and the gravitational constant, g. The term $\tau_{0} /\left(\gamma_{S}-\gamma\right) d$ is the ratio of the drag force to the gravitational force. It is a type of Froude Number that is related to the particle size and to a velocity term and is usually referred to as the Shields parameter. Laboratory flume studies by I. A. Shields, completed in 1936, constituted the first successful attempt to quantify the parameter, which has undergone only minor modifications since that time.

\subsection{LIFT FORCE MECHANISM}

Lift forces are caused by a pressure difference on the particle or by the upward velocity components due to turbulence. The pressure differences occur because of the steep velocity gradient, where the velocity at the top surface of a particle at rest on a channel bottom is greater than zero while the velocity at the bottom surface is zero. This sets up a higher pressure along the bottom of the particle and creates an upward force. If the magnitude of the lift force becomes equal to the submerged weight, the smallest drag force could move the particle.

Numerous investigators have tried to measure instantaneous and average lift forces under laboratory conditions, usually in an attempt to understand the mechanism, rather than to determine a critical lift criterion. Graf (1971) describes the results of a study by Einstein, who used plastic spheres ( $d=$ $0.225 \mathrm{ft}$ ) and natural gravel of about the same average size $\left(d_{50}=0.225 \mathrm{ft}\right)$. The gravel had a considerable spread in grain size. The results from the experiment could be expressed by

$$
\Delta p=C_{L} \frac{1}{2} \rho U_{y}{ }^{2}
$$

where $\Delta p=$ static pressure difference in the beds at top and bottom of the particle

$U_{y}=$ velocity at a distance of 0.35 diameter from the theoretical wall $C_{L}=$ a constant value of 0.178 .

This equation is of the form of Equation (5.5), which is the basic equation used to express the lift force.

The laboratory studies are useful in analyzing the phenomenon of lift, but are idealized situations that may bear little resemblance to field conditions. 
The above-described results were derived from uniformly shaped particles much smaller in mean diameter than the rock particles commonly used in riprap protection. Stevens (1969) describes the reported results of a series of lift force studies by Urbonas, who used rock particles closer to scale.

The tests were run on a sphere imbedded in rock particles in a riprapped basin below a culvert outlet. The findings are limited to the range of flow variables and bed characteristics that pertain to scour problems downstream from culvert outlets. The significant findings from this study are as follows:

- The lift force on a particle was much greater than the drag force (fluid shear stress neglected). In one instance the lift was 25 times the drag force; sometimes the drag was in the opposite direction to the mean flow velocity. The fact that the drag force sometimes acted opposite to the mean flow direction is an indication of the extreme turbulence developed along the rock boundary.

- The pressure at the lowest point of the particle almost equals the hydrostatic pressure.

- An average lift force and a fluctuating lift force are associated with the fluctuating pressures.

- Pressure fluctuations are highest near the top of the particles and are nearly zero at the lowest point. The pressure can be assumed to be hydrostatic for the lower half of the particle and constant with respect to time.

As part of Urbonas' experiment, an attempt was made to weigh a rock particle resting on the surface of the bed at flow conditions approaching incipient motion of the rock. The rock weighed approximately 3 ib and was 2-3/4 in. thick and was suspended from a fixed position above the rock bed by a platinum wire. The changes in the weight were monitored by measuring the instantaneous voltage drop between the platinum wire terminals.

The results of this study indicated that whereas the fluctuating particle weight averaged over the test period was $37 \%$ or more of the submerged weight, the instantaneous weight frequently decreased to near zero. These results point out the significance of the turbulent pressure fluctuations and their effect on lift.

Stevens (1969) concluded the following regarding lift and drag forces on rock particles (based on his studies and Urbonas' research):

- A combination of lift and drag forces resulting from the flow causes displacement of the particle. Either of the two forces can predominate, with the geometry of the individual particle and of the surrounding rock layer being the major factor in determining whether the particle is lifted or dragged from its position of rest. When 
the particle is sheltered by adjacent rock, the lift force will predominate, but when more exposed to the flow, the drag force will be the larger.

- The average velocity in the vicinity of the particle is only one of the flow properties governing initiation of motion.

- The important considerations are the total instantaneous lift that can develop from fluid flow and the ratio of this force to the mass of the particles. Even if a high lift force is generated, it must act for a sufficient length of time to accelerate the rock mass into the main flow.

- For uniform flow, the fluctuating forces are directly related to the flow properties of average velocity and turbulence level. These two properties are functions of the projected roughness of the rock layer. However, when abrupt changes in the flow boundary occur, large-scale turbulence may develop that could be considered independent of the rock roughness. In this case, the average velocity is unsuitable as an incipient motion criterion.

\subsection{DISCUSSION}

Three basic approaches have been used to mathematically describe the beginning of particle motion: 1) the critical velocity approach that considers a force balance of a rock particle where the flow velocity generates both a lift and a drag force, 2) the critical shear stress approach that considers a force balance on a water column and the resulting shear force on the rock, and 3 ) the lift force mechanism involving a pressure difference caused by the steep velocity gradient near the rock particle together with upward velocity components resulting from turbulence.

The lift force mechanism approach has not proved to be as useful as the other two approaches, although its importance is recognized. The contribution of lift to the incipient motion problem was pointed out by Stevens' (1969) research that rock particle weight can be reduced to near zero because of the flow velocity. Perhaps the main reason a lift criteria has not been developed is that the critical velocity and shear stress methods implicitly include the lift force effects.

The critical velocity approach considers both 1 ift and drag, but lacks a good definition of an appropriate velocity and its measurement. The velocity value should be as accurate as possible because both lift and drag forces are directly proportional to the square of the velocity term. The velocity just above and around the rock will be less than the mean cross-sectional value and is extremely difficult to measure. In spite of this problem, the critical velocity approach is used in certain riprap design methods by relying on physical model studies and field data. 
The critical shear stress approach relates the fluid shear stress on the rock layer to a mean flow velocity by using relationships such as Equations (5.11) and (5.12). This approach is perhaps the most ideal for riprap design for uranium mill tailings impoundments because only mean crosssectional velocities are easily obtainable for long-term flood conditions. The critical shear stress and velocity approaches are the basis for the riprap design methods discussed in the following section. 



\subsection{RIPRAP DESIGN METHODS}

Most riprap design methods were developed by Federal or state agencies when specific guidelines became necessary to maintain and protect public works projects against erosion by flowing water. Typical projects requiring riprap protection are highway embankments and bridges, flood channels, canals, and stilling basins. Riprap is used extensively in prevention of river bankline erosion, in which case the public works project is itself the application of riprap protection.

Because the flow velocity, flow patterns, and the intensity of turbulence vary for each type of application, the design methods also vary. Nonetheless, they are all based on the same principles of engineering mechanics discussed in the previous section. Many of the equations that form the basis for design can be solved graphically. A family of curves can be developed from the equations for a quick determination of a stone size either directly or by simple trial and error. The approach appears to be simple at first, but each application presents its own set of unique conditions. An example of this would be the protection of a river bank against erosion. A rock size can be determined if flow patterns and velocities are defined, but questions will arise as to how far to extend the protection under water, how many rock courses to use, or how much extra protection is needed at a location where the attack by the flow may be unusually severe. These problems may be dealt with by using a larger safety factor in design (which may be very costly), by determining the magnitude and characteristics of the flow patterns through physical model studies, or by using judgment based on past experience.

The experience of each agency is inherent in its adopted riprap design method. Design methods used by the U.S. Army Corps of Engineers and the California Highway Department are presented here in some detail to illustrate typical approaches to riprap design. Other agency methods are briefly described for purposes of comparison. Perhaps the most recent and comprehensive design procedure is the Riprap Design with Safety Factors Method developed by Colorado State University for the Wyoming Highway Department. The research was conducted in cooperation with the U.S. Department of Transportation, Federal Highway Administration, Bureau of Public Roads. This method is introduced in this section and is presented in more detail in Appendix $A$ as it offers more flexibility in design.

\subsection{RIPRAP DESIGN WITH SAFETY FACTORS METHOD}

The most comprehensive design procedure for rock riprap, which uses the concept of a design safety factor and versatility, has been proposed by Stevens and Simons (1971) and Stevens, Simons and Lewis (1976). The safety factor, SF, is defined as:

$$
\mathrm{SF}=\frac{\text { moments of forces resisting rotation }}{\text { moments of forces tending to dislodge rock }}
$$


where

SF $=1$ indicates critical conditions where incipient motion occurs

$\mathrm{SF}>1$ indicates that riprap is considered safe from failure

$\mathrm{SF}<1$ indicates that rocks would be washed from riprap layer and failure of protection could occur.

Some safety factor must always be included in riprap design because of assumptions inherent in the development of the design method and because of the possibility that the actual stress on the riprap will exceed those used in design. A value of $S F=1.5$ is usualiy an acceptable order of magnitude that would provide a stone weight 1.5 times that calculated to resist incipient motion. The Safety Factor Method offers an advantage over other methods because stone sizes $c$ an be determined directly for incipient motion conditions or for any value of safety factor desired. Other methods may or may not include some safety factor, and if so, the amount is not known. The usual procedure requires the engineer to add some safety factor during the design process, which could lead to overdesign and higher costs.

The design equations for this method involve theoretical considerations from engineering mechanics and empirical information from field and laboratory studies, including lift and drag forces on the rock and Shields criteria for incipient motion. The stability of an individual rock is represented by its submerged weight and its angle of repose. The angle of repose is the angle of slope formed by particulate material under the critical equilibrium condition of incipient sliding (Simons and Senturk 1977).

This approach to riprap design uses sets of equations to determine stone sizes for four possible design conditions involving embankments and channel bed surfaces. These conditions are: 1) oblique flow along an embankment slope, 2) horizontal flow along an embankment slope, 3) flow over a plane sloping bed, and 4) flow over a horizontal bed. The equation sets are summarized below are are derived in Appendix A.

\subsubsection{Nonhorizontal Flow Velocity Adjacent to Side Slope}

$$
\begin{aligned}
S F & =\frac{\cos \theta}{\eta^{\prime} \tan \frac{\tan \phi}{\phi+\sin \theta \cos \beta}} \\
\eta & =\frac{21^{\tau} s}{\left(S_{S}-1\right) \gamma k} \\
\frac{n^{\prime}}{n} & =\frac{1+\sin (\lambda+\beta)}{2}
\end{aligned}
$$




$$
\beta=\tan ^{-1}\left(\frac{\cos \lambda}{\frac{2 \sin \theta}{n \tan \phi}+\sin \lambda}\right)
$$

where

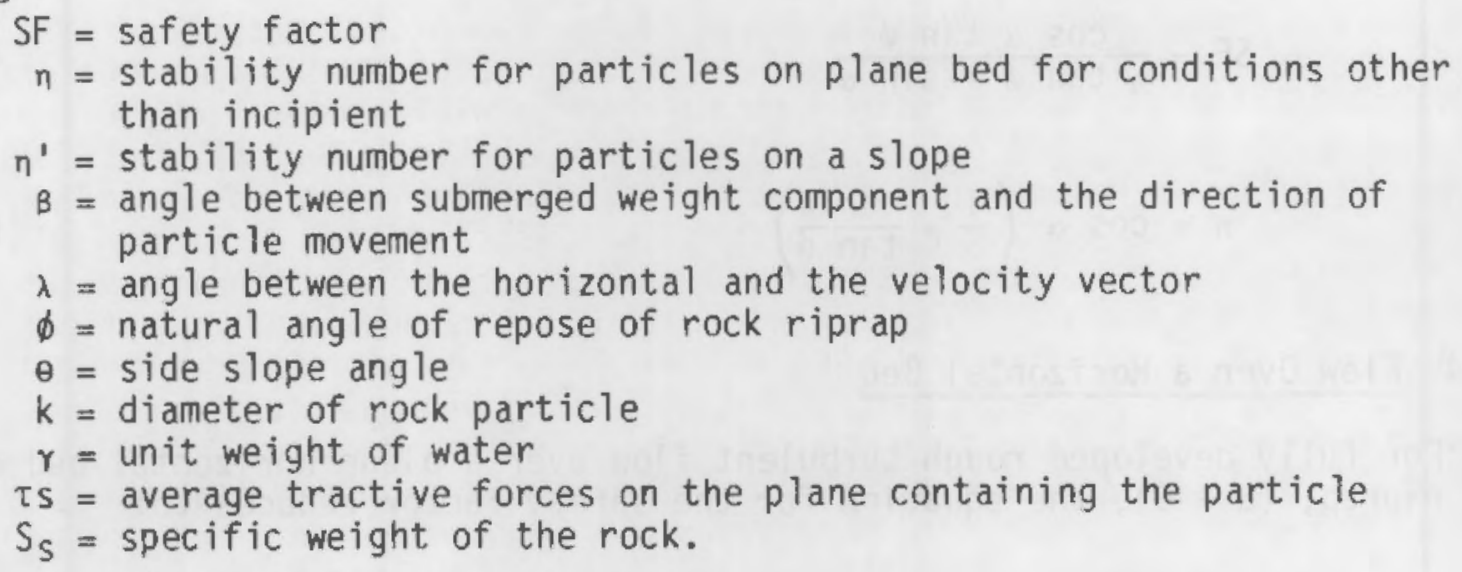

\subsubsection{Horizontal Flow on a Side Slope}

In many cases the flow angularity with the horizontal is small; therefore, $\lambda \approx 0$ and the equations are modified as follows:

$$
\begin{aligned}
B & =\tan ^{-1}\left(\frac{\eta \tan \phi}{2 \sin \theta}\right) \\
\eta^{\prime} & =\left(\frac{1+\sin B}{2}\right) \\
S F & =\frac{S F_{m}}{2}\left[\left(\xi^{2}+4\right)^{1 / 2}-\xi\right] \\
n & =\left(\frac{S F_{m}^{2}-S F^{2}}{(S F) S F_{m}^{2}}\right) \cos \theta
\end{aligned}
$$

where

$$
\begin{aligned}
S_{m} & =\frac{\tan \phi}{\tan \theta}=\text { safety factor for riprap on a side slope with no flow } \\
\xi & =S_{m} n \sec \theta .
\end{aligned}
$$




\subsubsection{Flow Over a Plane Sloping Bed}

The flow over a plane bed at a slope of a degrees in the downstream direction is equivalent to oblique flow on a side slope with $\theta=\alpha$ and $\lambda=90^{\circ}$. The equation is simplified to the following two expressions:

$$
\begin{aligned}
& S F=\frac{\cos \alpha \tan \phi}{\pi \tan \phi+\sin \alpha} \\
& n=\cos \alpha\left(\frac{1}{5}-\frac{\tan \alpha}{\left.\tan -\frac{\alpha}{\phi}\right)}\right.
\end{aligned}
$$

\subsubsection{Flow Over a Horizontal Bed}

For fully developed rough turbulent flow over a plane horizontal bed of rock riprap, $(\alpha=0)$, the equation for the safety factor reduces to:

$$
S F=\frac{1}{n}
$$

For conditions of incipient motion, $S F=1$; therefore, $n=1$ and

$$
\frac{{ }^{\tau} S}{\left(S_{S}-1\right)}=0.047
$$

The above sets of equations defining the stability of rock riprap permit the use of four possible design options for a fixed set of flow conditions on a side slope or on a plane bed as shown below:

- For a given rock size and side slope or bed slope, the safety factor can be computed and the design accepted or rejected on the basis of the value of the safety factor.

- For a given rock size, the side slope or bed slope can be chosen to provide a preselected safety factor.

- For a given side slope or bed slope, the rock size that gives a preselected safety factor can be computed.

- For a given safety factor, the proper combinations of rock size and side slope or bed slope can be computed. 


\subsection{U.S. ARMY CORPS OF ENGI NEERS METHOO}

The Corps of Engineers uses two separate design criteria for the application of riprap protection (U.S. Corps of Engineers 1970). One set of criteria is recommended for stilling basin riprap design where high turbulence conditions exist. It $c$ an al so be used for river closures where low turbulence conditions exist. The second set of criteria is recommended for riprap protection of natural and artificial flood control channels.

\subsubsection{Riprap Design for High Turbulence Conditions}

This set of criteria uses a critical velocity equation developed by a Russian engineer, S. V. Izbash (1932). The equation was originally developed for river channel closures where stone is dumped in flowing water, usually for the purpose of temporary river diversion. The equation estimates a rock size necessary to resist entrainment by the increasing flow velocity as river channel closure is approached. According to Izbash, the basic equation predicting the movement of stone in flowing water can be written as:

$$
V=C_{T}\left\{2 g\left(\frac{Y_{S}-Y}{\gamma}\right)\right\}^{1 / 2}(d)^{1 / 2}
$$

where

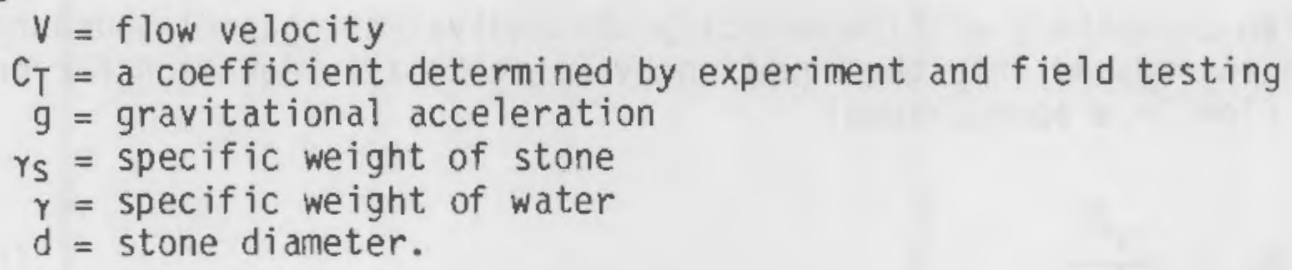

The diameter of a spherical stone in terms of its weight, $w$, is:

$$
d=\left(\frac{6 W}{\pi r_{s}}\right)^{1 / 3}
$$

The substitution for $d$ in the basic equation yields:

$$
V=C_{T}\left\{2 g\left(\frac{\gamma_{S}-\gamma}{\gamma}\right)\right\}^{1 / 2}\left(\frac{6 W}{\pi r_{S}}\right)^{1 / 6}
$$

Izbash determined the values for the coefficient, $C_{T}$, experimentally, with essentially no boundary layer development, using average flow velocities as representative of the velocity against the stone. The results indicated a coefficient value of 0.86 when the stone moved by sliding and 1.20 when it 
moved by rolling or overturning. The U.S. Army Corps of Engineers Waterways Experiment Station (WES) conducted extensive laboratory testing of riprap sizes for stilling basins. The results indicated that a $C_{T}$-value of 0.86 should be used with the average velocity over the end sill because of the excessively high turbulence level in the flow. A set of design curves was developed from the equations by considering incremental stone weights from 135 to $2051 \mathrm{~b} / \mathrm{ft}^{3}$ (Figures 6.1 and 6.2). The solid line curves are recommended for stilling basin riprap and other high turbulence conditions. The dashed line curves are recommended for river closures and similar low-level turbulence conditions.

\subsubsection{Riprap Design for Flood Channels}

The second set of hydraulic design criteria pertains to riprap protection of natural and artificial flood channels. The design equations are based on the concepts of the critical shear stress method and consider a local shear stress exerted on the rock protection. The lift and drag forces caused by flow velocities are proportional to the local boundary shear. The equation for average boundary shear, $\bar{\tau}_{0}$, over the wetted perimeter of a channel crosssection is given by

$$
\bar{\tau}_{0}=\gamma R S_{E}
$$

The design parameters of flow velocity and equivalent channel boundary roughness are introduced into the equation by using Chezy's equation for energy slope of the flow in a open channel:

$$
S_{E}=\frac{v^{2}}{c^{2} R}
$$

where

$$
\begin{aligned}
S_{E} & =\text { slope of the energy gradient } \\
V & =\text { average cross-sectional velocity } \\
R & =\text { hydraulic radius } \\
C & =\text { Chezy coeff icient. }
\end{aligned}
$$
equation:

By using equivalent roughness the value of $C$ is computed by the following

$$
C=32.6 \log _{10}\left(\frac{12.2 R}{k}\right)
$$

where $k$ is the equivalent roughness. By substitution of Equations (6.17) and (6.18) into Equation $(6.16)$ the average boundary shear stress, $\bar{\tau}_{0}$, becomes 


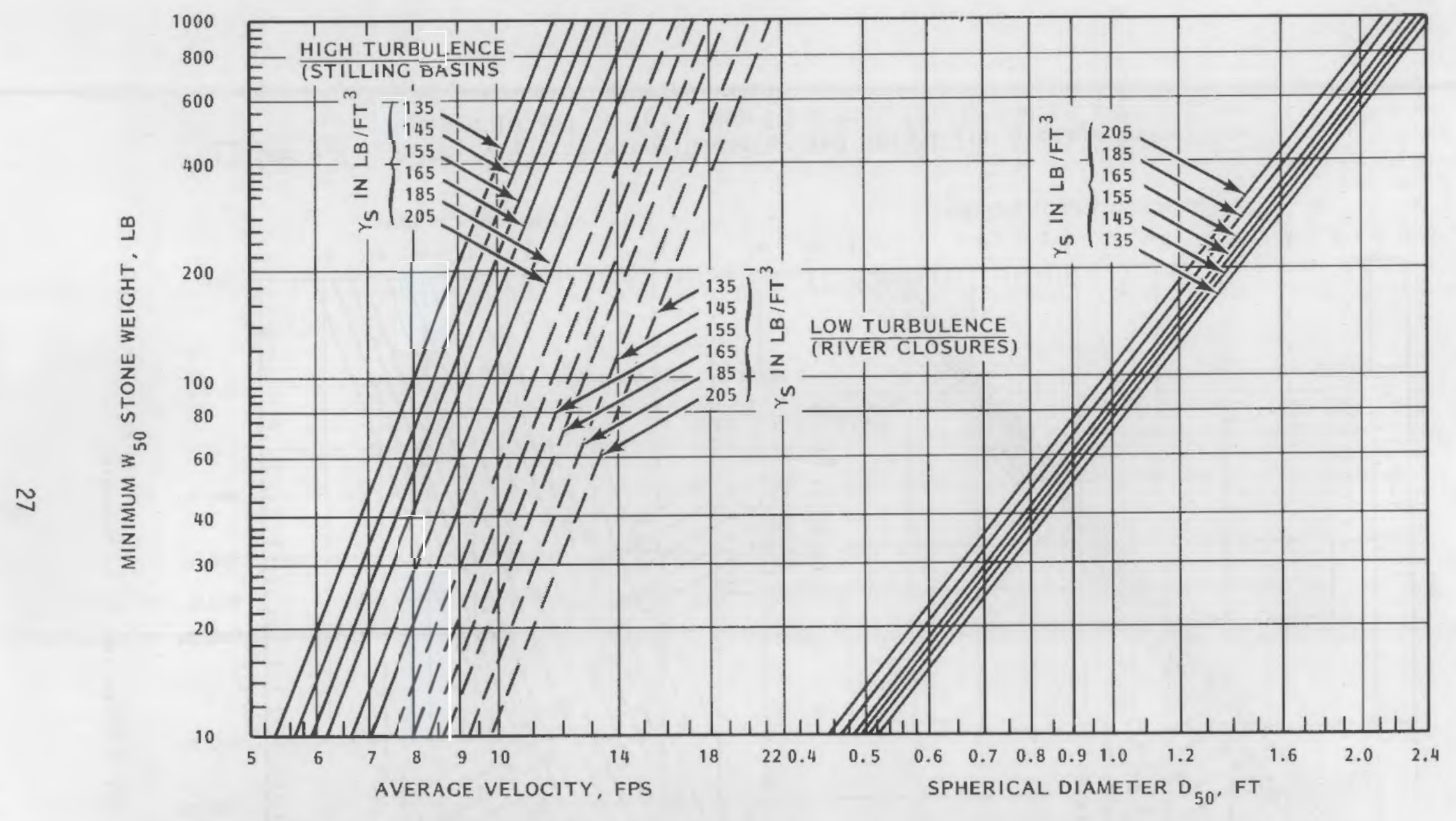

FIGURE 6.1. Velocity Versus Stone Diameter and Weight for Average Velocities Between 5 and $10 \mathrm{fps}$, from Equations (6.13) and (6.14) (U.S. Army Corps of Engineers 1970) 


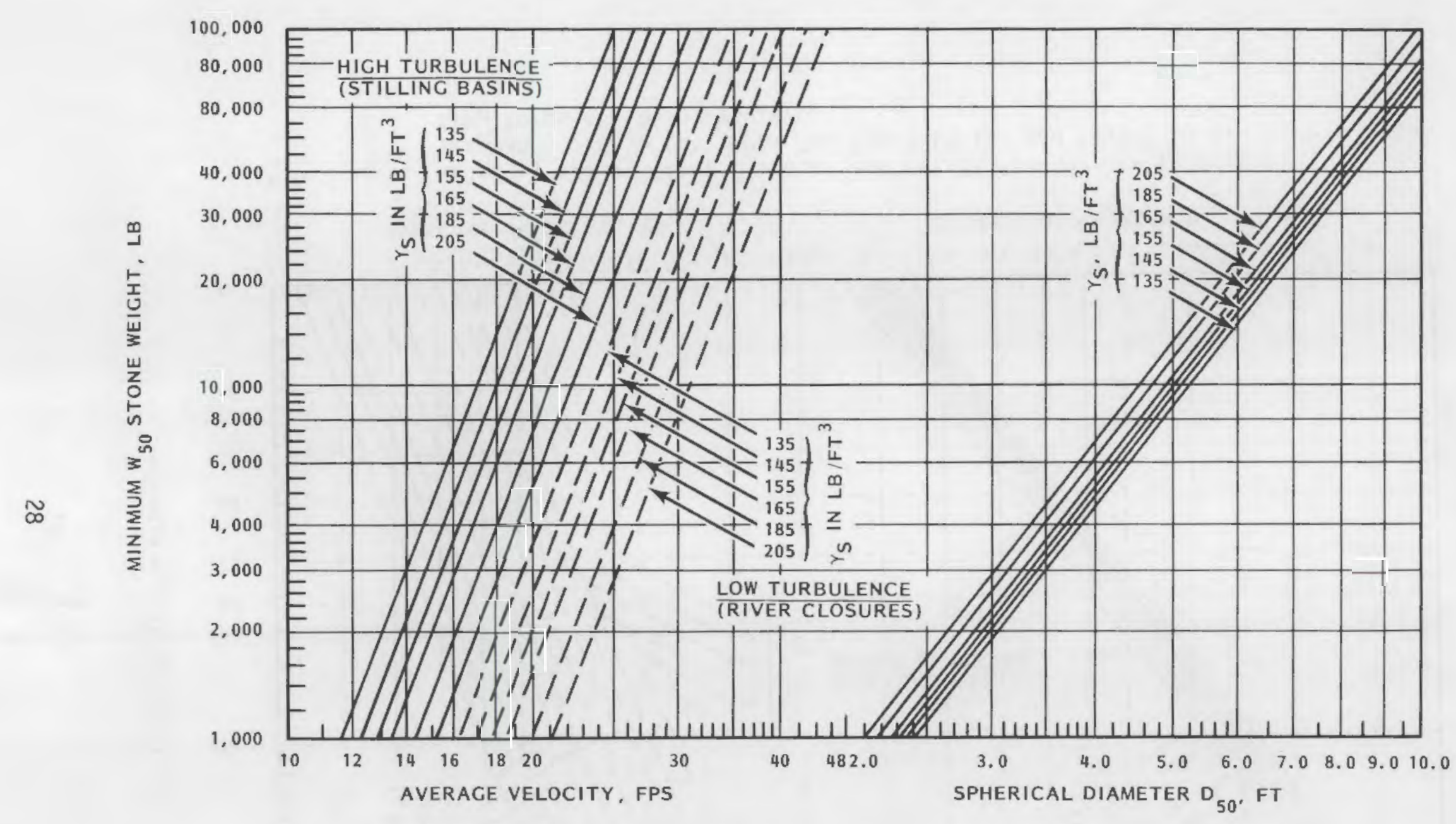

FIGURE 6.2. Velocity Versus Stone Diameter and Weight for Average Velocities Between 10 and $22 \mathrm{fps}$, from Equations (6.13) and (6.14) (U.S. Army Corps of Engineers 1970) 


$$
\bar{\tau}_{0}=\frac{\gamma v^{2}}{\left(32.6 \log _{10} \frac{12.2 R}{k}\right)^{2}}
$$

To compute the local boundary shear at a point in the cross-section, the average local velocity in the vertical, $\bar{V}$, is substituted for $V$; the depth at a point, $y$, is substituted for $R$, and the average stone diameter, $d_{50}$, is substituted for $k$. The local boundary shear, $\tau_{0}$, at any point on the wetted perimeter $c$ an be determined by:

$$
\tau_{0}=\frac{r V^{2}}{\left(32.6 \log _{10} \frac{12.2 y}{d_{50}}\right)^{2}}
$$

Figure 6.3 is a solution of Equation (6.20). To use Figure 6.3 , the ratio of the depth, $y$, and the mean rock gradation diameter, d 50 , is computed and entered in the graph to solve for the coefficient, $k_{2}$. Using the $k_{2}$ value and the average local velocity, the local boundary shear stress is computed. This value is used as a first step in design of riprap protection.

Flood channel bends cause higher localized shear values than do straight sections. From physical model study data the Corps of Engineers determined a relationship between the average boundary shear, $\tau_{0}$, in straight channel segments and local boundary shear, $\tau_{b}$, in channel bends. This relationship is presented in Figures 6.4 and 6.5 . The boundary shear values obtained from Figure 6.3 should be multiplied by the indicated ratios of $\tau_{b} / \tau_{0}$ to obtain local boundary shear values in a channel bend.

The riprap design shear, $\tau$, is defined as the intensity of local boundary shear that the in-place riprap will safely resist. The design shear for riprap placed on a nearly horizontal channel bottom is given by:

$$
\tau=a\left(\gamma_{s}-\gamma\right) d_{50}
$$

where $a=0.040$.

The design shear, $\tau^{\prime}$, for riprap placed on channel side slopes is given by:

$$
\tau^{\prime}=\tau\left(1-{\frac{\sin ^{2} \phi}{\sin ^{2} \theta}}^{0.5}\right.
$$




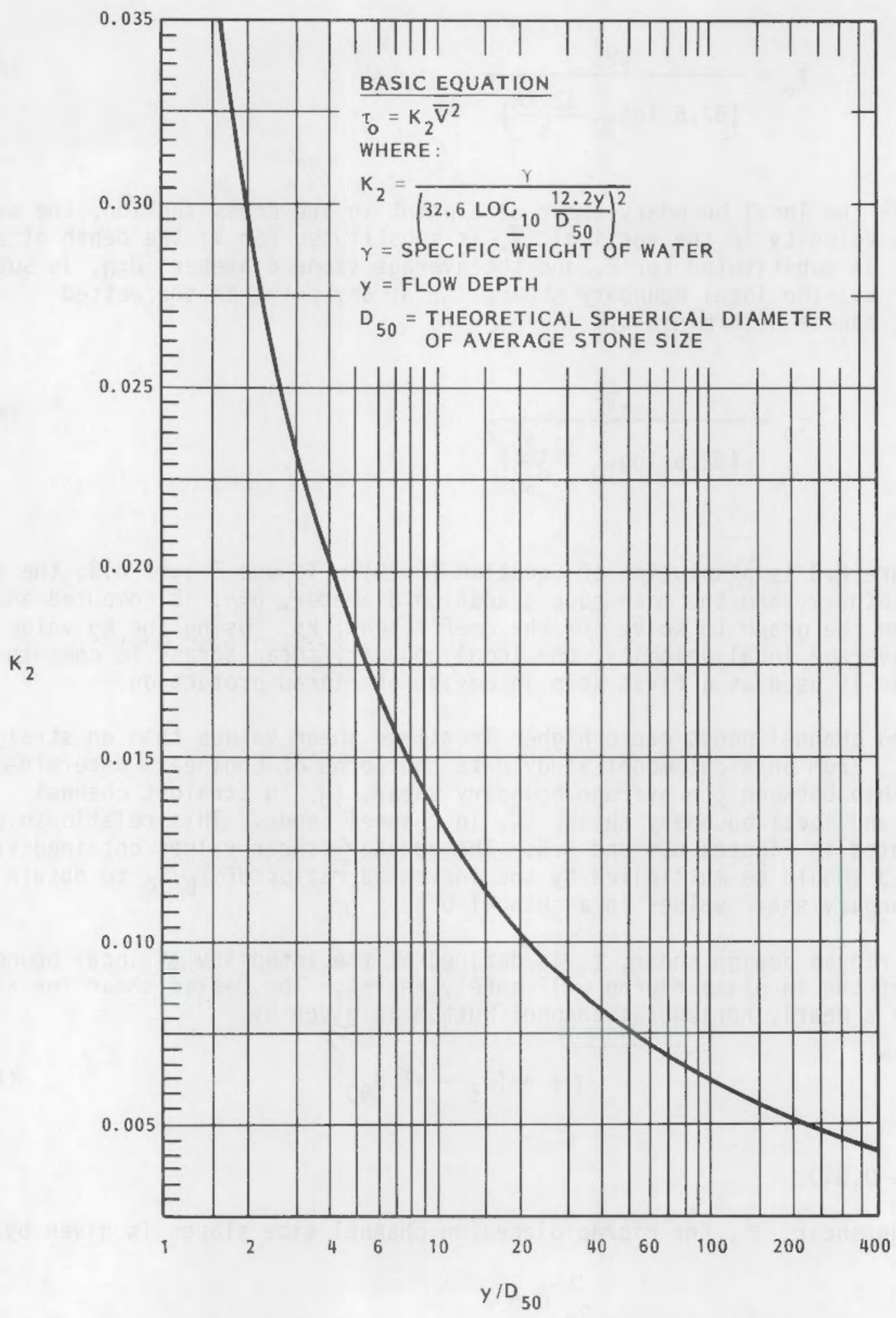

FIGURE 6.3. Relationship of Local Boundary Shear Stress to the Median Rock Diameter and Local Depth (U.S. Corps of Engineers 1970) 

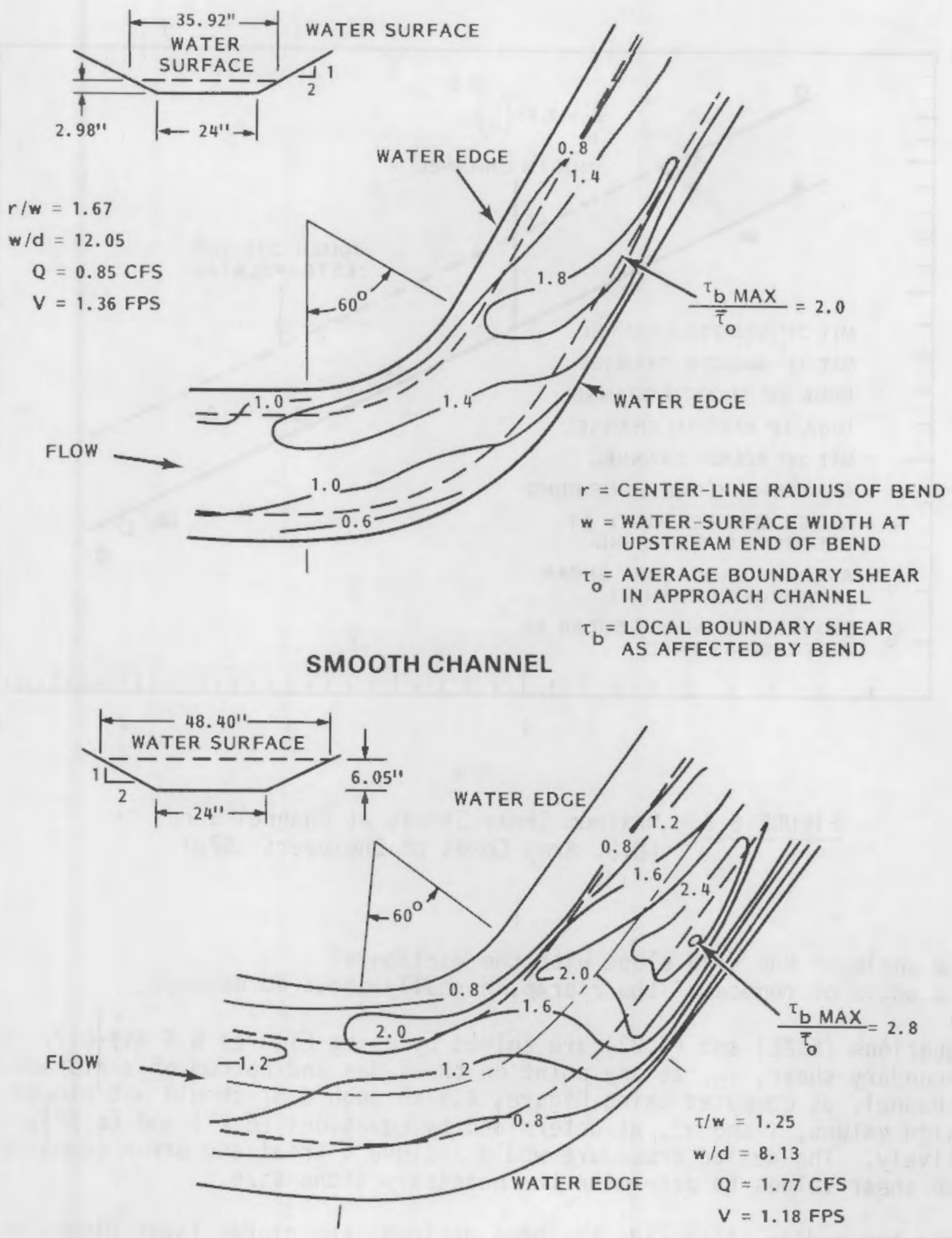

ROUGH CHANNEL

FIGURE 6.4. Relationship of Average Boundary Shear Stress in Approach Channel to Local Boundary Shear Stress in Bends Based on Experiments (U.S. Army Corps of Engineers 1970) 


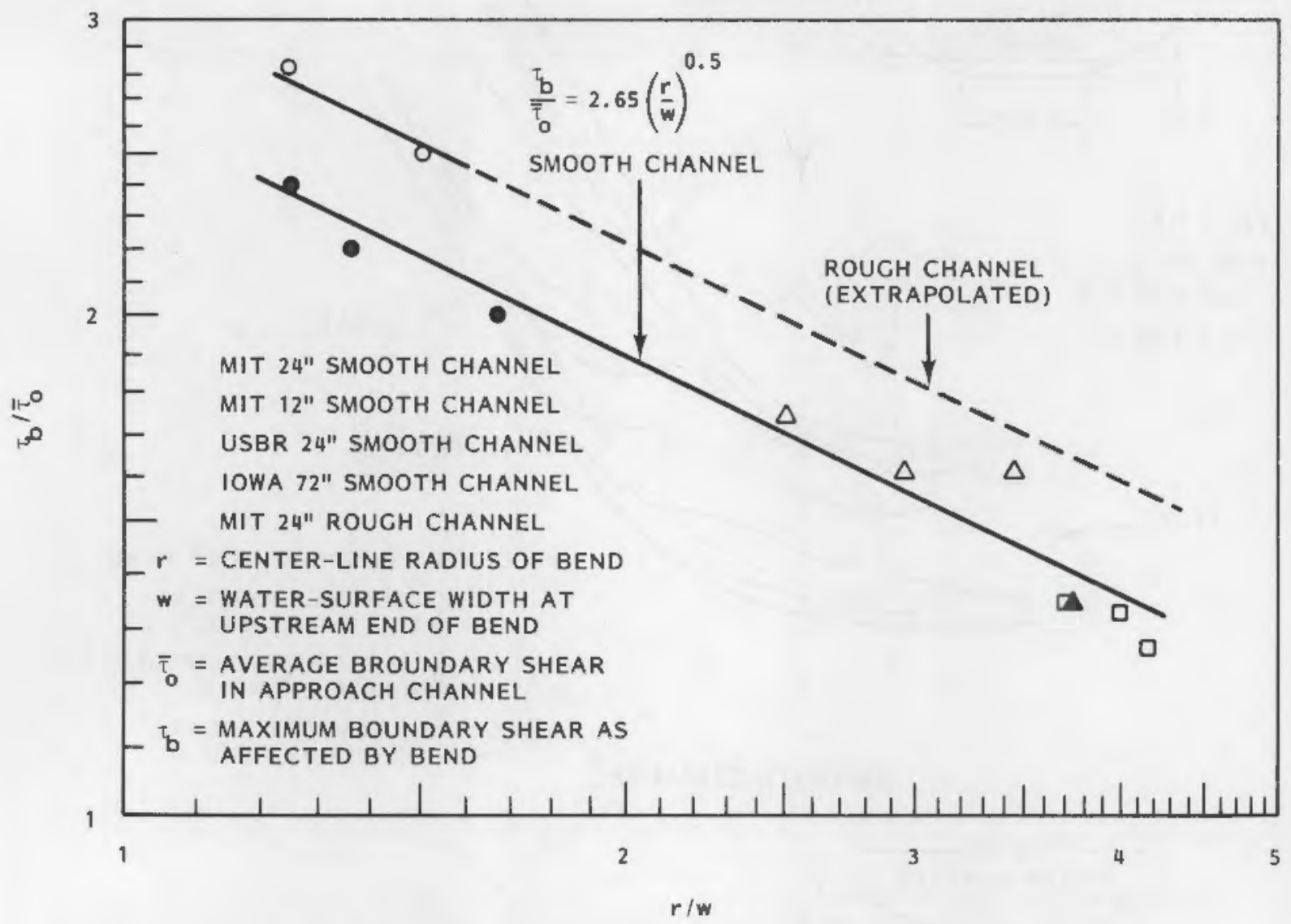

FIGURE 6.5. Maximum Shear Stress at Channel Bends (U.S. Army Corps of Engineers 1970)

where

$\phi=$ angle of the side slope with the horizontal

$\theta=$ angle of repose of the riprap, normally about 40 degrees.

Equations (6.21) and (6.22) are solved by using Figures 6.6 and 6.7 . The local boundary shear, $\tau_{0}$, at any point on the sides and bottom of a ripraplined channel, as computed using Figures 6.1 through 6.5 , should not exceed the design values, $\tau$ and $\tau^{\prime}$, as determined by Equations (6.21) and (6.22), respectively. The design procedure would include a trial and error comparison of these shear values to determine the necessary stone size.

Once the median stone size has been defined, the riprap layer dimensions must be determined based on a gradation of stone sizes. The Corps of Engineers uses specific guidelines for stone gradation and layer thickness together with Figures 6.1 through 6.7 to complete the design process. The guidelines have been developed through laboratory and field studies and experience. 


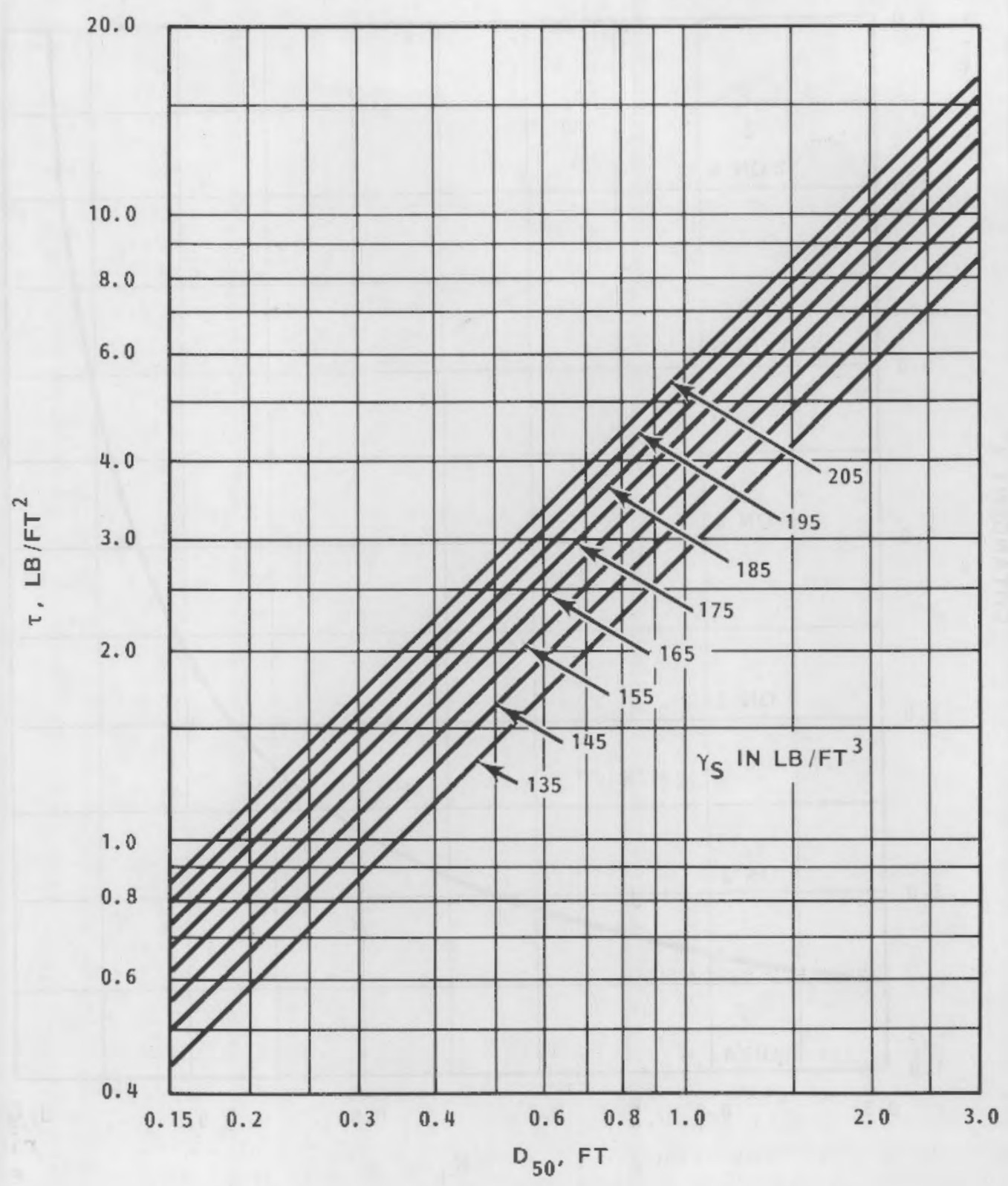

FIGURE 6.6. Design Shear for Riprap on the Channel Bottom from Equation (6.21) (U.S. Army Corps of Engineers 1970) 


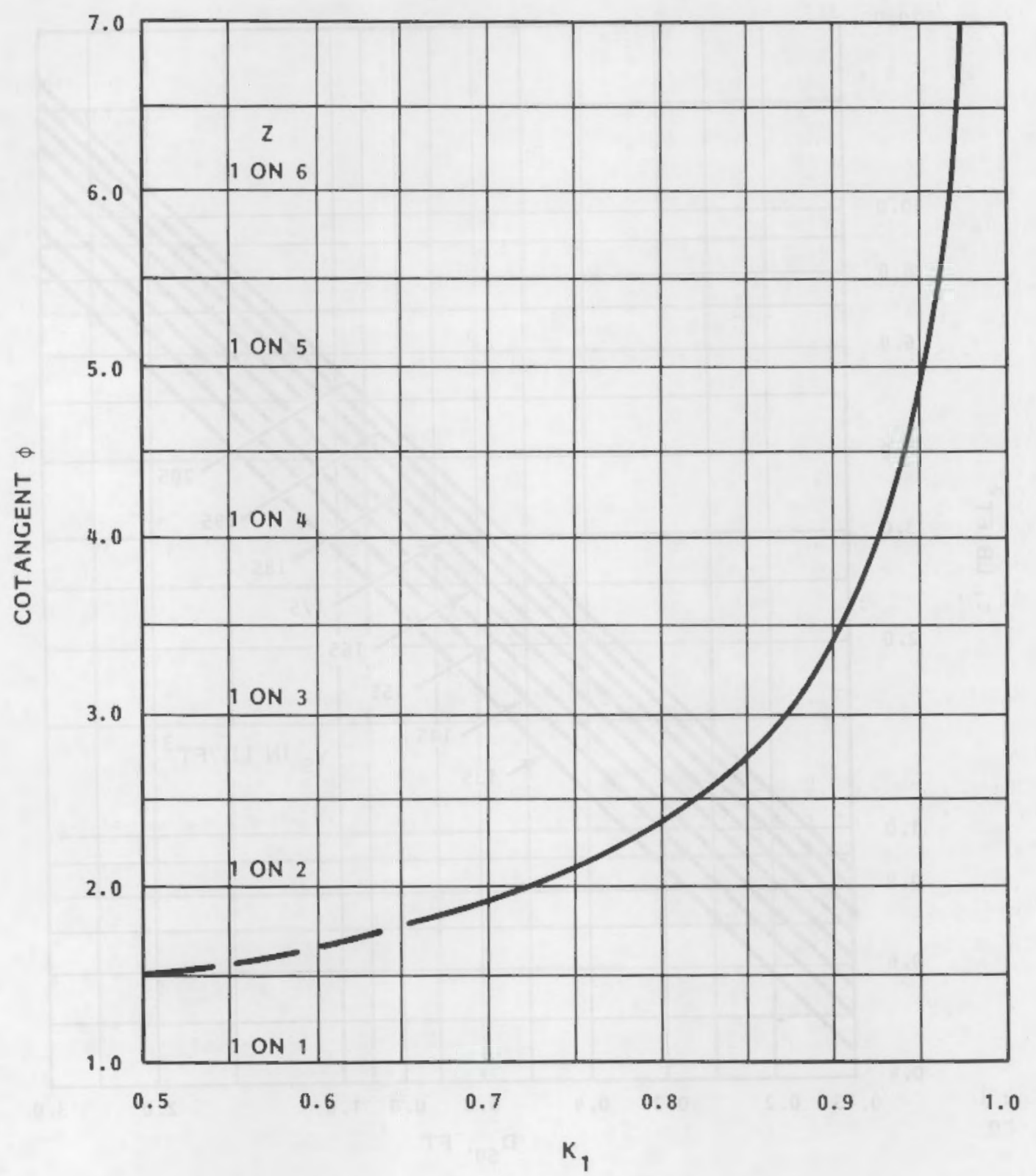

FIGURE 6.7. Design Shear Ratios for Riprap in Trapezoidal Channels Where $Z$ is the Side Slope (U.S. Army Corps of Engineers 1970) 


\section{Stone Gradation}

The gradation of stones affects the erosion resistance of the riprap; therefore, the stone should be reasonably well graded throughout the in-place layer thickness. The Corps of Engineers method specifies two limiting gradation curves where stone gradation (as determined from a field test sample) lies within these limits. The gradation limits should not be so restrictive that stone production costs at the quarry became excessive. The gradation limits also depend on the underlying filter requirements if a graded stone filter is used. The U.S. Army Corps of Engineers (1970) has established the following criteria to provide guidelines for gradation limits ( $W=$ stone weight; subscript indicates percent lighter by weight):

1. The lower limit of $W_{50}$ stone should not be less than the weight of stone required to withstand the design shear forces as determined by the riprap design procedure.

2. The upper limit of $W_{50}$ stone should not exceed that weight that can be obtained economically from the quarry, or that size that will satisfy layer thickness requirements.

3. The lower limit of $W_{100}$ stone should not be. less than two times the lower limit of $W_{50}$ stone.

4. The upper limit of $W_{100}$ stone should not exceed five times the lower limit of $W_{50}$ stone, that size that $c$ an be obtained economically from the quarry, or that size that will satisfy layer thickness requirements.

5. The lower limit of $W_{15}$ stone should not be less than one-sixteenth the upper limit of $W_{100}$ stone.

6. The upper limit of $W_{15}$ stone should be less than the upper limit of W50 stone, as required to satisfy criteria for graded stone filters.

7. The bulk volume of stone lighter than the $W_{15}$ stone should not exceed the volume of voids in revetment without this lighter stone.

8. Wo to $W_{25}$ stone may be used instead of $W_{15}$ stone in criteria (5), (6), and (7) if using available stone sizes is desirable. Design memoranda and specifications should indicate the permissible stone gradation limits by a tabulation, illustrated as follows:

\section{Sample Gradation}

\begin{tabular}{|c|c|}
\hline $\begin{array}{l}\text { Percent Lighter } \\
\text { by Weight, SSD }\end{array}$ & $\begin{array}{l}\text { Limits of Stone } \\
\text { Weight, 1b }\end{array}$ \\
\hline 100 & 260 to 640 \\
\hline 50 & 130 to 200 \\
\hline 15 & 40 to 150 \\
\hline
\end{tabular}

(a) Saturated surface dry 


\section{Riprap Layer Thickness}

All stones should be placed well within the riprap layer thickness for maximum resistance to displacement forces. Oversized stones, even in isolated spots, may reduce particle interlock between individual stones, provide large voids that expose filter and bedding materials, and create excessive local turbulence that removes smaller stones. The U.S. Army Corps of Engineers (1970) specifies the following criteria for designing riprap layer thickness:

1. The thickness should not be less than the spherical diameter of the upper limit $W_{100}$ stone or less than 1.5 times the spherical diameter of the upper limit $W_{50}$ stone, whichever is greater.

2. The thickness should not be less than $12 \mathrm{in.}$ for practical placement.

3. The thickness, determined by either (1) or (2), should be increased by $50 \%$ when the riprap is placed under water, to provide for uncertainties associated with this type of placement.

4. An increase in thickness of 6 to $12 \mathrm{in.,} \mathrm{accompanied} \mathrm{by} \mathrm{appropriate}$ increase in stone sizes, should be provided where riprap revetment may be attacked by large floating debris or by waves from boat wakes, wind, and bed ripples or dunes.

\subsection{CALIFORNIA HIGHWAY OEPARTMENT METHOD}

Highway departments use riprap to protect highway embankments and bridges from scour and erosion along stream channels, coastal areas, and lakes. The riprap protection adjacent to stream channels and at bridge crossings must resist stream flow velocity and turbulence, whereas protection works along coastlines and lake shores must resist erosion by wave action.

The California Highway Department uses one general equation for riprap design. The equation provides the basis for three different design methods where only one variable is changed, depending on the type of location and physical conditions at the site. For streambank protection the stream velocity is the significant design variable. In the case of shoreline protection there are two forms of the equation: one considers a significant wave height; the other considers a depth of water.

\subsubsection{Streambank Protection}

Where streamflow velocity governs, the following equation is used:

$$
w=\frac{0.0002 v^{6}(s g) \csc ^{3}(e-\alpha)}{(s g-1)^{3}}
$$


where

$V=$ stream velocity in feet per second (fps) to which the bank is exposed

$W=$ minimum weight in pounds of outside stone for no damage

$\mathrm{sg}=$ specific gravity of the stones

$\rho=70^{\circ}$ for randomly $\mathrm{placed}$ rubble

$\alpha=$ embankment slope.

The derivation of the above equation is not documented in the highway department design manual; however, it is very similar to Equation (6.15). Solving Equation (6.15) for the particle weight, $W$, would yield a relationship where the particle weight is directly proportional to the sixth power of the velocity.

The equation used to design riprap protection for streambank application is solved by using the nomograph of Figure 6.8. The specif ic gravity of the stone and streamflow velocity $c$ an be determined by measurement or through calculations. The embankment slope can be varied to suit engineering and economic considerations. These values $c$ an be entered in the nomograph to determine the stone weight, $W$.

\subsubsection{Shoreline Protection}

Two forms of the equation are used for designing shoreline protection. One form deals with the forces of deep water waves that are able to reach the embankment:

$$
w=\frac{0.00231 H^{3}(s g) \csc ^{3}(\rho-a)}{\left(\frac{s g}{s g_{w}}-1\right)^{3}}
$$

where

$$
\begin{aligned}
H & =\begin{array}{l}
\text { significant wave height defined as the average of the highest } \\
\text { one-third }
\end{array} \\
\mathrm{sg}_{W}= & \text { specific gravity of water (sea water }=1.0265 \text { ). }
\end{aligned}
$$

Wave runup is accommodated by using an elevation of rock protection twice the maximum depth of water or the maximum depth of water plus the deep water wave height, whichever is lower. This is to prevent wave wash from overtopping the rock too frequently. This equation is solved by the nomograph in Figure 6.9.

The other form of the equation considers shoal water conditions and uses a depth of water instead of a wave height. A relationship exists between the depth of water at the protected embankment and the maximum height of the breaker that expends its energy upon the protection. The wave that would ordinarily break at the depth of water near the embankment is the wave that will expend a maximum amount of energy on the rock riprap. The equation for this condition is as follows: 


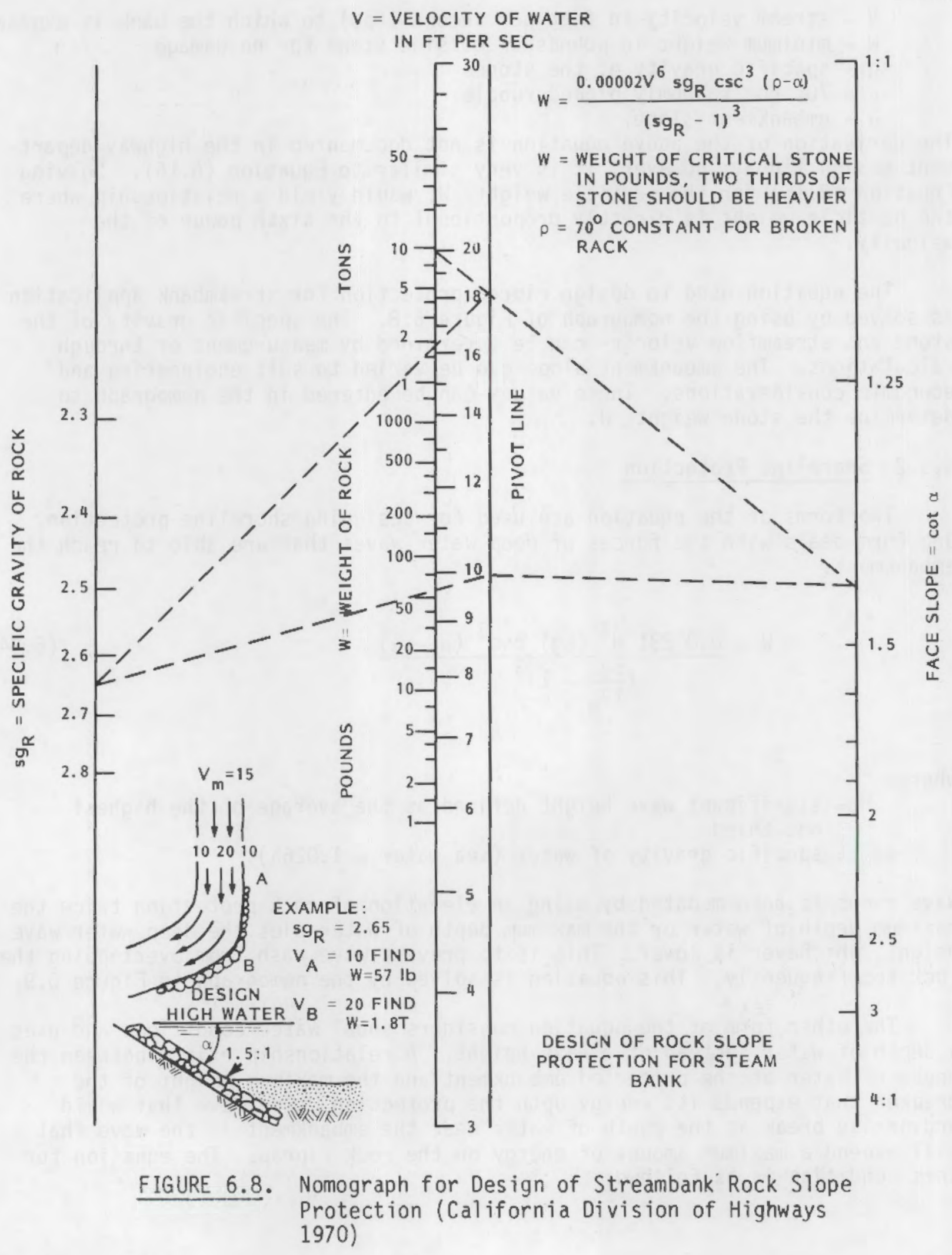




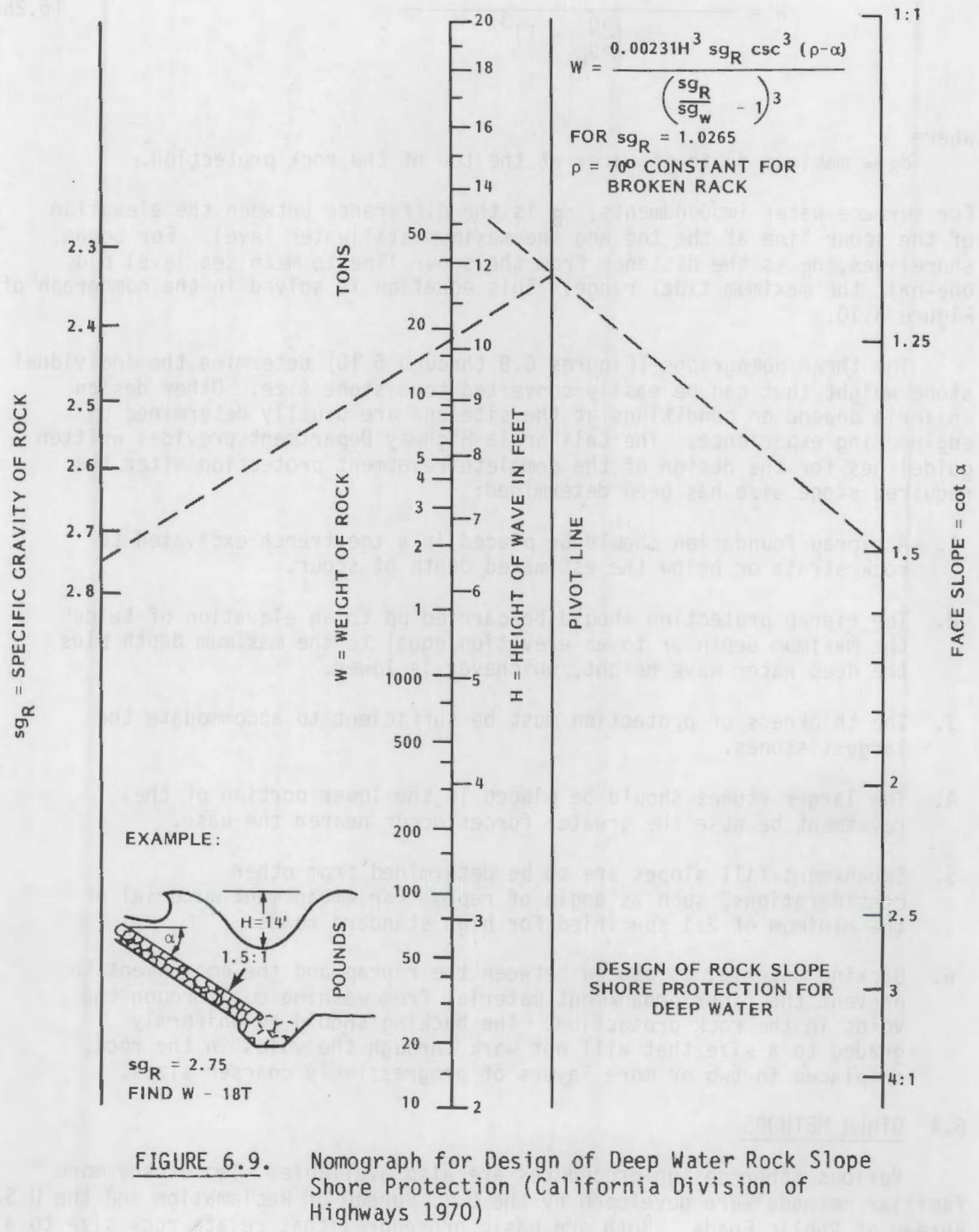




$$
W=\frac{0.003 d_{B}^{3}(s g) \csc ^{3}(0-a)}{\left(\frac{s g}{s g_{W}}-1\right)^{3}}
$$

where

$\mathrm{d}_{\mathrm{B}}=$ maximum depth of water at the toe of the rock protection.

For surface-water impoundments, $d_{B}$ is the difference between the elevation of the scour line at the toe and the maximum stillwater level. For ocean shorelines, $d_{B}$ is the distance from the scour line to mean sea level plus one-half the maximum tidal range. This equation is solved in the nomograph of Figure 6.10.

The three nomographs (Figures 6.8 through 6.10 ) determine the individual stone weight that can be easily converted to a stone size. Other design criteria depend on conditions at the site and are usually determined by engineering experience. The California Highway Department provides written guideiines for the design of the complete revetment protection after the required stone size has been determined:

1. A riprap foundation should be placed in a toe trench excavated to rock strata or below the estimated depth of scour.

2. The riprap protection should be carried up to an elevation of twice the maximum depth or to an elevation equal to the maximum depth plus the deep water wave height, whichever is lower.

3. The thickness of protection must be sufficient to accommodate the Targest stones.

4. The larger stones should be placed in the lower portion of the revetment because the greater forces occur nearer the base.

5. Embankment fill slopes are to be determined from other considerations, such as angle of repose for embankment material or the minimum of 2:1 specified for high standard roads.

6. Backing material is placed between the riprap and the embankment to prevent the finer embankment material from washing out through the voids in the rock protection. The backing should be uniformly graded to a size that will not work through the voids in the rock, or placed in two or more 1 ayers of progressively coarser sizes.

\subsection{OTHER METHODS}

Various other design procedures are also available. Two of the more familiar methods were developed by the U.S. Bureau of Reclamation and the U.S. Bureau of Public Roads. Both are basic procedures that relate rock size to a 


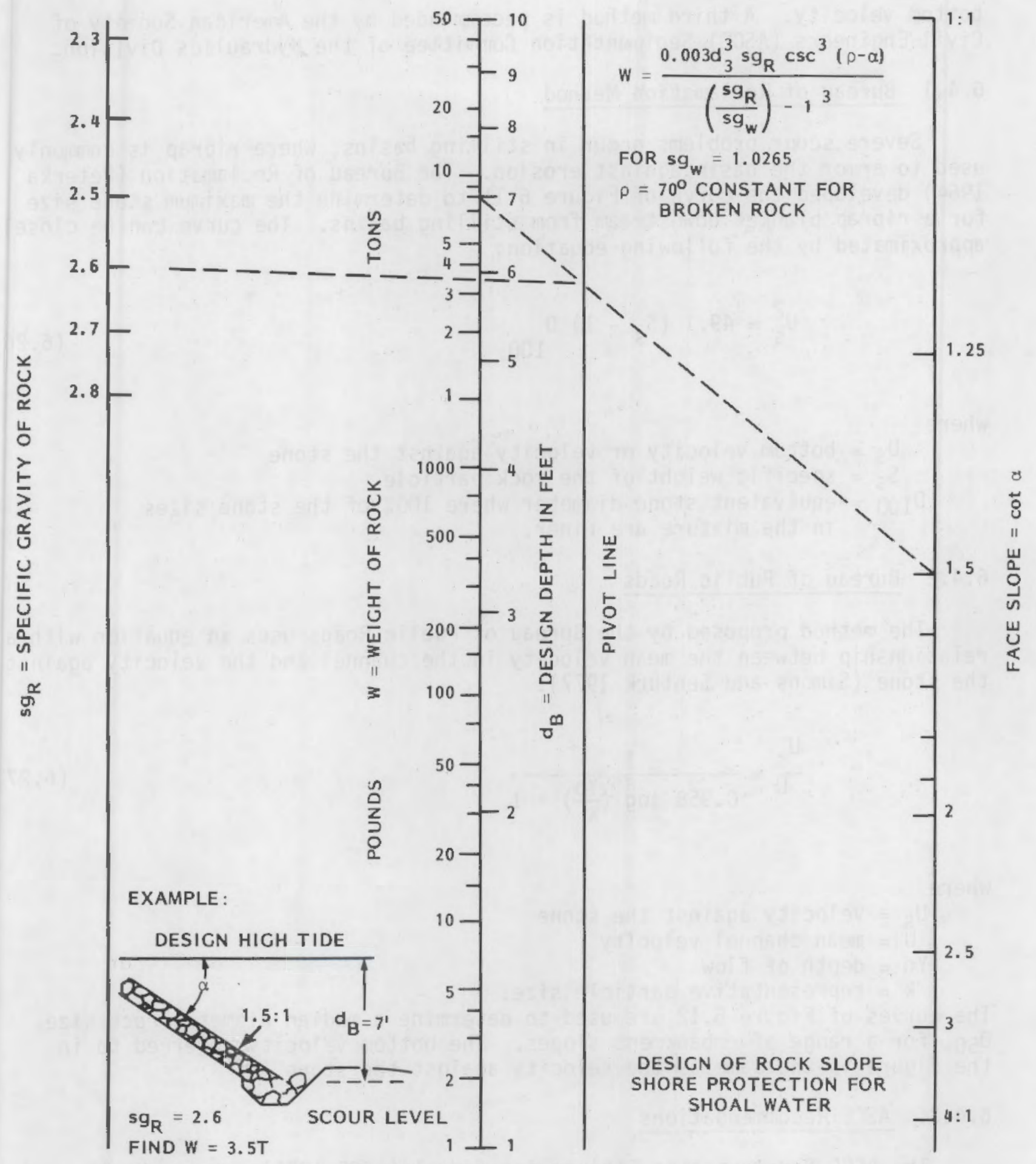

FIGURE 6.10. Nomograph for Design of Shoal Water Rock Slope Shore Protection (California Division of Highways 1970) 
bottom velocity. A third method is recommended by the American Society of Civil Engineers (ASCE) Sedimentation Committee of the Hydraulics Division.

\subsubsection{Bureau of Reclamation Method}

Severe scour problems occur in stilling basins, where riprap is commonly used to armor the basin against erosion. The Bureau of Reclamation (Peterka 1964) developed the curve of Figure 6.11 to determine the maximum stone size for a riprap blanket downstream from stilling basins. The curve can be closely approximated by the following equation:

$$
U_{s}^{2}=49.1\left(s_{s}-1\right) D_{100}
$$

where

$U_{S}=$ bottom velocity or velocity against the stone

$S_{S}=$ specific weight of the rock particle

$D_{100}=$ equivalent stone diameter where $100 \%$ of the stone sizes in the mixture are finer.

\subsubsection{Bureau of Public Roads}

The method proposed by the Bureau of Public Roads uses an equation with a relationship between the mean velocity in the channel and the velocity against the stone (Simons and Senturk 1977):

$$
\frac{U_{S}}{U}=\frac{1}{0.958 \log \left(\frac{Y_{0}}{k}\right)+1}
$$

where

$$
\begin{aligned}
U_{S} & =\text { velocity against the stone } \\
U & =\text { mean channel velocity } \\
Y_{0} & =\text { depth of flow } \\
K & =\text { representative particle size. }
\end{aligned}
$$

The curves of Figure 6.12 are used to determine a median diameter rock size, $D_{50}$, for a range of embankment slopes. The bottom velocity referred to in the figure is the same as the velocity against the stone.

\subsubsection{ASCE Recommendations}

The ASCE Sedimentation Engineering manual (ASCE 1975) recommends the use of Izbash's equation to determine a required stone weight: 


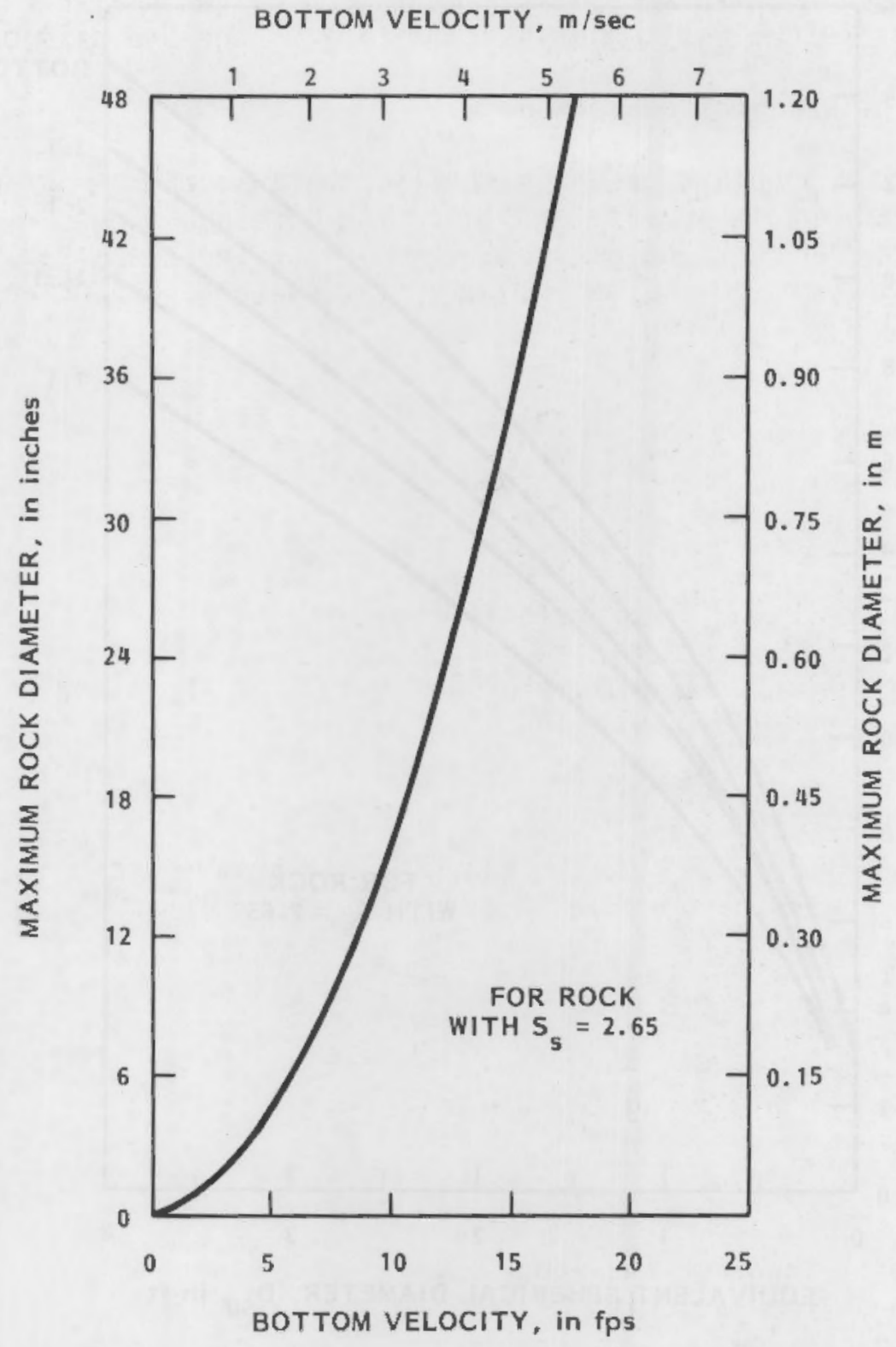

FIGURE 6.11. Rock Size for the Bureau of Reclamation Design (Simons and Senturk 1977)

$$
w=\frac{4.1 \times 10^{-5} \mathrm{sgv}^{6}}{(\mathrm{sg}-1)^{3} \cos ^{3} \phi}
$$

where

$$
\begin{aligned}
& W=\text { weight of stone } \\
& V=\text { velocity }
\end{aligned}
$$




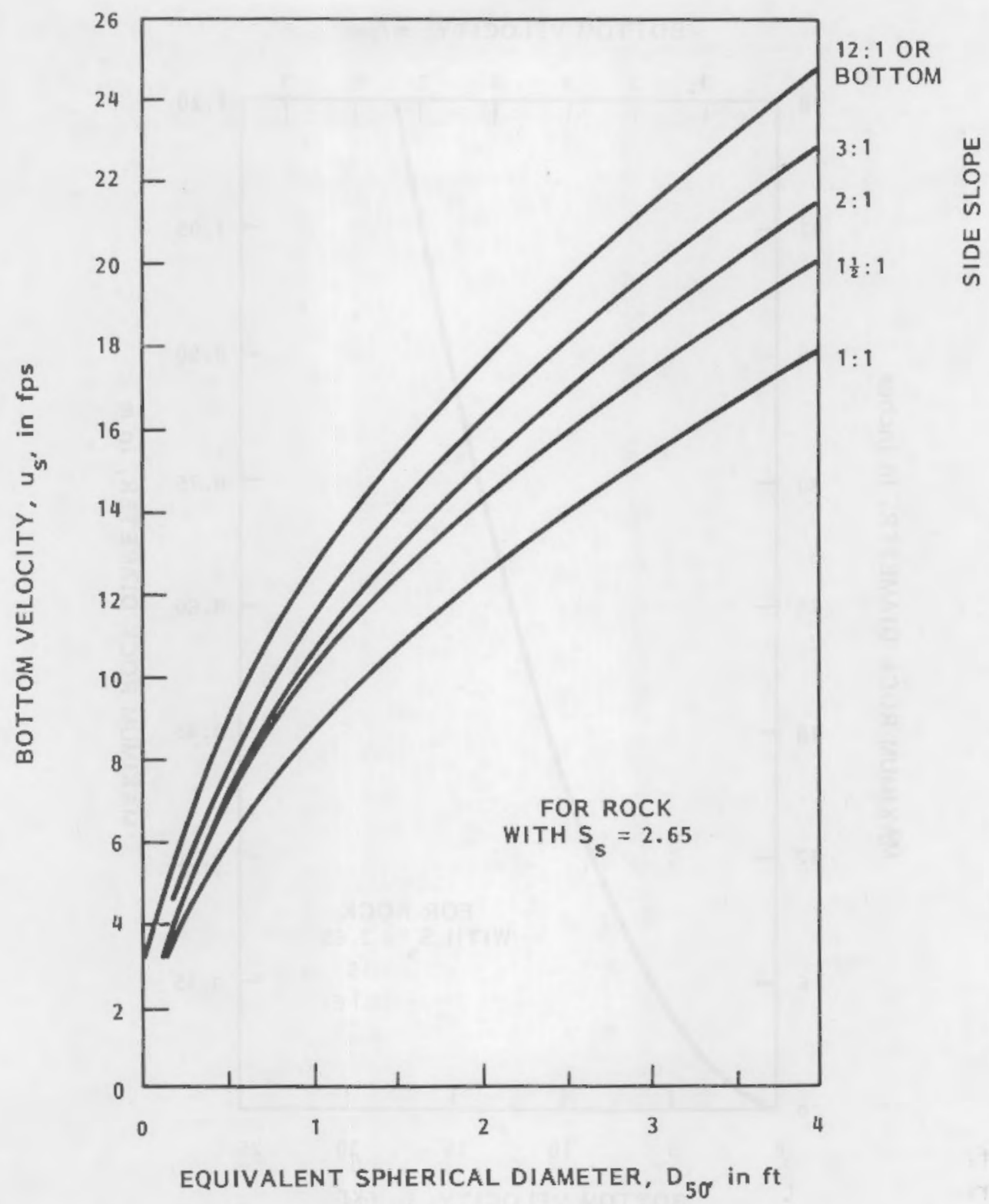

FIGURE 6.12. Rock Size for the Bureau of Public Roads Design (Simons and Senturk 1977)

sg = specific gravity of stone

$\phi=$ angle of pavement with the horizontal.

According to Simons and Senturk (1977), the stone weight, $W$, is the median stone weight. The ASCE manual suggests that the velocity used is usually the velocity at a distance of $10 \mathrm{ft}$ from the bank. The above equation is essentially the same as that used by the California Highway Department. 
The ASCE manual also lists the following guidelines for a design scheme to produce a stable rock revetment (ASCE 1975). The stone should:

1. be placed only on a bank that has been sloped and properly aligned

2. possess adequate strength to resist movement by the flow or breakage caused by the impact of debris, floating ice, etc.

3. be sufficiently tight to prevent removal of the underlying soil materials through the interstices

4. be sufficiently flexible to conform to any irregularities in the bank

5. be sufficiently mobile to settie into any breaks that might develop, by soil settlement or otherwise, and thus be self-healing.

In addition, the manual suggests that riprap revetments that need not extend more than $15 \mathrm{ft}$ vertically below the normal water surface should be sufficiently rough to create a zone of intensified turbulence and low velocity in the vicinity.

\subsection{COMPARISON OF METHODS}

The methods presented in the preceding sections were developed for various design conditions and applications. A variety of mathematical relationships and empirical data sets were used in their development; thus, a methodby-method comparison of the safety factor provided by each would be extremely difficult. Also, no simple way exists to obtain an equitable comparison between a design method developed for side slopes and one developed for horizontal beds. Only limited comparisons of the Safety Factor Method with others have been made by Simons and Senturk (1977) and Simons and Lewis (1971). These studies analyzed the various methods to determine the unknown amount of safety factor in each that could lead to either an uneconomical overdesign on an unsafe underdesign. The Safety Factor Method allows direct computation of a design safety factor or allows it to be specified before computing the stone size; therefore, for this method it is always a known value.

Simons and Senturk (1977) investigated the amount of safety factor provided by the Corps of Engineers and the California Highway Department methods. For both methods the basic form of the equations are identical and were evaluated using the same criteria. To perform the evaluation the equation for the stability factor (A.17)--(see Appendix A), was modified in terms of an average velocity to allow substitution of the Corps of Engineers and the California Highway Department velocity relationships into Equation (A.17). This provided for the comparison of the two design methods on the same basis as the Safety Factor Method by using the ratio of water depth, $Y_{0}$, to the $d_{50}$ stone size, $k\left(Y_{0} / k\right)$. The results are shown in Figure 6.13 . 


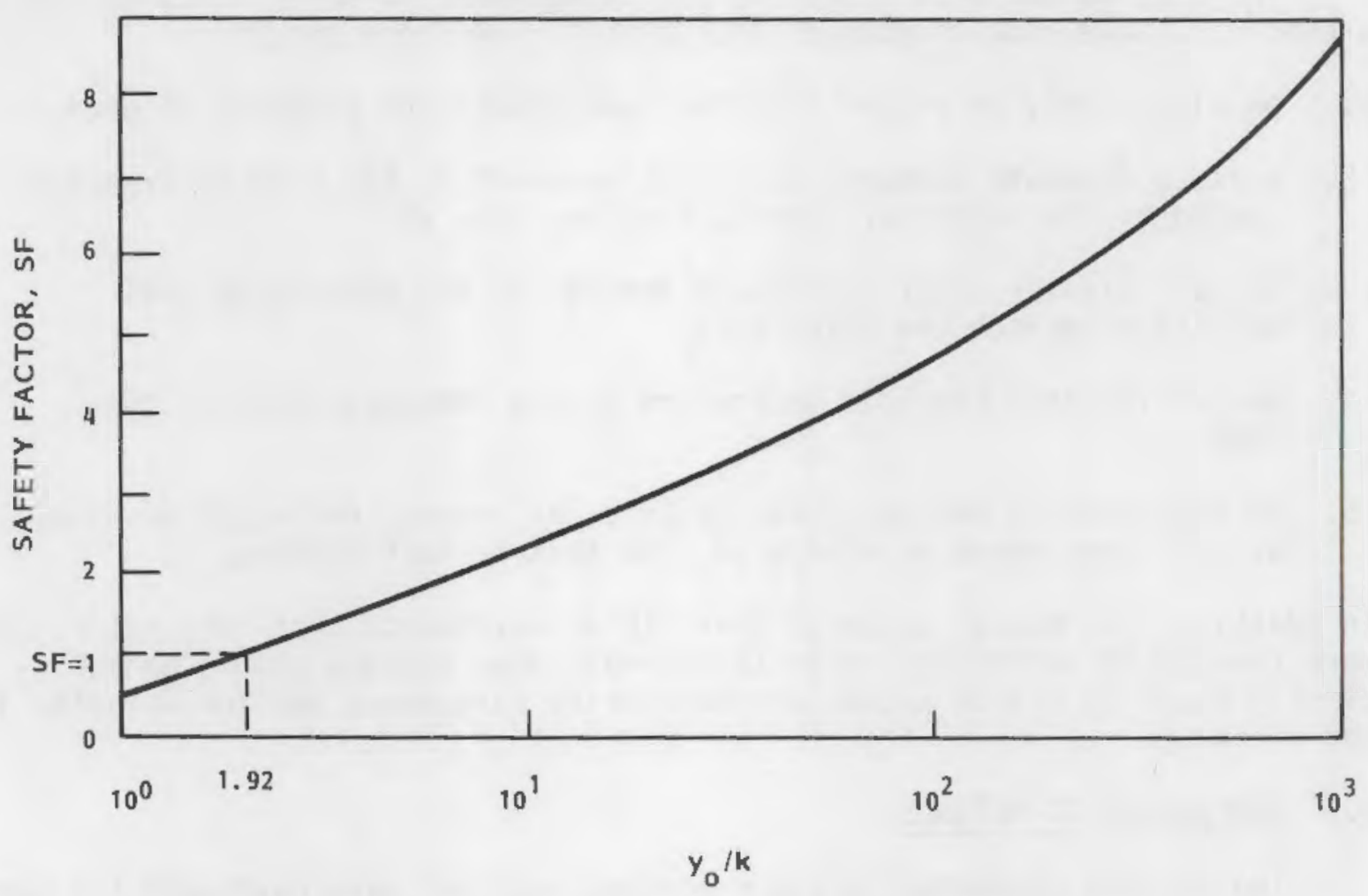

FIGURE 6.13. Safety Factors for Corps of Engineers and California Highway Department Riprap Design (Simons and Senturk 1977)

The safety factor is less than unity for very shallow flows and increases to unity where $Y_{0} / k=1.92$. For relative depths greater than 1.92 the safety factor is greater than unity and continues to increase as depths increase. This implies that as design depth increases so do the chances of overdesign. Although the California Highway Department equation is applicable for horizontal flow on side slope and flow over level beds, the safety factor analys is of Figure 6.13 is for the level bed case only. The side slope condition includes some simplifying assumptions by the California Highway Department not apparent in the literature.

Simons and Lewis (1971) compared the U.S. Bureau of Reclamation and the Safety Factor Methods design curves with actual riprap application results. Both curves are plotted in Figure 6.14. The safety factor for the Bureau of Reclamation curve would be 1.68 if the curve is to be used to design riprap for flow conditions over a plane horizontal bed. The Safety Factor Method included in Figure 6.14 is for a safety factor of 1.0 (incipient motion curve). The plotted points 15 through $5 S$ represent satisfactory riprap installations and points $1 F$ through 5F represent installations that failed (Peterka 1964). The two field structure failures between the curves (points IF and $4 F$ ) were both on side slopes that would require a more durable design than a horizontal 


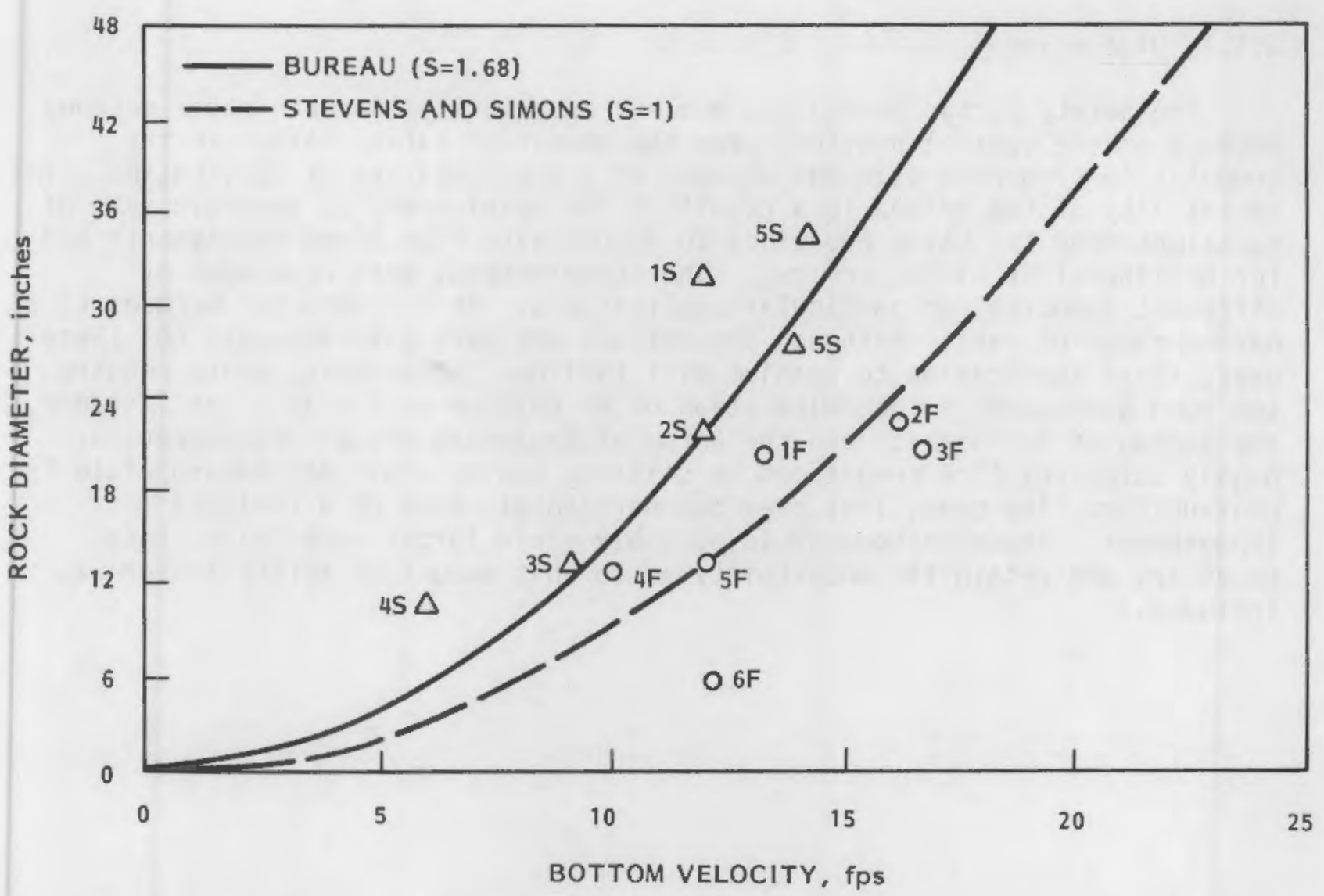

FIGURE 6.14. Comparison of the Bureau of Reclamation Method and the Incipient Motion Curve for the Riprap Design with Safety Factor Method (Simons and Lewis 1971)

plane bed. Point 5F located on the incipient motion curve $(S F=1.0)$ of the Safety Factor Method was a riprap failure on a channel bottom that resisted velocities of $12 \mathrm{fps}$ for a period of time but eventually failed. Although the observed field data are not as complete as would be desired, the plotted points tend to confirm the incipient motion curve of the Safety Factor Method.

Other investigations by Simons and Senturk (1977) analyzed the equation recommended by the ASCE and the Bureau of Public Roads method. The ASCE equation, although very similar to the California Highway equation, provides a $20 \%$ increase in safety factor over the California method, which further increases the opportunity for overdesign when the ASCE equation is used. The Bureau of Public Roads method accounts for side slope angles (Figure 6.12). The Safety Factor Method compares closely with the Bureau of Public Roads curves for plane beds and side slopes of $2 \mathrm{H}: 1 \mathrm{~V}$ or flatter. For steeper slopes the Safety Factor Method predicts a lower allowable flow velocity against the stone. 


\subsubsection{Discussion}

The Safety Factor Method has a clear superiority over the other methods because of the control provided over the amount of safety factor in the computation of a rock size and because of its versatility of application. The versatility of the method is a result of the development of separate sets of equations from the basic equations to accommodate flow along embankments and for horizontal or plane surfaces. The other methods were developed by different agencies for particular applications. This limits the methods to a narrow range of uses. Although the methods are more than adequate for these uses, their application to uranium mill tailings impoundments would require too much guesswork in the calculation of an optimum rock size. For instance, the Bureau of Reclamation and the Corps of Engineers design procedures for highly turbulent flow conditions in stilling basins would be inappropriate for near-uniform flow conditions over the horizontal crown of a tailings impoundment. These methods would possibly yield larger rocks sizes then necessary and retain the uncertainty as to what amount of safety factor was included. 


\subsection{APPLICATION OF RIPRAP DESIGN METHOOS TO TAILINGS IMPOUNOMENTS}

The decommissioning of uranium mill tailings impoundments will present several unique riprap design problems. As described in Section 4.3, some of the tailings are impounded behind retaining dams in small valleys or gulches, usually in the upper reaches of the watershed. Others are located in lower watershed areas and flood plains. Tailings not placed behind valley dam impoundments $c$ an either be placed above or below ground and $c$ an assume several different shapes. The $10 \mathrm{c}$ ation of the impoundment in the watershed drainage network will largely determine the type of hydrologic stress that will require consideration in design. All tailings impoundments will be subjected to overland erosional processes from rainfall-runoff and those impoundments located in the lowland watershed areas or flood plains will be subjected to both overland erosion and possibly severe flooding. The riprap design methods presented in this report would normally be used to design tailings protection works against flood erosion.

\subsection{RIPRAP DESIGN REQUIREMENTS OF TAILINGS IMPOUNOMENTS}

The basic riprap design requirements concerning the erosion of tailings impoundments includes 1) flood flows, 2) gully erosion, 3) sheet erosion, and 4) erosion of the surrounding land surface. Other design problems such as embankment slope failures can also produce serious consequences; however, the above four conditions are preventable by rock armoring.

Flooding will subject the impoundment cap to inundation and high flow velocities where the impoundment could be partially or totally submerged. This type of stress could breach or destroy an impoundment during one flood event. Failure of the $c$ ap as a result of flood erosion probably would occur initially at locations of severe scour because of irregularities in the shape of the cap.

Gully erosion can be expected to occur at impoundment embankments as a result of repeated overland flow from the rainfall-runoff process. The gullying would progressively develop from increasing concentrations of runoff water and would eventually lead to a breach of the impoundment.

Sheet erosion of the earthen $c$ ap is a gradual, near-uniform erosion or wearing away of the impoundment surface. This process would be expected to occur on the crown surface as well as on the embankment side slopes. Sheet erosion both precedes and occurs in conjunction with gully erosion.

The erosion of the land surface surrounding the armored tailings impoundment could involve all three of the above processes. Because the immediate watershed land surface would not be armored, the erosional processes would scour and erode the land surface to the extent that the ripap protecting the impoundment base would be undermined. This would lead to a failure of the rock layer. 
Flooding would present the most critical design conditions because of the high velocity flows and hydrodynamic forces on the impoundment. Each structure would need some degree of riprap protection, depending on the depth of the design flood. Perhaps only a portion of the embankment surface would require protection because the impoundment would not be overtopped. The riprap design methods presented in this report could be used to determine rock sizes, gradation, and possibly riprap layer thickness. A degree of judgment must be involved in determining the increase in rock size and layer thickness because of increase flow velocity and turbulence due to impoundment configuration. A local scour condition could develop at these locations if the stone is not of sufficient weight to resist dislodgement. The remainder of the cap surface not susceptible to flooding would still require protection from sheet and gully erosion but much smaller rock could be used.

The impoundments not affected much by flooding would require a somewhat different approach. The embankment slopes would require riprap protection along the base to prevent scouring by minor flood flows. Riprap would probably be necessary for the remainder of the embankment surface because of the severity of gully erosion. Much smaller rock such as gravel or cobbles could be used on the flatter crown surface. Riprap design methods are not directly applicable to this type of design problem, with the possible exception of the Safety Factor Method. A procedure to design light-duty armoring form protecting side slopes against gullying, where no lateral flood flows are expected, could be derived from this method because computations can be performed for riprap stability on side slopes with no lateral flow.

The potential erosion of the adjacent land surface by the combined erosional processes could be accomodated by estimating the approximate extent of the scour for long-term conditions and by excavating the riprap blanket to that depth. This type of design problem is site-specific, but should be relatively easy to handle.

\subsection{GENERAL DESIGN PROCEDURE}

To design rock riprap protection for worst-case flood conditions the procedure would initially involve the determination of the expected flood magnitude and the related hydraulic design criteria such as flow velocity and depth. This information, together with the identification of an available rock type and its properties, would be used to determine the rock size and weight to safely resist the flood forces. The rock size and weight would be calculated by using the selected riprap design method. Because long-term protection is required, allowances for processes such as weathering and fracturing would need to be included in the safety factor when computing the final rock size and weight. Once the rock size is known, the gradation of rock sizes to be used in the armor layer, the layer thickness, and foundation requirements $c$ an be determined using written specifications and engineering judgment. The larger stone sizes necessary to protect against local scour problems resulting from nonuniform flow conditions have to be considered at some point in the calculations. Currently, no design criteria are available to estimate these requirements for tailings impoundments. Some streamlining of the impoundment 
cap may be necessary. On completion of the rock layer design, the underlying gravel filter specifications would then be determined.

Because of the irregular shapes of tailings impoundments and the long-term protection requirements, certain design problems must be addressed. These are the selection of a proper design flood criteria, the potential for local scour, and rock durability. These problems are discussed in more detail in the following section. 



\subsection{OTHER DESIGN CONSIDERATIONS}

The design of rock riprap for long-term protection of decommissioned tailings impoundments presents three general problem areas: 1) the estimation of a flood magnitude, 2) local scour and forces on the structure during floods, and 3 ) rock durability over long time periods. The problem of flood magnitude arises because of possible climate changes over the long-term time period. Reasonable estimates of flood magnitude, flow velocity, and water surface elevation are required to determine the stone size to resist dislodgment from the riprap protection. Local scour around the impoundment foundation, together with the associated hydrodynamic forces, could undermine the protective cap and cause a failure of the entire impoundment structure. Rock durability is important because of the long-term protection requirement and the tendency of certain types of rock to break down in relatively short periods of time as a result of weathering.

\subsection{DESIGN FLOOD CRITERIA}

Because decommissioned mill tailings impoundments must remain undisturbed for extremely long periods of time, their chances of exposure to large flood events is increased significantly. Concurrently, the chances of regional climate changes would increase, which could result in a wetter climate and even larger flood events.

According to recent research sponsored by the Nationa? Academy of Sciences, significant climate changes have occurred in the northern hemisphere in the last 1000 years (U.S. Committee for the Global Atmospheric Research Program 1975). Historical records were used to develop an index of winter severity. The trends indicated by this index for the period around the year 1700 have been validated through comparison with thermometer records. Other portions of the record have been cross-checked with data on glacial fluctuations, oxygen isotope variations, and tree growth.

These data indicate that the early part of the last 1000 years (about A.D. 1100 to 1400) was a warm epoch, but not as warm as the first half of the twentieth century. The significant trend in the climate pattern occurred from about 1430 to 1850 , a period commonly known as the Little Ic? Age. This period was characterized in western Europe and western North America by short, wet summers and long, severe winters. During the Little Ice Age, many glaciers in Alaska, Scandinavia, and the Alps reached positions closest to their maximum advance since the last major ice age thousands of years ago.

The important concern here is that a much wetter climate than that of today existed only about 150 years ago and extended back in time several hundred years. Flood prediction methods used today in the design of water resource projects do not include significant climatic changes because the recorded hydrologic data do not extend that far back and because the expected life of most engineering projects is about 50 to 100 years. An in-depth 
analysis of possible changes in the climatic regime is beyond the scope of this report; however, shifts in climatic regime may need to be allowed for in the design flood computations.

\subsection{DESIGN FLOOO ANALYSIS}

A design flood for water resources projects is normally calculated in terms of a peak discharge by two basic methods: 1) statistical analysis of historical data, and 2) maximizing hydrologic and meteorologic data to determine a probabie maximum flood (PMF).

A statistical flood such as the 1000-year event, is determined by plotting recorded peak flood discharges versus frequency of occurrence using historical data from stream gaging records. These data seldom extend back in time more than 100 years with any continuity of record; however, events such as the 500or 1000-year floods would be estimated by extrapolating the curves to determine the probable peak discharge for a selected recurrence interval. Design flood criteria determined from historical data would not be sufficient for designing riprap to protect tailings impoundments. The long-term protection requirement would be better addressed by the PMF approach.

The determination of a PMF event is a much more detailed study in which the hydrologic and meteorologic processes are maximized to produce a flood that theoretically has zero probability of occurring, even though a comparison can be made with the extrapolated historical data. If the PMF plots as a 500 - or 1000-year flood, the PMF assumptions should be re-evaluated, as this would be too frequent a recurrence interval.

An example of a PMF study can be found in the Memorandum Report by the U.S. Army Corps of Engineers (1969) for the Columbia River Basin. The combination of conditions for the PMF was the most severe considered "reasonably possible" in the Columbia River Basin. The general approach was to determine the water equivalent of snow on the ground on the basis of exceptionally cold and wet weather during the seven-month snow accumulation season. All precipitation was assumed to fall as snow and most of it was to remain in storage until the onset of spring melting. The weather conditions for the two-month snowmelt period were conducive to unusually rapid melt rates over the entire basin. Two basin-wide rainstorms were assumed to occur during the snowmelt season with a short time period between storms. These maximized conditions were combined to produce a PMF hydrograph at key points along the Columbia River.

\subsection{LOCAL SCOUR POTENTIAL}

The irregular shape of a decommissioned tailings impoundment projecting above the flood plain surface would set up nonuniform flow regions at points along its boundary. The severity of the localized scour would increase as the free stream flow velocity increased. This type of scour could undermine the riprap protection if the scour hydraulically excavates the adjacent flood plain materiais below the riprap foundation. Economically, this type of scour can be 
difficult to protect against. Coincident with the development of local scour, the flood would exert hydrodynamic forces against the impoundment structure itself. The impoundment would have to withstand these forces or run the risk of severe damage or even a breach of the structure, especially if the riprap failed.

A common approach to the solution of nonuniform flow problems is the use of physical model studies. In this way the problems can be analyzed in three dimensions. The design of many hydraulic structures is based on the results of flume studies because of the uncertainties of nonuniform flow conditions set up by the structure's geometry. Therefore, impoundment geometry will need to be a consideration, with some design criteria developed from flume studies.

\subsection{DURABIL ITY OF RIPRAP STONE}

The other variable of importance with respect to the long-term protection of tailings impoundments is the durability of the rock riprap. No available historical data exists on the durability of rock when used for riprap protection extending much beyond 50 or 60 years. Information of a historical nature on the long-tem durability of rock exposed to the physico-chemical processes of weathering could possibly be obtained from archaeological sources. More commonly, the rock is subjected to laboratory testing to determine its durability.

Durability is a measure of the resistance the rock offers to the processes of mechanical weathering or physical disintegration, and chemical weathering or decomposition. Mechanical weathering is caused by such agents as frost action, temperature change, and abrasion. Chemical weathering involves actual changes in rock composition, such as the alteration of minerals to clay. Decomposition is caused mainly by atmospheric water and carbon dioxide, and in some cases by organic or mineral acids.

The California Division of Highways (1970) testing program evaluated a series of laboratory tests that could possibly be used to determine rock durability. Most of these tests were originally developed to determine the durability of gravel used in reinforced concrete. Based on the test program results, the California Division of Highways recommended the following three tests to insure better control over the quality of rock used for riprap:

- Absorption Testing--A general correlation exists between percentage of absorption and the degree of weathering. The more weathered specimens have a higher absorption as a result of a greater porosity. The percentage of absorption should not exceed $2 \%$.

- Soundness Testing--The application of sodium sulphate acts as an accelerated mechanical weathering test, which is assumed similar to frost action. This test does not simulate chemical weathering. 
- Wetting and Drying Testing--This test measures the percentage of loss of sample weight after cyclic wetting and drying and is helpful in eliminating rocks with readily soluble material. Some hygroscopic minerals would be affected. A loss 1 imit of $5 \%$ after 10 cycles is assumed appropriate.

Another study, by the U.S. Bureau of Reclamation (1965), investigated 149 case histories of upstream slope protection for dams. Rock breakdown had occurred more rapidly than had been expected and was the most common type of failure. Many of the accepted laboratory tests did not reliably indicate rock durability. Three tests were identified as the most valuable methods for determining sound, durable rock:

- Specific Gravity--Rocks with higher specific gravities, which indicates a denser material, are more desirable for riprap. The rock rated "excellent" had a medium specific gravity of 2.70 .

- Absorption--The 24-hour absorption water expressed as percent dry weight is relatively low for "excellent"-rated riprap rock. These materials recorded values from 0 to $2.1 \%$ absorption. The rock in disintegration failures extended the absorption maximum to $23.5 \%$.

- Petrographic Examination--Petrographic analysis uses thin section stides and $x-r$ ay diffraction methods to identify distinguishing characteristics of geologic materials. Clayey or platy minerals that have a destabilizing effect on rock durability were identified. Petrographic analysis is recommended as a valuable tool in recognizing the destabilizing qualties.

The above tests may assure improved quality in the rock selected, but they do not provide an estimate of the time the rock will remain effective. The durability of stone is usually considered to be adequate for the life expectancy of engineering structures. Archaeological evidence suggests that certain types of stone may be durable for thousands of years with a minimum of weathering and loss of strength. This evidence could be used with laboratory tests and petrological investigations to develop criteria for stone selection. Such guidelines for the selection of stone also will have a significant economic impact regarding availability near the site. Further information concerning rock weathering and riprap durability is given in Lindsey, Long and Begej (1982). 


\subsection{PLACEMENT OF RIPRAP}

For sound riprap protection, a well-graded rock mixture should be placed in a well-knit, uniform layer without segregation of the rock. The structural integrity of riprap depends on the following design characteristics:

- rock size, weight, and gradation

- rock shape and quality

- embankment slope

- thickness of riprap

- stability and effectiveness of the filter.

The size of rock sufficient to withstand the design hydrodynamic forces is determined by using a riprap design method typical of those discussed in this report. The embankment slope is determined by either the design method or by other project requirements. In many situations, the slope angle could economically be calculated together with the stone size by trial and error.

The shape, quality, and gradation of stone size would be determined by other design criteria (e.g., the specifications provided by the Corps of Engineers). A gradation of stone sizes would be based on the design stone size determined analytically to resist the forces of flowing water or wave action. The range of sizes is required to form a tightly interlocking stone blanket. The thickness of the riprap layer would be determined by a similar procedure. Specifications, based on past experience, engineering judgment, and project economics would be provided.

The stability of the underlying filter material relies on the gradation of stone size and riprap size. The filter blanket usually is composed of crushed stone or gravel that will prevent the embankment material from being washed out and that will not be washed out itself. Close supervision must be exercised and a construction sequence followed to insure that these design specifications are met.

The discussion by Sherard et al. (1967) on causes of riprap failures and recommended $\mathrm{placement}$ techniques offers insight into the construction of riprap protection. Although their discussion is concerned with the protection of earthen dam embankments from wave erosion, the methods apply to other embankments such as those of uranium mill tailings impoundments.

\subsection{GRAVEL FILTERS}

Filters placed underneath the riprap layer are recommended to prevent the finer embankment material from washing out through the voids in the riprap layer. Sizes of gravel in the filter bianket should be from $3 / 16$ in. to an upper limit of about 3 to 3-1/2 in. The upper limit would depend on the riprap gradation. Thickness of the filter will vary depending on riprap thickness but should not be less than 6 in. Thicknesses equal to one-half the riprap thickness have proved to be satisfactory. Simons and Senturk (1977) summarized the suggested specifications as follows: 
(1) $\frac{\mathrm{O}_{50} \text { (Filter) }}{\mathrm{D}_{50} \text { (Base) }}<40$

(2) $5<\frac{D_{15} \text { (Filter) }}{D_{15} \text { (Base) }}<40$

(3) $\frac{D_{15} \text { (Filter) }}{D_{85} \text { (Base) }}<5$

The base refers to the embankment material.

Sherard et al. (1967) listed four factors that influenced the selection of filter thickness for riprap on dam embankments:

1. Wave action--The less the wave action, the less the need for a thick filter.

2. Gradation of riprap--A well-graded riprap with plenty of quarry fines filling the voids reduces the stress on the filter.

3. Plasticity and gradation of the embankment material-Embankment material composed of a well-graded granular soil with a tough clay binder needs less protection than fine silty sand.

4. Cost of filter-If the filter material is obtained without washing or screening as a pit-run natural gravel and, consequently, is not very expensive, minimum filter thicknesses need not be used.

Simons and Senturk (1977) state that no definite rule can be given for the minimum necessary thickness and that the problem is not subject to analytical treatment. Most filters are constructed with thicknesses varying from 9 to $30 \mathrm{in.}$ for earthen dam surfaces.

\subsection{CAUSES OF RIPRAP PROTECTION FAILURES}

Sherard et al. (1967) cite the results of a study by the U.S. Army Corps of Engineers on slope protection performances of about 5 to 50 years, with widely different climatic, topographic, and geologic conditions. The study compared all types of slope protection commonly used, including riprap protection placed by both the dumped-rock and hand-placed methods. The main conclusions regarding rock protection were:

- Failures that resulted in rock displacement and loss of slope protection occurred in only two of the forty dams that were protected by layers of dumped-rock riprap. The riprap layers varied 
between 9 and 96 in. in thickness. The average rock sizes on the two dams that failed were only $5 \mathrm{in}$. in average diameter and the estimated wave heights were 2.5 and $4.0 \mathrm{ft}$. Also, loss of the underlying gravel filter layer caused damage to three other dams in this group.

- Failures occurred in six of the twenty dams that had hand-placed riprap, with layer thickness varying from 12 to $48 \mathrm{in}$. The failures involved displacement of rock layers between 12 and 36 in. thick. The maximum wave heights were estimated to be between 1.5 and $8.0 \mathrm{ft}$. In four of the six dams, the primary damage was attributed to floating trees or ice.

The study results indicate that layers of dumped-rock riprap are more successful than an equivalent thickness of hand-placed rock. This had been suspected for a number of years but was not confirmed until the Corps of Engineers study. The primary reason is that a moderate movement of any individual rock in dumped riprap has little influence on the structural integrity of the rock layer. If one large rock in a hand-placed layer is moved, the underlying filter is exposed, allowing erosion to the filter and embankment material. Hand-placed riprap is particularly vulnerable to damage by floating trees and ice layers, which can cause displacement of individual rocks out of the layer. The individual rocks of a dumped-rock layer are only slightly jostled when subjected to the same stresses and the layer tends to remain intact because the dumped rock reaches a more stable position in the layer.

The filter layer can fail when large rocks of uniform size are used without enough small rocks to make a well-graded blanket. Erosion of the embankment material causes progressive settlement of the larger rocks and eventual displacement. This type of failure can be prevented by including enough of the smaller-size rock to reduce the area of the interstitial openings between the large rocks.

\subsection{CONTROL OF RIPRAP GRADATION}

The best time to control riprap gradation of quarried rock is during the quarrying. The spacing of the blast holes and the size of the charge can determine the various sizes and gradations of the rock. This usually requires some experimentation. Suitable gradations can be obtained by wasting some of the fines through selective excavation in the quarry or by breaking down some of the larger rocks with a wrecking ball or with secondary blasting.

The gradation is controlled through visual inspection of a selected pile of rock with the desired gradation. The pile should contain 5 to 10 tons of selected individual rocks with the rocks combined in the correct proportion. In the event of controversy, the actual gradation can be determined by measurement. 


\subsection{RIPRAP PLACEMENT PROCEDURES}

The rock is dumped directly from trucks on top of the previously prepared filter material. The rock should never be dropped down a chute or pushed down the slope with a bulldozer because this could cause excessive segregation. Dumped riprap requires minimum hand work, although some is required. If the material is well-graded, the rock $c$ an be placed with very little additional rearrangement. After dumping, the individual rocks are reworked by man with bars or with power equipment (e.g., draglines and backhoes).

The placement of riprap on uranium mill tailings impoundments could present some problems regarding the structural integrity of the impoundment and decommissioning cap. The use of heavy equipment on the unprotected cap surface may not be possible because of potential damage to the cap and impoundment. Dropping the stone from a point several feet above the surface could cause impact load damage that could lead to an eventual failure of a part of the impoundment. To protect against this type of damage, temporary earthen ramps may be required for the heavy equipment along with special placement procedures for tailings impoundments. 


\section{REFERENCES}

American Society of Civil Engineers (ASCE). 1975. Sedimentation Engineering, ed. V. A. Vanoni, Task Committee for the Preparation of the Manual on Sedimentation, Hydraulics Division, ASCE, New York.

California Division of Highways. 1970. Bank and Shore Protection in California Highway Practice. Business and Transportation Agency, Dept. of Public Works, Sacremento, California.

Garde, R. J., and K. G. Ranga Raju. 1977. Mechanics of Sediment Transportation and Alluvial Stream Problems. John Wiley and Sons, New York.

Graf, W. H. 1971. Hydraulics of Sediment Transport. McGraw-Hil1, New York.

Izbash, S. V. 1932. Construction of Dams by Dumping Stones Into Flowing Water. Moscow-Leningrad, trans. A. Dovjikov, 1935, U.S. Army Engineer office, Eastpoint, Maine.

Lindsey, G. C., L. W. Long and C W. Begej. 1982. Long-Term Survivability of Riprap for Armoring Uranium Mill Tailings and Covers: A Literature Review. NUREG/CR-2642, PNL-4225, Pacific Northwest Laboratory, Richland, Washington.

Peterka, A. J. 1964. Hydraulic Design of Stilling Basins and Energy Dissipators, Engineering Monograph No. 25, U.S. Bureau of Reclamation, Denver, Colorado.

Robertson, A. M., S. A. Bamberg and G. Lange. 1978. "Current Uranium Mill Waste Disposal Concepts: A Multinational Viewpoint." Uranium Mill Tailings Management, Civil Engineering Department, Colorado State University, Ft. ColTins, Colorado.

Shepherd, T. A., and J. D. Nelson. 1978. "Long-Term Stability of Uranium Mill Tailings." Uranium Mill Tailings Management, Civil Engineering Department, Colorado State University, Ft. Collins, Colorado.

Sherard, J. L., et al. 1967. Earth and Earth-Rock Dams. John Wiley and Sons, New York.

Simons, D. B., and G. L. Lewis. 1971. Flood Protection of Bridge Crossings, CER71-72DBS-GLL10. Prepared for the Wyoming Highway Dept. in cooperation with the U.S. Dept. of Transportation, Federal Highway Administration, Bureau of Public Roads, Colorado State University, Ft. Collins, Colorado.

Simons, D. B., and F. Senturk. 1977. "Sediment Transport Technology." Water Resources Publications, Ft. Collins, Colorado.

Stevens, M. A. 1969. Scour in Riprap at Culvert Outlets. Ph.D. Dissertation, Colorado State University, Ft. Collins, Colorado. 
Stevens, M. A., and D. B. Simons. 1971. "Stability Analysis for Coarse Granular Material on Slopes." River Mechanics, Vol. 1, ed. H. W. Shen, Colorado State University, Ft. ColTins, Colorado.

Stevens, M. A., D. B. Simons and G. L. Lewis. 1976. "Safety Factors for Riprap Protection." Journal of the Hydraulic Division, ASCE, Vo1. 102, No. HY5, Proc. Paper 12115.

U.S. Army Corps of Engineers. 1969. Lower Columbia River Standard Project Flood and Probable Maximum Flood. North Pacific Division, Portland, Oregon.

U.S. Army Corps of Engineers. 1970. Hydraulic Design of Flood Control Channels. EM 1110-2-1601, Office of the Chief of Engineers, Washington, D.C.

U.S. Army Corps of Engineers. 1976. HEC-2 Water Surface Profiles. Hydrologic Engineering Center, Davis, California.

U.S. Bureau of Reclamation. 1965. Design of Small Dams. Water Resources Technical Publication, USBR, U.S. Government Printing Office, Washington, D.C.

U.S. Committee for the Global Atmospheric Research Program. 1975. Understanding Climatic Change. National Academy of Sciences, Washington, D.C. 


\section{APPENDIX A}

RIPRAP DESIGN WITH SAFETY FACTORS METHOO 
APPENDIX A

\section{RIPRAP DESIGN WITH SAFETY FACTORS METHOD}

The method of riprap design discussed here was developed by M. A. Stevens and D. B. Simons at Colorado State University under a study program for the Wyoming Highway Dept. (Stevens 1969; Stevens and Simons 1971). The objective of the study was to develop design criteria for riprapped stilling basins at circular culvert outlets. An extensive physical modeling program was used to investigate the mechanism of local scour under typical flow conditions.

Further studies were conducted by Simons and Lewis (1971) using the same methodology for riprap protection of highway bridge crossings of rivers. Spill-through abutments protected by riprap were constructed in the hydraulic facilities of Colorado State University to test the validity of the design procedures. This study also was conducted for the Wyoming Highway Dept., with the cooperation of the Federal Highway Administration.

\section{DERIVATION OF DESIGN CRITERIA}

The method uses the concept of a safety factor, a consideration in practically all engineering design problems. The safety factor, SF, for rock riprap is expressed as follows:

$$
\mathrm{SF}=\mathrm{Safety} \mathrm{F} \text { actor }=\frac{\text { Moments of forces resisting rotation }}{\text { Moments of forces tending to dislodge rock }}
$$

where

$\mathrm{SF}=1$ indicates a critical condition for the flow where incipient motion occurs

$\mathrm{SF}>1$ indicates that riprap is considered safe from failure

SF $<1$ indicates that rocks are washed from riprap layer and failure of protection may occur.

The method considers the stability of rock riprap to be a function of :

- the magnitude and direction of stream velocity in the vicinity of the rock particles

- the angle of side slope

- rock characteristics, including geometry, angularity, and density. 
The equations developed in the derivation are based on:

- hydrodynamic lift of fluid on rock

- hydrodynamic drag of fluid on rock

- Shields criteria for incipient particle motion as modified by Gessler (1971).

The magnitude of the lift force is directly proportional to the magnitude of the drag force and the lift force is considered to be normal to the drag force. The stability criteria of individual rocks is obtained from its submerged weight and angle of repose.

The general case of oblique flow across an embankment side slope is shown by the diagrams of Figure A.1, where:

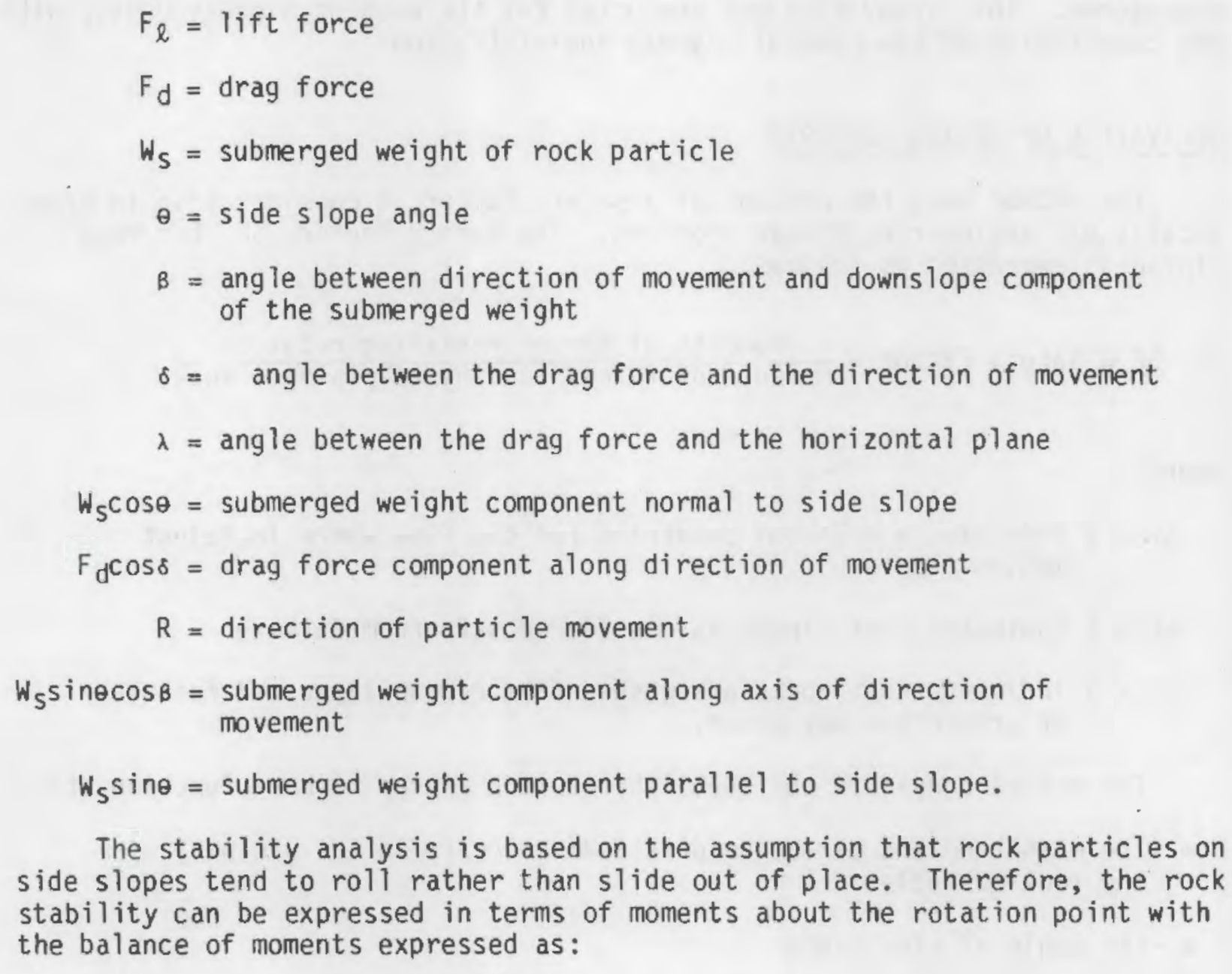

The stability analysis is based on the assumption that rock particles on side slopes tend to roll rather than slide out of place. Therefore, the rock stability can be expressed in terms of moments about the rotation point with the balance of moments expressed as:

$$
e_{2} W_{s} \cos \theta=e_{1} W_{s} \sin \theta \cos \beta+e_{3} F_{d} \cos \delta+e_{4} F_{\ell}
$$




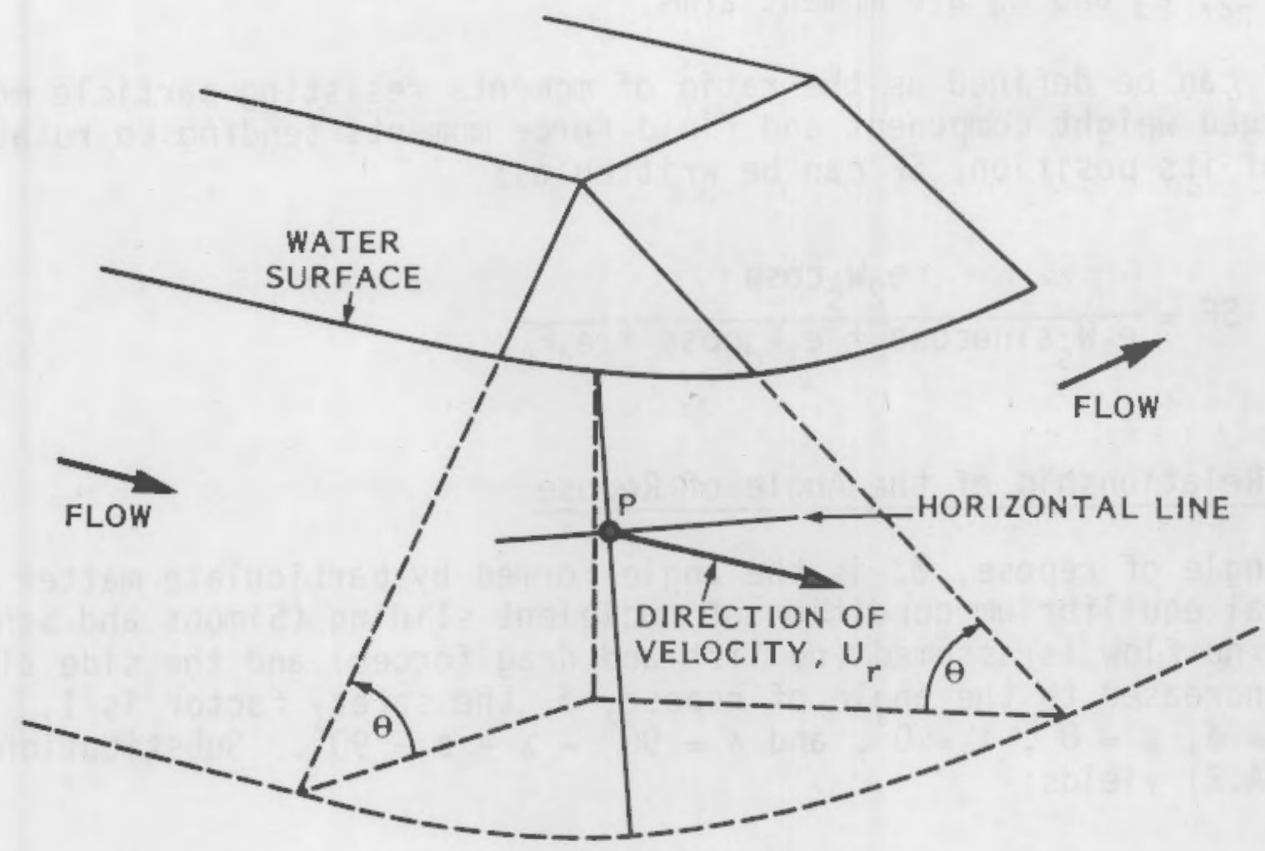

a GENERAL VIEW
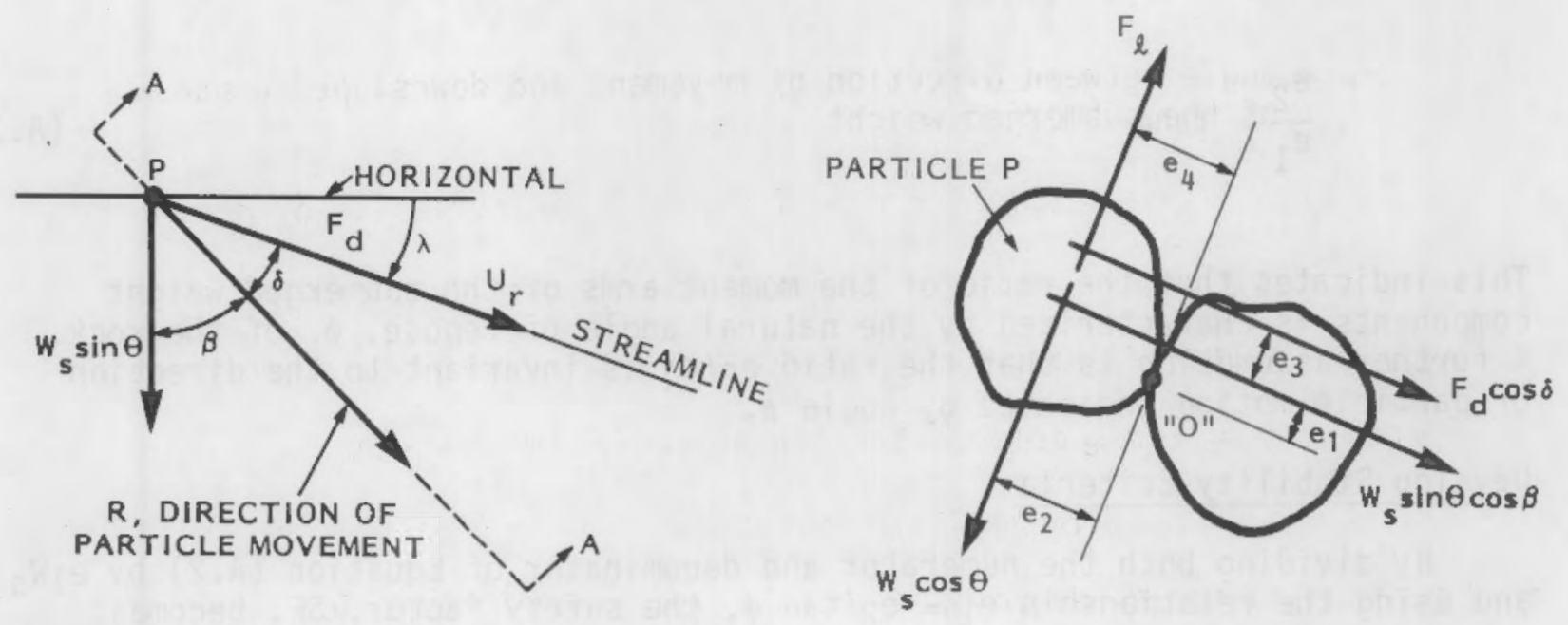

b VIEW NORMAL OF THE SIDE SLOPE

C SECTION A - A

FIGURE A.1. Diagrams for Riprap Stability Analysis (Stevens, Simons and Lewis 1976) 
where $e_{1}, e_{2}, e_{3}$ and $e_{4}$ are moment arms.

Because SF can be defined as the ratio of moments resisting particle motion to the submerged weight component and fluid force moments tending to rotate the rock out of its position, SF can be written as:

$$
S F=\frac{e_{2} W_{s} \cos \theta}{e_{1} W_{s} \sin \theta \cos \beta+e_{3} F_{d} \cos \delta+e_{4} F_{l}}
$$

Determine Relationship of the Angle of Repose

The angle of repose, $\phi$, is the angle formed by particulate matter under the critical equilibrium condition of incipient sliding (Simons and Senturk 1977). If no flow is assumed (no lift and drag forces) and the side slope angle is increased to the angle of repose, $\phi$, the safety factor is 1 . Then $\mathrm{SF}=1, \theta=\phi, \beta=0^{\circ}, \lambda=0^{\circ}$, and $\delta=90^{\circ}-\lambda-\beta=90^{\circ}$. Substitution into Equation (A.2) yields:

$$
\begin{aligned}
& S F=\frac{e_{2} \cos \phi}{e_{1} \sin \phi}=1 \text { and since } \tan \phi=\frac{\sin \phi}{\cos \phi} \\
& \frac{e_{2}}{e_{1}}=\tan \phi
\end{aligned}
$$

This indicates that the ratio of the moment arms of the submerged weight components is characterized by the natural angle of repose, $\phi$, of the rock. A further assumption is that the ratio $e_{2} / e_{1}$ is invariant to the direction of particle motion indicated by angle $\beta$.

\section{Develop Stability Criteria}

By dividing both the numerator and denominator of Equation (A.2) by $e_{1} W_{S}$ and using the relationship $e_{1}=e_{2} / \tan \phi$, the safety factor, SF, becomes:

$$
\mathrm{SF}=\frac{\cos \theta \tan \phi}{\eta \tan \phi+\sin \theta \cos \beta}
$$

where

$$
n^{\prime}=\frac{e_{3} F_{d}}{e_{2} W_{s}} \cos \delta+\frac{e_{4} F_{\ell}}{e_{2} W_{s}}
$$


and $\eta^{\prime}$ is the stability number for each rock on an embankment slope.

The angle between the horizontal and the force component $W_{\mathrm{s}}$ sine $=90^{\circ}$, therefore:

and

$$
\delta+\lambda+\beta=90^{\circ}
$$

$$
\delta=90^{\circ}-\lambda-\beta
$$

The assumption is made that the moments of the drag force, $F_{d}$, and the submerged weight component, $W_{s} \sin \theta$ nomal to path $R$, are balanced so the direction of rock motion will be along $R$, therefore:

$$
e_{3} F_{d} \sin \delta=e_{1} W_{s} \sin \theta \sin \beta
$$

From Equations (A.6) and (A.7) a relationship for $\sin \beta$ can be developed:

$$
\sin \beta=\frac{e_{3} F_{d}(\cos \lambda \cos \beta-\sin \lambda \sin \beta)}{e_{1}{ }_{s} \sin \theta}
$$

Dividing by $\cos \beta$ yields a relationship for $\tan \beta$ :

$$
\tan \beta=\frac{\cos \lambda}{\frac{e_{1}{ }^{W} s}{e_{3} F_{d}} \sin \theta+\sin \lambda}
$$

The stability number, $n$, for rocks on a plane bed with $\theta=0$ (no embank ment slope) and $\delta=0$ (no angle between drag force and direction of movement) according to Equation (A.5) is:

$$
\eta=\frac{e_{3} F_{d}}{e_{2} W_{s}}+\frac{e_{4} F_{\ell}}{e_{2} W_{s}}
$$

and Equation (A.4) becomes:

$$
S=\frac{1}{n}
$$

Equations (A.10) and (A.11) are applicable to flow over a plane bed. 


\section{Relationship Between Stability Criteria and Fluid Shear Stress}

The hydrodynamic drag and lift are related to the square of the fluid velocity and the exposed area of the particle. The fluid shear stress or tractive force is also related to the square of the velocity; therefore, the drag and lift force equations $c$ an be written as:

$$
\begin{aligned}
& F_{d}=C_{1} k^{2} \tau_{s} \\
& F_{d}=C_{2} k^{2} \tau_{s}
\end{aligned}
$$

where

$$
\begin{aligned}
\tau_{s}= & \text { average tractive force on the plane containing the particle } \\
k= & \text { diameter of the rock particle } \\
C_{1}, C_{2}= & \text { coefficients dependent on the exposed particle area, lift } \\
& \text { and drag coefficients, and the relation between velocity and } \\
& \text { tractive force. }
\end{aligned}
$$

The submerged weight, $W_{S}$, of the rock particle can be written as:

$$
W_{s}=c_{3}\left(s_{s}-1\right) \gamma k^{3}
$$

where

$$
\begin{aligned}
\gamma & =\text { unit weight of water } \\
S_{S} & =\text { specific weight of rock } \\
C_{3} & =\text { coefficient depending only on particle shape } \\
k & =\text { particle diameter. }
\end{aligned}
$$

Substitution of Equations (A.12), (A.13), and (A.14) into Equation (A.10) yields:

$$
n=\frac{c_{1} e_{4}+c_{2} e_{3}}{c_{3} e_{2}}\left\{\frac{\tau_{s}}{\left(s_{s}-1\right) r k}\right\}
$$

where $\tau_{s} /\left(S_{S}-1\right) r k$ is known as Shie1ds parameter.

When incipient motion conditions are reached during flow over a plane $f l$ at bed, the safety factor $S F=1.0$; therefore, from Equation (A.11) the stability 
number $n=1.0$. According to Gessler (1971), the Shields parameter for incipient motion is 0.047; therefore, by substitution in Equation (A.15):

$$
\frac{c_{1} e_{4}+c_{2} e_{3}}{c_{3} e_{2}}=\frac{1}{0.047}=21
$$

For flow conditions other than incipient, Equation (A.15) becomes:

$$
n=\frac{21 \tau_{s}}{\left(S_{s}-1\right) r_{k}}
$$

Relationship of Embankment Slope and Plane Bed Stability Factors

For convenience let:

$$
M=\frac{e_{4} F_{l}}{e_{2} W_{s}}
$$

and

$$
N=\frac{e_{3} F}{e_{2} W_{s}}
$$

Substitution into Equations (A.5) and (A.10) yields:

and

$$
n^{\prime}=M+N \cos \delta
$$

$$
n=M+N
$$

Therefore, $\eta^{\prime}$ and $n$ are related by:

$$
\frac{\eta^{\prime}}{\eta}=\frac{\frac{M}{N}+\cos \delta}{\frac{M}{N}+1}
$$

Equation (A.22) is the ratio of stability numbers for rock particles on an embankment slope and on a plane horizontal bed. The problem is to select the proper value of $M / N$ so that the embankment slope stability factor, $\eta^{\prime}$, can be related to the stability factor for a plane horizontal bed, $n$, which in turn is related to the Shields parameter. Equation (A.22) is represented graphically by Figure A.2. 


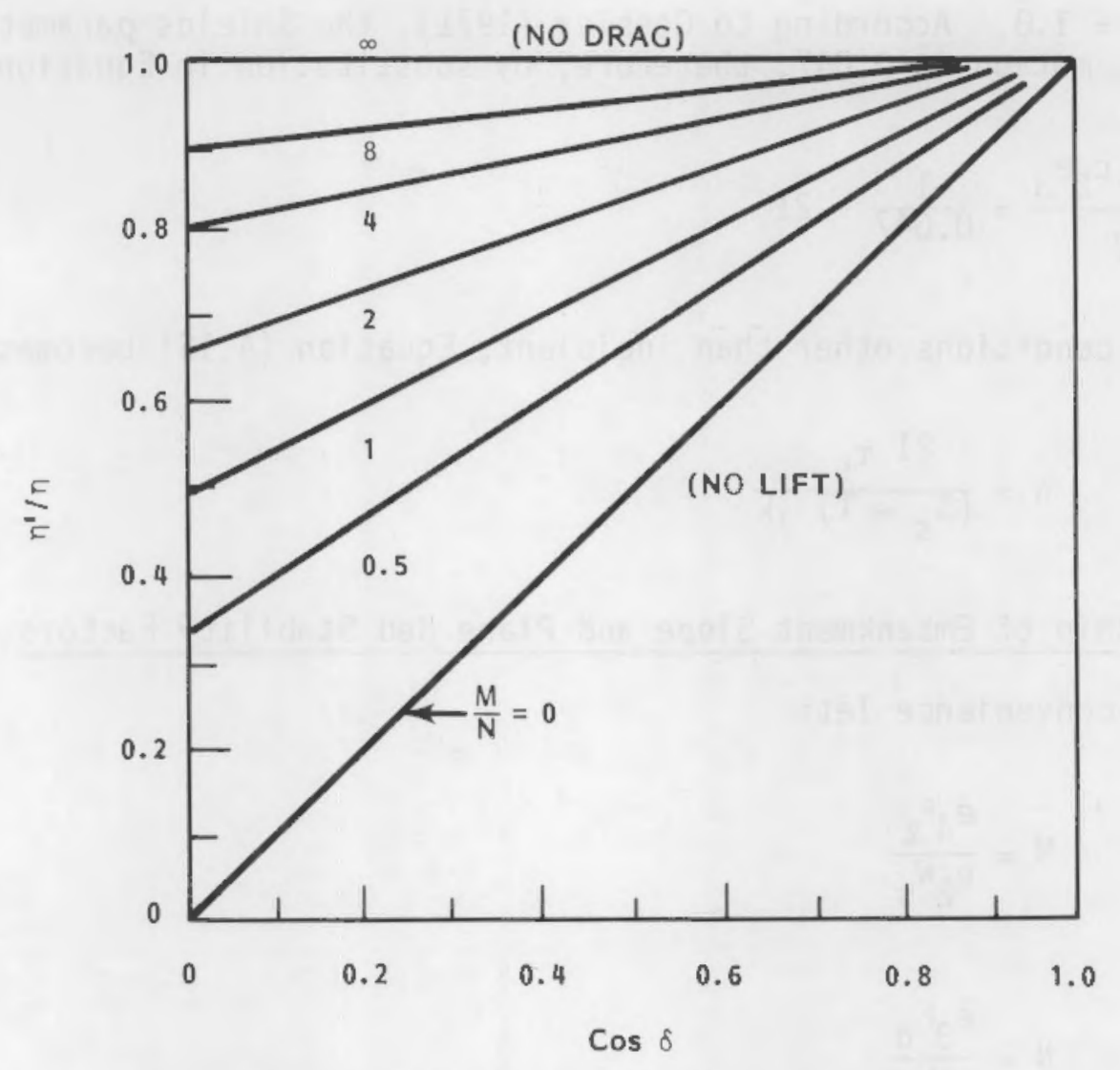

FIGURE A.2. Ratio of Stability Factors

(Simons and Senturk 1977)

The stability factor ratio limits can be determined as follows:

For $F_{d}=0, M / N$ is $\infty, \beta=0$, and $\eta^{\prime}=n$

For $F_{l}=0, M / N=0$ and $n^{\prime} / \pi=\cos \delta$

Therefore, for finite values of lift and drag forces, stability factor ratios are between the limits 0 and cos $\delta$. When considering incipient motion of riprap particles, the ratios $F_{\ell} / F_{d}$ and $e_{4} / e_{3}$ depend on the turbulent flow conditions and particle interlock. The value of $M / N$ is assumed to be approximately equal to 1 to facilitate analysis (Stevens and Simons 1971):

$$
\frac{M}{N}=\frac{e_{4} F_{\ell}}{e_{3} F_{d}} \cong 1
$$

For $M / N=1$, Equation (A.22) becomes: 


$$
\frac{n^{\prime}}{n}=\frac{1+\cos \delta}{2}
$$

or, by using Equation (A.6) $\left(\delta=90^{\circ}-\lambda-\beta\right)$ :

$$
\frac{n^{\prime}}{n}=\frac{1+\sin (\lambda+\beta)}{2}
$$

The term $e_{1} W_{s} / e_{3} F_{d}$ in Equation (A.9) can be written as follows according to Equations (A.3) and (A.19):

$$
\frac{e_{1} W_{s}}{e_{3} F_{d}}=\frac{e_{2}}{e_{3}} \frac{W_{s}}{F_{d}} \frac{e_{1}}{e_{2}}=\frac{1}{N} \frac{1}{\tan \phi}
$$

For $M / N=1$, Equation $(A .21)$ becomes:

$$
N=\frac{\pi}{2}
$$

By substitution of Equations (A.26) and (A.27) into Equation (A.9), the expression for $B$ becomes

$$
B=\tan ^{-1}\left(\frac{\cos \lambda}{\frac{2 \sin \theta}{n \tan \phi}+\sin \lambda}\right)
$$

The safety factor for rock riprap on embankment slopes where the flow has a nonhorizontal velocity vector is related to properties of the rock, side slope, and flow by Equations (A.4), (A.17), (A.25), and (A.28).

$$
\begin{aligned}
& S F=\frac{\cos \theta \tan \phi}{n^{\prime} \tan \phi+\sin \theta \cos \beta}=\text { safety factor } \\
& n=\frac{21 \tau_{S}}{\left(S_{S}-1\right) \gamma \bar{k}} \\
& \frac{n^{\prime}}{n}=\frac{1+\sin (\lambda+B)}{2}=\begin{array}{l}
\text { stability number ratio for } \\
\text { particles on a slope to }
\end{array}
\end{aligned}
$$




$$
\beta=\tan ^{-1}\left(\frac{\cos \lambda}{\frac{2 \sin \theta}{n \tan \phi}+\sin \lambda}\right)
$$

Horizontal Flow on an Embankment Slope

In many cases, the slope of the energy gradient of the flow is small and $\lambda \cong 0$. Then, Equations (A.25) and (A.28) reduce to:

$$
\begin{aligned}
B & =\tan ^{-1}\left(\frac{n \tan \phi}{2 \sin \theta}\right) \\
\eta^{\prime} & =\left(\frac{1+\sin \beta}{2}\right)
\end{aligned}
$$

By substituting Equations (A.29) and (A.30) into Equation (A.4), the safety factor becomes:

$$
S F=\frac{S F}{2}\left\{\left(\xi^{2}+4\right)^{1 / 2}-\xi\right\}
$$

where

$$
\xi=S F_{m} n \sec \theta
$$

and

$$
S F_{m}=\frac{\tan \phi}{\tan \theta}=\begin{aligned}
& \text { safety factor for riprap on an } \\
& \text { embankment slope with no flow. }
\end{aligned}
$$

Solving Equations (A.32) and (A.33) for $n$ yields:

$$
\eta=\left(\frac{S F_{m}^{2}-S F^{2}}{(S F) S F_{m}^{2}}\right) \cos \theta
$$

Flow on a Plane Sloping Bed

Flow over a plane bed of slope $\alpha$ degrees in the downstream direction is equivalent to oblique flow on an embankment slope with $\theta=a$ and $\lambda=90^{\circ}$. Therefore, by Equation (A.28), $B=0^{\circ}$ and Equation (A.25), $\eta^{\prime}=\pi$ :

from Equation (A.4) 


$$
S F=\frac{\cos \alpha \tan \phi}{n \tan \phi} \frac{\sin \alpha}{\sin }
$$

Solving for $n$ in Equation (A.35):

$$
\eta=\cos \alpha\left(\frac{1}{S F}-\frac{\tan \alpha}{\tan \phi}\right)
$$

Flow on a Horizontal Bed

For fully developed rough turbulent flow over a plane horizontal bed $(a=0)$ of rock riprap, Equation (A.35) reduces to:

$$
\mathrm{SF}=\frac{1}{\pi}
$$

For conditions of incipient motion, $S F=1$, so $n=1$ and we revert back to Equation (A.17) for Shields equation of incipient motion with $n=1$.

\section{REFERENCES}

Gessler, J. 1971. "Beginning and Ceasing of Sediment Motion." In River Mechanics, Vol. 1, ed. H. W. Shen, Colordo State University, Ft. CoTाins, Colorado.

Simons, D. B., and G. L. Lewis. 1971. Flood Protection of Bridge Crossings, CER71-720BS-GLL10. Prepared for the Wyoming Highway Dept. in cooperation with the U.S. Dept. of Transportation, Federal Highway Administration, Bureau of Public Roads, Colorado State University, Ft. Collins, Colorado.

Simons, D. B., and F. Senturk. 1977. "Sediment Transport Technology." Water Resources Publications, Ft. Collins, Colorado.

Stevens, M. A. 1969. Scour in Riprap at Culvert Outlet. Ph.D. Dissertation, Colorado State University, Ft. Collins, Colorado.

Stevens, M. A., and D. B. Simons. 1971. "Stability Analysis for Coarse Granular Material on Slopes." River Mechanics, Vol. 1, ed, H. W. Shen, Colorado State University, Ft. Collins, Colorado.

Stevens, M. A., D. B. Simons and G. L. Lewis. 1976. "Safety Factors for Riprap Protection." Journal of the Hydraulic Division, ASCE, Vol. 102, No. HY5, Proc Paper 12115. 


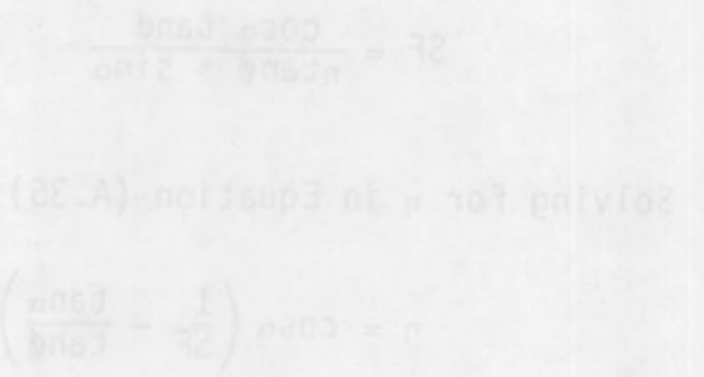

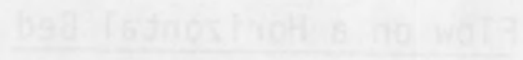

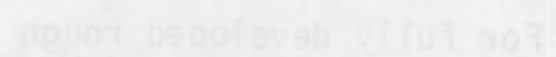

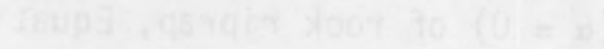


APPENDIX B

DEFINITIONS 


\section{APPENDIX B}

\section{DEFINITIONS}

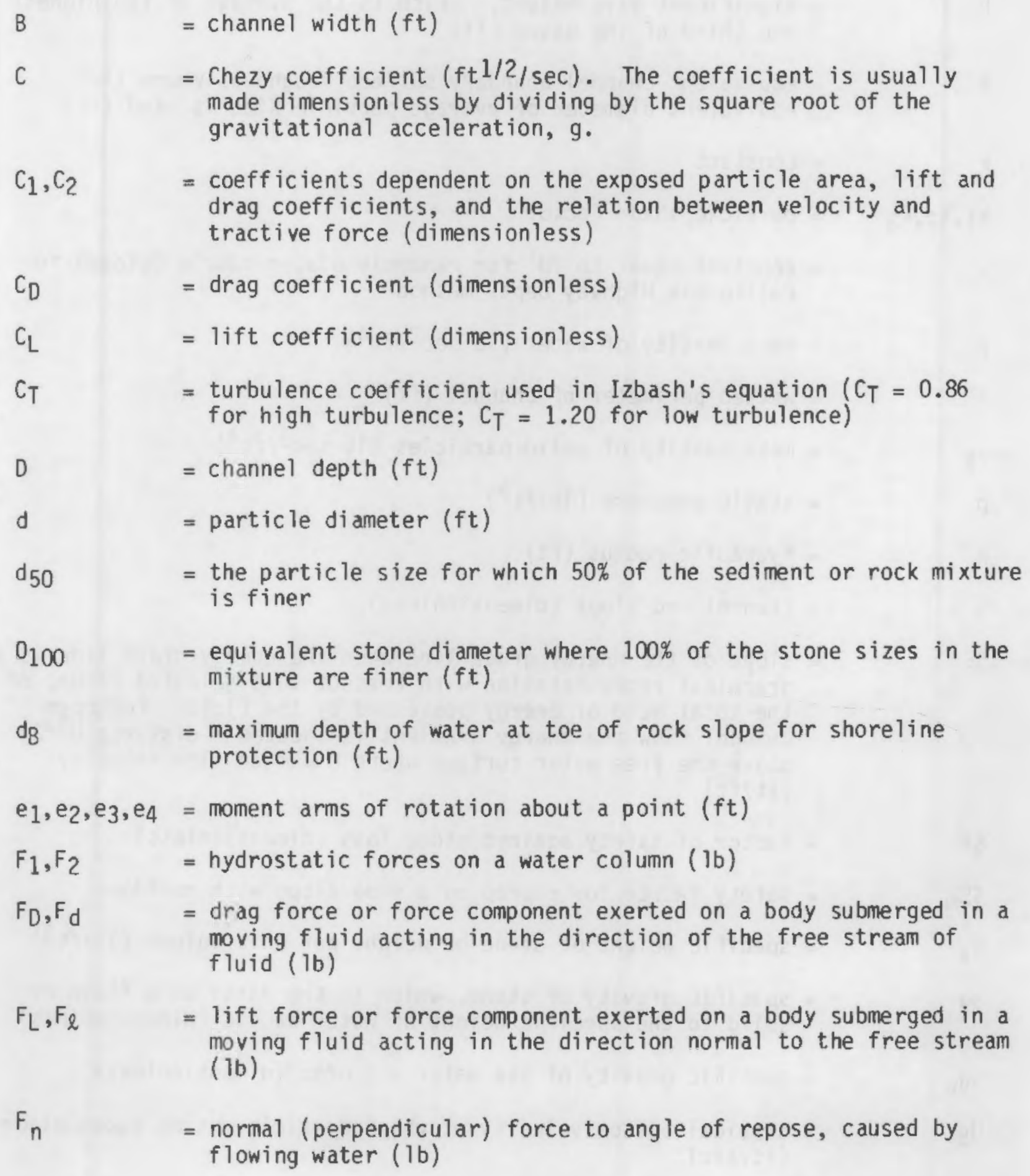
moving fluid acting in the direction of the free stream of fluid (1b)

$\mathrm{F}_{\mathrm{L}}, \mathrm{F}_{\ell}=$ lift force or force component exerted on a body submerged in a moving fluid acting in the direction normal to the free stream (1b)

$\mathrm{F}_{\mathrm{n}} \quad=$ normal (perpendicular) force to angle of repose, caused by flowing water (1b) 


$$
\begin{aligned}
& \mathrm{F}_{\mathrm{t}} \quad \text { = parallel (tangential) force to angle of repose, caused by } \\
& \text { flowing water (1b) } \\
& \text { g = gravitational constant }\left(\mathrm{ft} / \mathrm{sec}^{2}\right) \\
& \mathrm{H}=\text { significant wave height, which is the average of the highest } \\
& \text { one third of the waves }(\mathrm{ft} \text { ) } \\
& \text { k = equivalent channel boundary surface roughness where the } \\
& \text { equivalent diameter of average particle size is used }(\mathrm{ft}) \\
& k \quad=\text { constant } \\
& k_{1}, k_{2}, k_{3}=\text { particle shape factor } \\
& \text { - = constant equal to } 70^{\circ} \text { for randomly placed rubble (stone) for } \\
& \text { California Highway Dept. method } \\
& \text { } \quad=\text { mass density of water }\left(1 \mathrm{~b} \sec ^{2} / \mathrm{ft}^{4}\right) \\
& P \quad=\text { wetted perimeter of channel }(f t) \\
& \rho_{S}=\text { mass density of solid particles }\left(1 \mathrm{~b} \mathrm{sec} 3 / \mathrm{ft}^{4}\right) \\
& \mathrm{p} \quad=\text { static pressure }\left(\mathrm{lb} / \mathrm{ft}^{2}\right) \\
& \mathrm{R}=\text { hydraulic radius }(\mathrm{ft}) \\
& \mathrm{S}=\text { channel bed slope (dimensionless) } \\
& \mathrm{SE}_{\mathrm{E}} \quad=\text { slope of the energy grade line when the energy grade line is a } \\
& \mathrm{S}_{\mathrm{S}} \quad=\text { specific weight of stone or weight per unit volume }\left(1 \mathrm{~b} / \mathrm{ft}^{3}\right) \\
& \text { sg = specific gravity of stone, which is the ratio of a fluid or } \\
& \text { solid to the specif ic weight of water at } 4^{\circ} \mathrm{C} \text { (dimensionless) } \\
& \mathrm{sg}_{\mathrm{W}} \quad=\text { specific gravity of sea water }=1.0265 \text { (dimensionless) } \\
& U_{\mathrm{b}} \quad=\text { critical bottom velocity at which particle motion takes place }
\end{aligned}
$$




$$
\begin{aligned}
& \mathrm{U}_{\mathrm{S}} \quad=\text { bottom velocity or velocity against the stone }(\mathrm{ft} / \mathrm{sec} \text { ) } \\
& U, V=\text { free stream flow velocity or average channel cross-section } \\
& \text { velocity }(\mathrm{ft} / \mathrm{sec}) \\
& \text { Uy } \quad=\text { velocity at a distance of } 0.35 \text { times the particle diameter from } \\
& \text { the boundary ( } \mathrm{ft} / \mathrm{sec}) \\
& \bar{v} \quad=\text { average local velocity in the vertical }(\mathrm{ft} / \mathrm{sec}) \\
& \text { W } \quad \text { minimum weight of outside stone for no damage, California } \\
& \text { Highway Department method (1b) } \\
& W_{15}, W_{50}, W_{100}=\text { weight of individual stone where subscript denotes percent } \\
& \text { of stones that are lighter, used in Corps of Engineers design } \\
& \text { criteria (1b) } \\
& W_{S}, W=\text { submerged weight of a particle }\left(1 \mathrm{~b} / \mathrm{ft}^{3}\right) \\
& y=\text { local depth of water }(\mathrm{ft}) \\
& \text { Yo } \quad \text { = depth of flow }(\mathrm{ft}) \\
& \alpha, \delta, \beta, \theta=\text { angles as defined by Figure A.1 for safety factor method } \\
& \text { a } \\
& \text { = angle of channel bed slope } \\
& \text { = embankment face slope for California Highway Dept. method } \\
& \text { = specific weight of water }\left(\mathrm{Ib} / \mathrm{ft}^{3}\right) \\
& =\text { specific weight of rock }\left(i b / \mathrm{ft}^{3}\right) \\
& \text { = stability number for riprap on plane beds (dimensionless) } \\
& \text { = stability number for riprap on embankment slope (dimensionless) } \\
& \text { = design shear stress defined as the intensity of local boundary } \\
& \text { shear that riprap will safely resist on a plane bed for Corps } \\
& \text { of Engineers method ( } \left.1 \mathrm{~b} / \mathrm{ft}^{2}\right) \\
& \tau^{1} \quad=\text { design shear stress defined as this intensity of local boundary } \\
& \text { shear that riprap will safely resist on a side slope for Corps } \\
& \text { of Engineers method ( } \left.1 \mathrm{~b} / \mathrm{ft}^{2}\right) \\
& \tau_{b} \quad=\text { local boundary shear in a channel bend }\left(1 \mathrm{~b} / \mathrm{ft}^{2}\right) \\
& \tau_{0} \quad=\text { average shear stress on particle bed }\left(1 \mathrm{~b} / \mathrm{ft}^{2}\right) \\
& \tau_{0} \quad=\text { average boundary shear stress for the wetted perimeter of a } \\
& \text { channel cross-section }\left(\mathrm{kg} / \mathrm{m}^{2}, 1 \mathrm{~b} / \mathrm{ft}^{2}\right)
\end{aligned}
$$


$\tau_{\mathrm{s}} \quad=$ average shear stress (tractive $f$ ace) on the $p$ lane of rock particles for safety factor method ( $1 \mathrm{~b} / \mathrm{ft}^{2}$ )

$\emptyset$

= side slope angle for Corps of Engineers method

$\theta$

$=$ angle of repose of non-cohesive particles, which is the angle of slope formed by particulate material under critical equilibrium condition of incipient sliding for safety factor method

$\emptyset$

= riprap paving angle with respect to the horizontal for ASCE recommended method 


\section{DISTRIBUTION}

No. of

Copies

OFFSITE

485 U.S. Nuc lear Regulatory Commission

Division of Technical

Information and Document Control

7920 Norfolk Avenue

Bethesda, MD 20014

2 DOE Technical Information Center

5 J. J. Davis

D. F. Harmon

NRC Office of Nuclear Regulatory Research

Washington, DC 20555

T. L. Johnson

P. J. Garcia

G. N. Gnugnoli

NRC Office of Nuclear Material

Safety and Safeguard

Washington, DC 10555

P. J. Magno

M. S. ANR 60

USEPA

401 M. St. SW

Washington, D.C. 20460
No. of

Copies

ONSITE

50 Pacif ic Northwest Laboratory

T. J. Bander

L. L. Cadwe 11

J. M. Doesburg

A. F. Gasperino

G. W. Gee

J. N. Hartley

D. R. Kalkwarf

S. E. King

C. G. Lindsey

B. K. Marshall

J. Mishima (10)

I. C. Nelson

R. W. Nelson

G. B. Parker

L. C. Schwendiman (5)

R. J. Serne

R. W. Vallario

C. M. Unruh

W. H. Walters (10)

N. J. Wogman

J. K. Young

Publishing Coordination (BE)(2)

Technical Information (5) 


\begin{tabular}{|c|c|c|c|c|}
\hline \multirow{3}{*}{\multicolumn{3}{|c|}{ 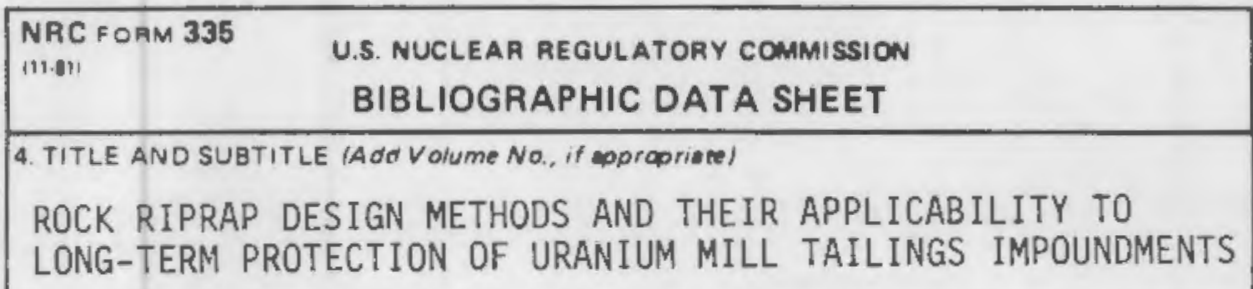 }} & \multicolumn{2}{|c|}{$\begin{array}{l}\text { 1. AEPORT NUMEER (Assigned or DOC) } \\
\text { NUREG/CR }-2684 \\
\text { PNI }-4252\end{array}$} \\
\hline & & & \multicolumn{2}{|l|}{ 2. (Leave bienk) } \\
\hline & & & \multicolumn{2}{|c|}{ 3. RECIPIENT'S ACCESSION NO. } \\
\hline \multirow{2}{*}{\multicolumn{3}{|c|}{$\begin{array}{l}\text { 7. AUTHOR(S) } \\
\text { W. H. Walters }\end{array}$}} & \multicolumn{2}{|c|}{ 5. DATE REPOAT COMPLETED } \\
\hline & & & \multicolumn{2}{|c|}{\begin{tabular}{|l|r}
$\begin{array}{l}\text { MONTH } \\
\text { July }\end{array}$ & 1982 \\
\end{tabular}} \\
\hline \multirow{2}{*}{\multicolumn{3}{|c|}{$\begin{array}{l}\text { 9. PERFORMING ORGANIZATION NAME AND MAILING ADDRESS Inciude Zio Codel } \\
\text { Pacif ic Northwest Laboratory }\end{array}$}} & \multicolumn{2}{|c|}{ DATE REPORT ISSUED } \\
\hline & & & \multicolumn{2}{|c|}{$\begin{array}{lr}\text { MONTH } & \text { IYEAF } \\
\text { AUguSt } & 1982 \\
\end{array}$} \\
\hline \multirow{2}{*}{\multicolumn{3}{|c|}{ Richland, WA 99352}} & \multicolumn{2}{|l|}{ 6. (Leave brank) } \\
\hline & & & \multicolumn{2}{|l|}{ 8. (Leave blank) } \\
\hline \multirow{2}{*}{\multicolumn{3}{|c|}{$\begin{array}{l}\text { 12. SPONSORING OAGANIZATION NAME AND MAILING ADDRESS (Include Zip Code) } \\
\text { U. S. Nuclear Regulatory Commission } \\
\text { Division of Health, Siting, and Waste Management } \\
\text { office of Nuclear Regulatory Research } \\
\text { Washington, O.C. } 20555\end{array}$}} & \multicolumn{2}{|c|}{ 10. PFOJECT/TASK/WORK UNIT NO } \\
\hline & & & \multicolumn{2}{|l|}{ 11. FIN NO. } \\
\hline \multirow{2}{*}{\multicolumn{3}{|c|}{ 13. TYPE OF REPOAT }} & D (Inclusive alares) & \\
\hline & & & \multicolumn{2}{|l|}{ 14. (Leave olark) } \\
\hline \multicolumn{5}{|c|}{ 16. ABSTRACT (200 words or less) } \\
\hline \multicolumn{5}{|c|}{$\begin{array}{l}\text { This report reviews the more accepted or recommended riprap design } \\
\text { methods currently used to design rock riprap protection against soil erosion } \\
\text { by flowing water. The basic theories used to develop the various methods are } \\
\text { presented. The Riprap Design with Safety Factors Method is identified as the } \\
\text { logical choice for uranium mill tallings impoundments. This method is } \\
\text { compared to the other methods and its applicability to the protection } \\
\text { requirements of tailings impoundments is discussed. Other design problems are } \\
\text { identified and investigative studies recommended. }\end{array}$} \\
\hline \multicolumn{5}{|c|}{$\begin{array}{l}\text { 17. KEY WORDS AND DOCUMENT ANALYSIS } \\
\qquad \text { ROCK Riprap; Uranium Mill Tailings; Riprap Design }\end{array}$} \\
\hline \multicolumn{5}{|c|}{ 17b. IDENTIFIERS OPEN-ENDED TERMS } \\
\hline \multirow{2}{*}{\multicolumn{2}{|c|}{$\begin{array}{l}\text { 18. AVAILABILITY STATEMENT } \\
\text { Unlimited }\end{array}$}} & \multirow{2}{*}{\multicolumn{2}{|c|}{\begin{tabular}{|l|} 
19 SE CURITY CLASS ITnis report \\
UnClaSS ified \\
20 SECURITY CLASS (This page) \\
UnClass ified \\
\end{tabular}}} & 21 NO OF PAGES \\
\hline & & & & $\begin{array}{l}\text { 22. PRICE } \\
\mathrm{S}\end{array}$ \\
\hline
\end{tabular}


